\title{
Covalent Functionalizations of Poly(vinyl chloride) in Tune with Applications: An Update
}

\author{
Saad Moulay*
}

Laboratoire de Chimie-Physique Moléculaire et Macromoléculaire, Département de Chimie Industrielle, Faculté de Technologie, Université Saâd Dahlab de Blida, B. P. 270, Route de Soumâa, 09000, Blida, Algeria

\begin{abstract}
Poly(vinyl chloride), PVC, stands as one of the best polymer candidates as far as polymeric materials are strongly sought for in our today's life. Functionalization of poly(vinyl chloride) (PVC) remains an appropriate way to fashion materials for specific applications. Molecules of different functionalities and sizes, up to macromolecules, were affixed to PVC matrix. Graft polymerization led to functionalized PVC with several properties for different applications. Some covalently modified PVCs, mainly with heteroatom-containing and cyclic molecules, proved to be biologically active and efficient scaffolds for enzyme/protein immobilization. Suitable functionalizations of PVC even ensured the effectiveness of the polymers as separative, ion-selective electrode, and fuel cell membranes. Some modifying agents incorporated in PVC made the polymeric materials convenient and reliable for solar cells design. Reactions of PVC with metal chelating molecules engendered PVC-metal complexes that were efficient polymer-supported catalysts for Heck, Sonogashira, and Suzuki-Miyaura coupling reactions. Heavy metal sorbents were also made by tailored functionalization of PVC. Modifications of PVC with allotropic carbon nanoparticles, including fullerene $\mathrm{C}_{60}$, carbon nanotubes, and graphene and their applications in the nanocomposites making are herein discussed. The newly emerged "click chemistry" and "living controlled radical polymerization, LCRP" were exploited in the functionalization of poly(vinyl chloride).
\end{abstract}

Keywords: Allotropic carbons, Applications, Functionalization, Membranes, Modification, Poly(vinyl chloride), PVCsupported catalysts.

\section{INTRODUCTION}

For decades, it has become orthodox to focus one's research on subjects that are contingent with our nowadays needs and solving daily problems. In fact, research outcome that is devoid of targeted applications is viewed as worthless. Truly acknowledged is the fact that all research disciplines resort, in one way or another, to the use of polymeric materials. Fortunately, there are a myriad of these materials, synthetic and natural, endowed with the tuned properties. The brilliant advance of chemistry science successfully brings bright solutions for realizing such materials, either by making them up or, utmost, by modifying them. Their modification is chiefly conceived via two alternatives: 1) adjunction of exogenous compounds (either molecular or macromolecular one) as in a composite formulation, and 2) chemical functionalization through known reactions, giving rise to covalent binding between the polymer and the functionalizing entity. The latter type of modification requires reactive functional groups both within the polymer and the functionalizing molecule. The proneness of the organic groups within the polymer makes it reactive and functionalizable. Chemical modification is generally applied to the bulk polymers,

*Address correspondence to this author at the Laboratoire de Chimie-Physique Moléculaire et Macromoléculaire, Département de Chimie Industrielle, Faculté de Technologie, Université Saâd Dahlab de Blida, B. P. 270, Route de Soumâa, 09000, Blida, Algeria; Tel/Fax: +21325433631;

E-mails: polymchemlab@hotmail.com, saadmoulay@univ-blida.dz but, in some instances, the modification concerns only the surface of the polymeric material as per their ultimate applications [1]. Chemical grafting may stem on outer surface [2] as in membranes (films, sheets, mats) and microspheres, or inner surface as in a hollow tube shape; one shape of the fabricated mats is the one from electrospun nanofibers [3], widely employed in medical devices [4]. Besides, graft polymers and polymer surface grafting may occur either via 'grafting from', 'grafting onto', or 'grafting through' mechanism [5].

Poly(vinyl chloride), the second most produced plastic worldwide, is reputed by a number of aspects related to its synthesis, chemical modification, stabilization, and recycling [6]. Although it looks so simple as its nomenclature may suggest, poly(vinyl chloride) concealed a number of complications related to its heterogeneous structure. Its intrinsic structural defects arising during the manufacture and its thermal degradation at elevated temperatures make it a unique plastic to deal with; henceforth, several measures and add-ons need to be considered before its commercialization. Indeed, a PVC macromolecule contains not only the expectedly trivial $\mathrm{CH}_{2}-\mathrm{CHCl}$ unit but also several other ones, giving rise to labile chlorine atoms [7, 8]. As a consequence, a chemical modification of PVC is not obviously and merely a nucleophilic substitution of chlorine atoms, but other pathways, such as elimination mechanism, would parallel. Furthermore, the morphology and the tacticity 
of PVC are important factors to take into consideration for the success of any chemical transformation and to divulge the right account for it. The chemical modifications of polymers are, in fact, value-added means to the materials with tune applications. The conventional as well as the newly developed chemistries were adequately referred to for the chemical modifications of poly(vinyl chloride). Indeed, since its emergence in 2001 [9], click chemistry has opened new avenues not only in related chemistry synthesis [10,11], but also in several other research aspects $[12,13]$. Its application was even extended to polymer field for specific uses [14-16], and, more interesting, to biopolymers [17]. Like poly(vinyl alcohol) [18], poly(vinyl chloride) has undergone several covalent modifications using click chemistry. The new polymerization methods termed "living/controlled radical polymerization (LCRP)", namely reversible addition-fragmentation chain transfer (RAFT), atom transfer radical polymerization (ATRP), nitroxidemediated polymerization (NMP), have been soundly exploited in the PVC functionalization.

The present review is deliberately confined to the chemical functionalizations of poly(vinyl chloride) published from the year 2010 up to now; reports prior to this date were surveyed [8]. Functionaliza-tions of PVC germane with applications are outlined below as: functionalizations for covalent PVC plastici-zation, functionalizations for PVC-based membranes, functionalizations for PVC uses in biologicals, functionalizations for PVC chemistry enrichment, functionalizations of PVC by allotropic carbons, functionalizations for optical properties, functionalizations for PVC waste recycling, functionalizations for desalination, and functionalizations for miscellaneous applications.

\section{COVALENT PLASTICIZATION}

The adversity of the common plasticizers such as dioctyl phthalate (DOP) (or di-2-ethylhexyl phthalate, DEHP) incorporated in a poly(vinyl chloride) films is, by now, well established and is reportedly linked to their leaching propensity to the media in contact, such as in food packagings and medical devices (intravenous tubing and bags, catheters, dialysis tubing and bags, and blood bags). For several decades, an intensive work has been undertaken towards solving these major drawback and constraint; although an ultimate solution has not been reached yet, a glimmer of hope is still on way. To cite but a few of such endeavors, succinate esters [19] and safer polyphthalates [20] are possible potential substitutes. Raju and his co-workers [21] adopted the strategy of coating PVC sheets with poly(azidoacrylate)s (poly(azidoethyl acrylate), poly(azidopropyl acrylate), poly(azidopropylmethacrylate)) to prevent or reduce the external plasticizer migration. The work-up of this approach was to dip PVC sheets into a dichloromethane (DCM) solution containing poly(azidoacrylate), followed by UV irradiation treatment for $5 \mathrm{~h}$; such an operation engenders crosslinking networks that act as a barrier for the plasticizer migration.

Another alternative to solve the plasticizer leaching from plasticized PVC is to covalently linked the plasticizer onto to poly(vinyl chloride) matrix through the functionalization methodology. Spanish school [22] had the privilege to report the first results on such strategy. In this approach, PVC was allowed to react with two prepared isomers of thiolated DOP (di(2ethylhexyl) 4-mercaptophthalate and the di(2ethylhexyl) 5-mercaptoisophthalate) in cyclohexanone at $60{ }^{\circ} \mathrm{C}$ to afford PVC-DOPs with a degree of functionalization of 23 and $31 \mathrm{~mol} . \%$, respectively (Eq. 1). The glass transition temperatures $T_{\mathrm{g}}$ 's of internally plasticized PVC-DOPs were higher than that of the externally plasticized PVC/DOP, that is, a temperature range of $\sim 0-20{ }^{\circ} \mathrm{C}$ against $-60{ }^{\circ} \mathrm{C}$ for PVC/DOP $(\sim 20$ mol.\% DOP); the internal plasticization led to PVC with lower flexibility. However, the migration experiment proved a complete loss of DOP in the PVC/DOP after less than $3 \mathrm{~h}$ of extraction with $n$-heptane, and no loss of DOP of the internally PVC-DOPs was detected.

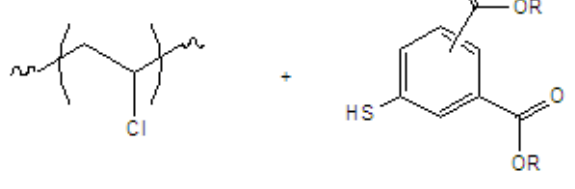

$\frac{\mathrm{K}_{2} \mathrm{CO}_{3}, \text { cyclohexanone }}{\mathrm{N}_{2}, 60^{\circ} \mathrm{C}}$

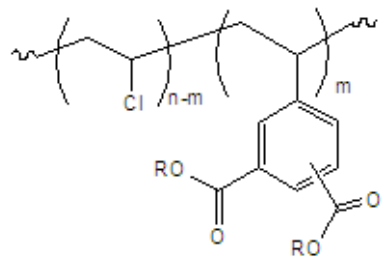

PVC-DOP 


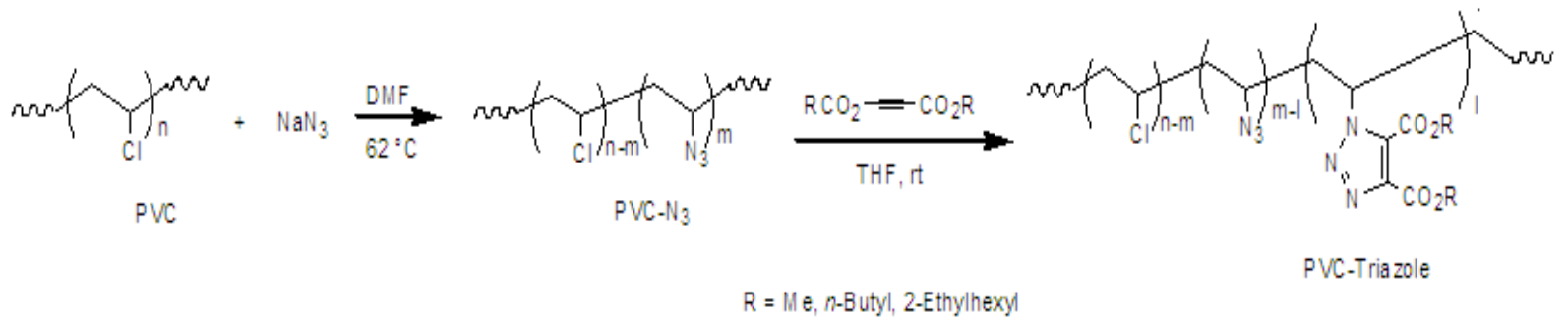

(2)

Earla and Braslau [23, 24] applied "click chemistry" to attach triazole analogues of phthalate plasticizers, namely di(2-ethylhexyl)- $1 H$-triazole-4,5 dicarboxylate, di( $n$-butyl)-1H-1,2,3-triazole-4,5-dicarboxylate, and dimethyl-1H-triazole-4,5-dicarboxylate, onto poly(vinyl chloride) backbone (Eq. 2). The azidation of PVC proceeded with sodium azide in $N, N$ dimethylformamide (DMF) at $62{ }^{\circ} \mathrm{C}$, afforded about $15 \%$ of chlorine substitution for a reaction of $2.5 \mathrm{~h}$. The copper-free "azide-alkyne" click chemistry was applied to azidated PVC with dimethyl acetylenedicarboxylate, di( $n$-butyl) acetylenedicarboxylate and di(2-ethyl-hexyl) acetylenedicarboxylate; the click reaction was run in tetrahydrofuran (THF) at room temperature for $27 \mathrm{~h}$.

Yang and his collaborators [25] recently reported the covalent fixation of cardanol, a natural compound (the main component of cashew nutshell) as green internal plasticizer, onto PVC matrix. The modification reaction was carried according to via Huisgen copper(I)-catalyzed azide-alkyne cycloaddition (CuAAC) of PVC- $\mathrm{N}_{3}\left(10 \mathrm{~mol}^{\circ} \% \mathrm{~N}_{3}\right)$ as illustrated in Eq. 3. The glass transition temperature $T_{\mathrm{g}}$ of the modified PVC, PVC-cardanol, was $51.0^{\circ} \mathrm{C}$, a temperature lower than those of PVC- $\mathrm{N}_{3}\left(81.0^{\circ} \mathrm{C}\right)$ and virgin PVC (87.1 $\left.{ }^{\circ} \mathrm{C}\right)$, and was about equal to that of PVC-DOP (48.8

${ }^{\circ} \mathrm{C}$ ), suggesting the mobility effect of the cardanol due

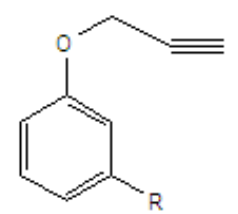

propargyl ether cardano to its fatty alkyl/alkenyl chains. Experiment migration had proved that the leaching of covalently-attached plasticizer was nil. PVC-cardanol showed higher thermal stability than PVC-DOP, a result attributed to the triazole units in the cardanol-functionalized PVC; hence, the latter could be subjected to conditions of elevated temperatures.

Recently, Pan and his co-workers [26] developed a PVC composite made by grafting poly(butyl acrylate) (PBA) onto poly(butyl acrylate)/poly(vinyl chloride) particles via a multistep emulsion polymerization. The thus-made PVC composite, that is PBA/PVC- $g$-PBA, exhibited a flexibility comparable to that of the PVC plasticized with DOP; the elongation break of the former with 40 wt. $\%$ of PBA was measured to be $353 \%$ against $225.5 \%$ for PVC plasticized with $40 \mathrm{wt} . \%$ of DOP. The corresponding tensile strengths were 2.81 and $0.66 \mathrm{MPa}$, respectively.

\section{MEMBRANES}

\subsection{Separative Membranes}

Poly(vinyl chloride) has been widely employed in membranes for separation techniques, including pervaporation, gas permeation, ultrafiltration (UF), microfiltration (MC), and reverse osmosis (RO).
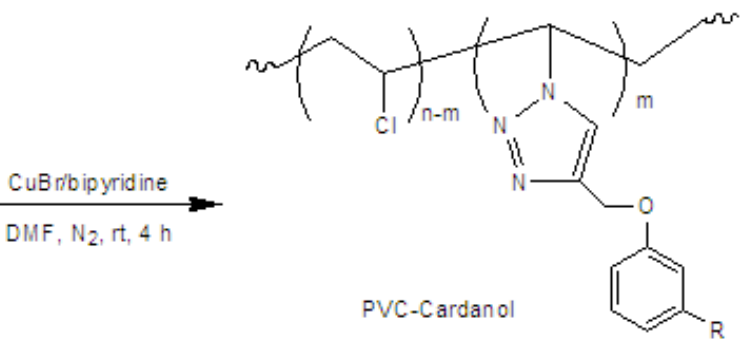

PVC- $\mathrm{N}_{3}$

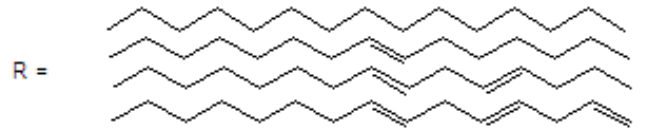

(3) 
According to a specific separation, PVC was covalently modified by an adequate functionalization. Spanish school [27-29] reported on bulk and surface functionalization of PVC with fluorothiophenol entities. PVC with a molecular weight of $M_{\mathrm{w}}=112000 \mathrm{~g} / \mathrm{mol}$ underwent bulk functionalization with fluorothiophenyls via nucleophilic substitution reaction with 4fluorothiophenol (PVC-1F), 3,4-difluorothiophenol (PVC-2F), and pentafluorothiophenol (PVC-5F), in cyclohexanone at $60{ }^{\circ} \mathrm{C}$ and in the presence of potassium carbonate. Degrees of modification of as high as 80,60 , and $40 \mathrm{~mol} . \%$, respectively, could be reached after five-hour reactions, and with negligible concomitant degradation through the dehydrochorination. This order of degree of modification was on par with the nucleophilicity powers of the modifiers. For gas transport study, three functionalized PVC-based membranes were evaluated: PVC-1F with $18 \mathrm{~mol} \%$, PVC-2F with $15 \mathrm{~mol} . \%$, and PVC-5F with $12 \mathrm{~mol} \%$. The $T_{\mathrm{g}}$ 's of the latter membranes did not vary in a systematic way, that is in the order of the number of fluorine atoms on the benzene ring, and were measured to be $78.1,77.5$, and $85.4{ }^{\circ} \mathrm{C}$, respectively; that for virgin PVC was 83.0 ${ }^{\circ} \mathrm{C}$. In general, the gas permeation parameters (diffusion coefficient $D$, permeability coefficient $P$, and solubility coefficient $S$ for the experimented gases $\left(\mathrm{O}_{2}\right.$, $\mathrm{N}_{2}, \mathrm{H}_{2}, \mathrm{CO}_{2}$ )) in the case of functionalized PVC-based membranes were generally enhanced compared with those in the case of unmodified PVC-based one (Table 1). Slight decrease in permeability and diffusion of the functionalized PVC-based membranes after a one-year age at ambient temperature was observed. The improvement of permeability and diffusion of gases through these membranes was explained in terms of increasing free volume by the pendant bulky groups. Also, the modification of PVC film surface was achieved in $\mathrm{H}_{2} \mathrm{O} / \mathrm{DMF}$ at 45 at $60^{\circ} \mathrm{C}$ in the presence of potassium carbonate, and the degree of modification of the PVC surface was as follows: PVC-1F> PVC-2F> PVC-5F.

For an antifouling purpose in the membrane ultrafiltration separation of oil/water emulsion, the aminated PVC/chlorinated PVC (CVPC) blend membrane was perfluoroalkylated with pentadecafluorooctanoic acid [30]. Immersion of the membrane into an aqueous solution of pentadecafluorooctanoic acid for $12 \mathrm{~h}$ at $30^{\circ} \mathrm{C}$ afforded material for such a goal. After a measurement time of $10 \mathrm{~min}$, the static water contact angle of the perfluoroalkylated membrane (Figure 1) was nil and that of unmodified membrane was about $40^{\circ}$. The water flux using perfluoroalkylated membrane was greater than that using unmodified one; in both cases, the water flux increased with pressure and attained nearly 180 and $100 \mathrm{~L} / \mathrm{m}^{2} \mathrm{~h}$, respectively, at a pressure of about $0.10 \mathrm{MPa}$. As to the permeability issue, the

Table 1: Gas Permeation Parameters $\left(\mathrm{T}=30^{\circ} \mathrm{C}\right.$, Gas Pressure $\left.=1 \mathrm{Bar}\right)$

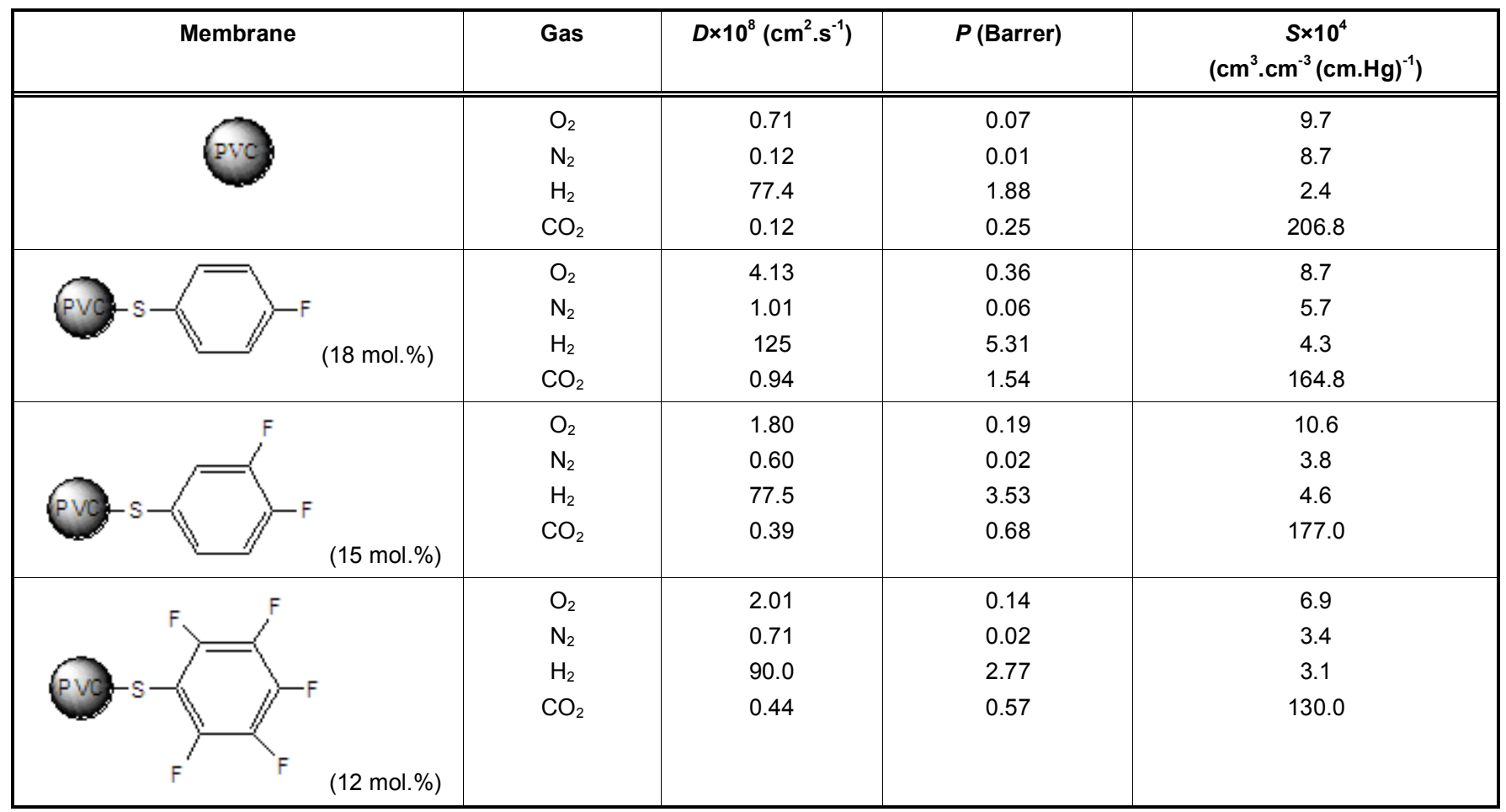


protein bovine serum albumin (BSA) $(66.5 \mathrm{kDa})$ rejection ratio was $95.21 \%$ for PVC/CPVC membrane and $84.48 \%$ for the perfluoroalkylated membrane at an operation pressure of $0.02 \mathrm{MPa}$. Also, BSA rejection ratios dropped at high permeate flux with a high operation pressure: 84.05 and $66.54 \%$, respectively, at an operation pressure of $0.1 \mathrm{MPa}$. This difference in permeability was accounted in terms of pore size difference; the greater pore size of the perfluoroalkylated membrane was claimed to be due to the chemical treatment in preparing the functionalized membrane. However, the rejection ratio of oil/water emulsion droplets was $99.3 \%$ by both membranes regardless the operation pressure. The antifouling effect of the perfluroalkyl groups was demonstrated by the difference in the permeate flux drops $(\Delta J)$ of oil/water emulsion after $400 \mathrm{~min}$ of operation at a pressure of $0.04 \mathrm{MPa}: \Delta J$ was only $11.8 \mathrm{~L} / \mathrm{m}^{2} \mathrm{~h}$ for the perfluoroalkylated membrane and $23 \mathrm{~L} / \mathrm{m}^{2} \mathrm{~h}$ for the unmodified membrane. While with the latter ultrafiltration membrane, no flux recovery was seen, a high flux recovery for the former one was observed.

The presence of zwitterionic functionality onto PVC ultrafiltration membrane would improve its hydrophilicity by providing active centers on its surface. Su and his co-workers [31] introduced the zwitterionic $(\mathrm{Zw})$ of amino acid via the reaction of aminated PVC membrane (thickness $=240 \mu \mathrm{m}$ ) with sodium chloroacetate (Eq. 4). The ensued functionalized PVC membranes, PVC-NH $\mathrm{N}_{2}-\mathrm{Zw}$, were examined for their antifouling properties using BSA as probe. The PVC$\mathrm{NH}_{2}-\mathrm{Zw}$, obtained at a temperature of $80{ }^{\circ} \mathrm{C}$ and for a reaction time of $12 \mathrm{~h}$, was characterized with the following parameters: $\theta_{w}$ (water contact) $=36.1^{\circ} ; \zeta$ (zeta potential) $=-33.77 \mathrm{mV} ; J_{\mathrm{w}}$ (flux of pure water) $=$ $160 \mathrm{~L} / \mathrm{m}^{2} \mathrm{~h}$; BSA rejection $=63.6 \%$. Those of PVC and PVC-NH $\mathrm{N}_{2}$ membranes were, respectively: $\theta_{\mathrm{w}}=65.8^{\circ}$,

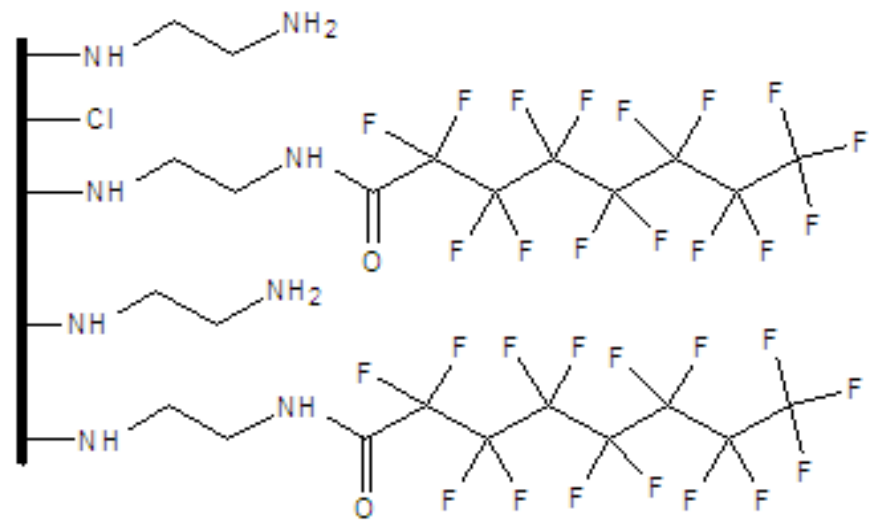

Perfluoroalkylated PVC/chlorinated PVC membrane

Figure 1: Perfluoroalkylated PVC/CPVC membrane.

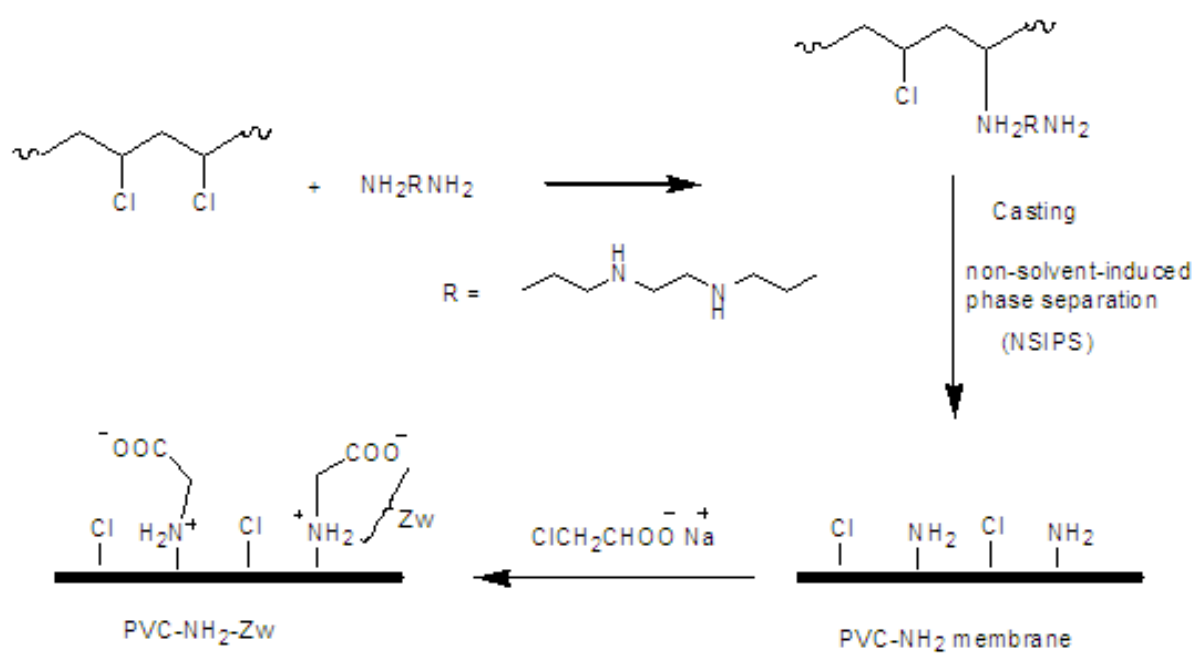


55.3; $\zeta=-33.76 \mathrm{mV},-25.58 \mathrm{mV} ; J_{\mathrm{w}}=137.5 \mathrm{~L} / \mathrm{m}^{2} \mathrm{~h}$, $171.7 \mathrm{~L} / \mathrm{m}^{2} \mathrm{~h}$; BSA rejection $=81.6 \%, 79.5 \%$. All the changes in these parameters, mainly the fouling one, were provoked by the hydrophilicity enhancement of the PVC membrane.

\subsection{Ion-Selective Electrodes}

Ion-selective electrode (ISE) acts as a sensing tool that is able to convert the activity of a specific ion into an electrical potential. Membrane is often employed in the ISE set-up, behaving as ionophore. Poly(vinyl chloride), particularly in its modified forms, has been one of the largest used polymers in the design of such membranes. Bakker's school undertook diverse functionalizations of high molecular weight PVC for elaborating ion-selective membrane electrodes, providing the use of click chemistry [32-37]. The ferrocene moiety was anchored onto PVC matrix via CuAAC of PVC- $\mathrm{N}_{3}$ with ethynylferrocene. An optimum degree of substitution in ferrocene of $6.1 \%$ occurred for an azidation reaction of $168 \mathrm{~h}$, and the substitution of azide groups seemed to be complete [32]. Some advantages in the electrochemical process by using the thus-modified PVC, PVC-FC (FC = ferrocene; Figure 2A), were claimed. Indeed, in the chronopotentiometric measurements, the PVC-Fc-based membrane displayed a dual role: an ion-to-electron transducer and an initiator of the ion-transfer process from the aqueous to the membrane phase [35]; a selectivity was observed for the following Hofmeister series: chloride, nitrate, thiocyanate and perchlorate. Also, phenomena such as the diffusion and the electrochemical behavior of PVC-Fc, a high molecular weight polymer with a single redox active unit, were noticed [36]. Bakker's investigations were extended to the use of CuAAC method for the surface modification of plasticized PVC$\mathrm{N}_{3}$-based membranes (PVC with $8 \mathrm{~mol} \%$ of $\mathrm{N}_{3}$ ), employing clickable dyes such as Nile blue derivatives and fluorescein, and clickable tetraethylene glycol (TEG) and poly(ethylene glycol)s (PEG) with different chain lengths [33, 34]; the dyes were used as visual probes and TEG/PEG for biocompatibility/hydrophilicity enhancement of the PVC-based membrane in the electrochemical measurements. Clickable D-mannose with a TEG moiety (Figure 2B) was synthesized and subjected to 1,3-dipolar cycloaddition with plasticized $\mathrm{PVC}^{-\mathrm{N}_{3}}$ (7 mol\% of azide) to yield PVC-mannose [37]. The latter modification was conceived as an electrochemical sensor for Concanavalin A, a lectin plant used in blood typing and widely employed for characterizing and purifying sugar-containing molecules and cellular structures; mannose binds selectively to Concanavalin A. The hydrophilicity of the modified PVC was enhanced as its contact angle of $64^{\circ}$ may suggest, compared to that of the untreated $\operatorname{PVC}\left(80^{\circ}\right)$.

Potassium-selective electrode membrane was designed using high molecular weight PVC modified with benzo-18-crown-6 ether as ionophore via CuAAC approach, as delineated in Eq. 5 [38]. The functionalization was quantitative. The thus-altered PVC-based electrode membrane showed a good selectivity and a fast Nernstian response towards potassium ion with a slope of $58.8 \mathrm{mV} /$ decade, results better than those of free 4-bromobenzo-18-crown-6 ionophore.

Polish workers [39] made up fluoride-selective electrode membranes by means of aminated and carboxylated PVC. lonophores employed in this work

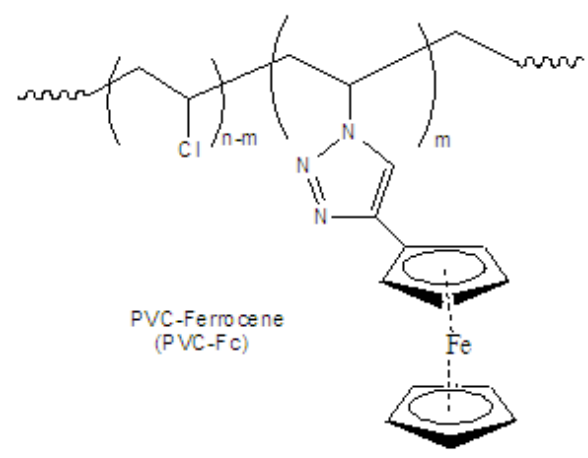

A

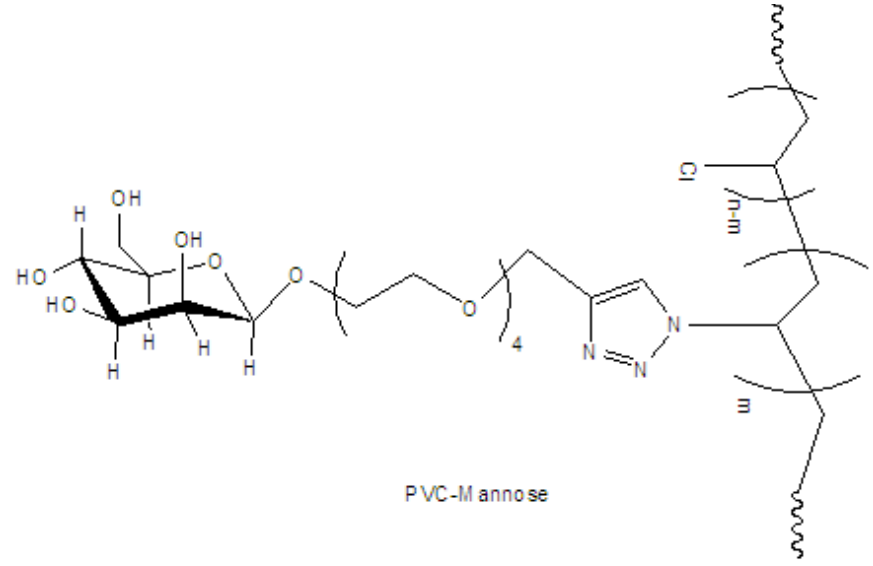

B

Figure 2: Chemical structures of ferrocene- and D-mannose-functionalized PVCs, A and B. 


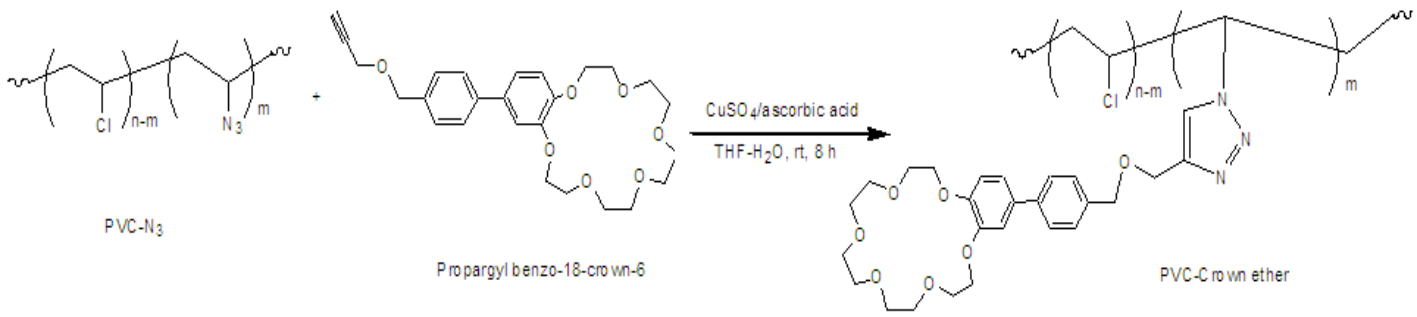

(5)

were the complexes of $\mathrm{Zr}(\mathrm{IV})$ and $\mathrm{Al}(\mathrm{III})$ cations with tert-butyl substituted tetraphenylporphyrin and tetraazaporphine. The functionalizations of PVC, that is amination and carboxylation, had an impact on the complexing properties of the ionophores and consequently on the fluoride-selectivity of the electrode membrane.

\subsection{Fuel Cell Membranes}

Among a myriad of properly functionalized polymers that were evaluated as exchange membranes for fuel cells (EMFC) [40, 41], there is only one report dealing with functionalized PVC in such application. Alkaline anion-exchange membranes designed for direct alcohol fuel cells (DAFCs) were developed by plasma grafting polymerization of poly(vinylbenzylchloride) (PVBC) onto PVC membrane [42]. Plasma-treated $P V C$ was allowed to react with vinylbenzylchloride at $60{ }^{\circ} \mathrm{C}$ for $24 \mathrm{~h}$ (Eq. 6). The VBC content in PVC-gPVBC graft copolymer was estimated as $32.37 \%$. Quaternization of the ensued PVC-g-PVBC with trimethylamine (TMA) at room temperature for $48 \mathrm{~h}$ and subsequent treatment with $\mathrm{KOH}$ led to the desired membrane, PVC-g-QPVBCTMAOH. PVC-g-PVBC, PVC-g-QPVBCTMACI, and PVC-g-QPVBCTMAOH were thermally less stable than the parent PVC. The mechanical properties of PVC- $g$-QPVBCTMAOH membrane at a relative humidity of $100 \%$ were: tensile strength of $8.74 \mathrm{MPa}$, elongation at break of $5.1 \%$, and Young modulus of $374.7 \mathrm{MPa}$. Water uptake, ionexchange capacity, methanol permeability, and hydroxide ion $\left(\mathrm{OH}^{-}\right)$conductivity of PVC-gQPVBCTMAOH membrane were $65.63 \%, 1.01$ $\mathrm{mmol} / \mathrm{g}, 9.59 \times 10^{-12} \mathrm{~m}^{2} \mathrm{~s}^{-1}$, and $0.0145 \mathrm{~S} \mathrm{~cm}^{-1}$. Such conductivity and methanol permeability values are a good indication for application of the membrane in fuel cell technology.

\section{BIOLOGICALS}

Poly(vinyl chloride) continues to gain a foothold in medical uses. Yet, some of its drawbacks, such as high
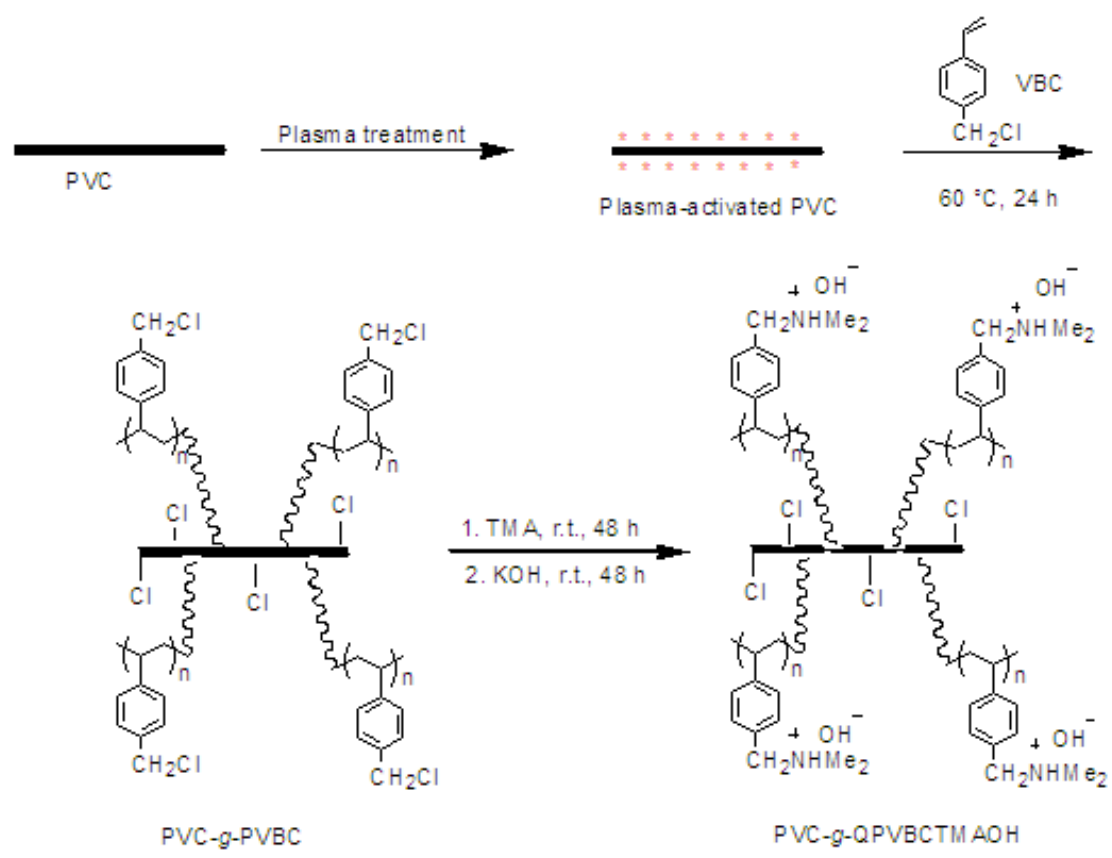
hydrophobicity, very poor biocompatibility, low surface free energy, and non-specific protein adsorption potency would impede its use in its bare form. One alternative to alleviate some of its shortcomings is the covalent chemical functionalization with an adequately chosen modifying agent. For example, one way to enhance the PVC biocompatibility has been to complex the aminated PVC with heparin, or to graft poly(ethylene glycol) (PEG) onto PVC.

\subsection{Biological Activity}

Polymers are by now inevitably indispensable materials for the design of biological assays (antibacterial, pharmaceuticals, ...). Of these, poly(vinyl chloride) is the one that has acquired a foothold in medical applications. Polymers with antibacterial activity commonly contain heteroatoms (nitrogen, sulfur), and ammonium, phosphonium, and sulfonium groups, moieties responsible for this activity [43-45].

Click chemistry was nowadays a means to introduce an anti-bactericidal polymeric material onto PVC matrix [46, 47]. Under CuAAC strategy, PVC surface was grafted with cationic copolymers, by immersing films of PVC- $\mathrm{N}_{3}$ in ethanol/water medium in the presence of copolymers containing alkyne groups and quaternary ammonium or phosphonium groups (Figure 3A, B, C, D) at ambient temperature for two days [46]. Such graftings allowed hydrophilicity enhancement of the PVC and the PVC- $\mathrm{N}_{3}$ as indicated

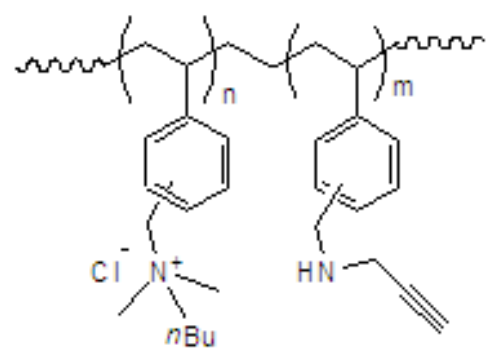

A

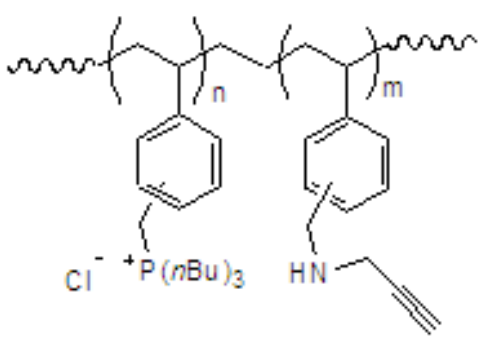

C by the water angle values which neared $70^{\circ}$, their polar energy values which ranged from 5.6 to $7.9 \mathrm{mN} / \mathrm{m}$, and their polarity which fluctuated between 13 and $20 \%$; those of PVC and PVC- $\mathrm{N}_{3}$ were respectively: 90 and $78^{\circ}, 1$ and $3.1 \mathrm{mN} / \mathrm{m}$, and 0.9 and $8.7 \%$. The biological assays of the copolymers-grafted PVC against Escherichia coli and Staphylococcus epidermidis strains demonstrated a faster and quantitative attachment of the bacteria to the cationic surfaces; PVC grafted with quaternary ammonium copolymers A and $\mathbf{D}$ showed higher biocidal effect, a killing efficiency of about $99 \%$ after a one-hour contact. The cationic PVC surfaces with quaternary phosphonium copolymers B and $\mathbf{C}$ exhibited lower bactericidal effect with a killing efficiency of $86 \%$ and $96 \%$ against $S$. epidermidis and of $96 \%$ and $95 \%$ against E. coli, respectively.

Yoshioka et al. [48] valorized the antibacterial activity of the products of PVC thiocyanation. A detailed discussion on the thiocyanation reaction of PVC is delineated below. The adhesion of bacteria (Staphylococcus capitis) onto thiocyanated PVC films was largely reduced (about $67-79 \%$ reduction) compared with that for the bare PVC ones. The study revealed that the best antibacterial results were observed for PVC functionalized exclusively with isothiocyanate, $\quad \mathrm{PVC}-\mathrm{N}=\mathrm{C}=\mathrm{S}$, obtained using tetrahydrofuran/dimethylsulfoxide (THF/DMSO) solvent system. It seems that the thiocyanate group is biologically inactive.

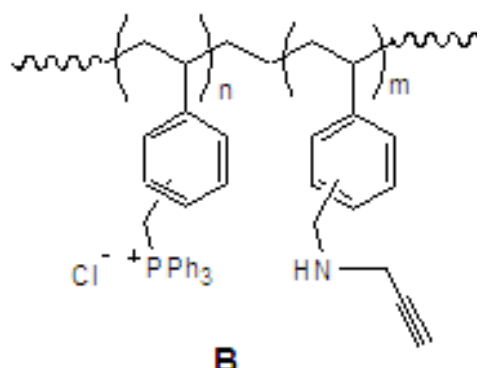

B

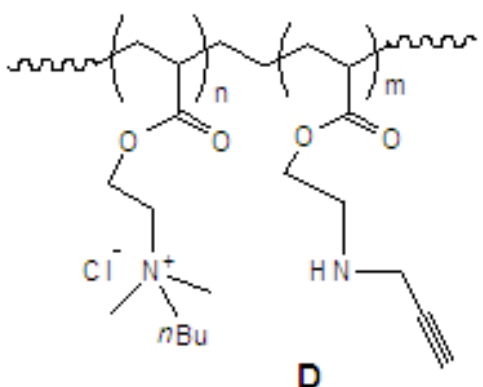

Figure 3: Chemical structures of some anti-bacterial polymeric materials. 
Sedlařík's group launched a series of undertakings on PVC-based antibacterial materials, in form of either formulations $[49,50]$ or through covalent functionalizations [51-53]. Towards coating antibacterial materials onto medical-grade $\mathrm{PVC}$, this group radically grafted poly(acrylic acid) (PAA) onto PVC film after a surface activation by diffuse coplanar surface barrier discharge plasma as shown in Scheme 1; the grafting reaction was run at $30{ }^{\circ} \mathrm{C}$ for $24 \mathrm{~h}$. The deposition of the anti-bacterial substances onto PVCPAA sheets required the activation of carboxylic groups of PAA branches with $N$-(3-dimethylaminopropyl)- $N$ 'ethyl carbodiimide hydrochloride; such an activation ensured the formation of $O$-acylisourea, a highly active intermediate. The coated biomolecules were: bronopol, chitosan, benzalkonium chloride, chlorhexidine, and irgasan. Hydrophilicity of PVC films increased upon plasma treatment and PAA grafting as indicated by the water contact angle values $\theta_{\mathrm{w}}, 64.9$ and $46.5^{\circ}$ versus $85.9^{\circ}$ for pristine PVC. However, the hydrophilicity decreased upon coating with the antibacterial agents in the order cited-above, as $\theta_{\mathrm{w}}$ may reveal: $63.2,63.5$, 66.6 , and $68.7,69.6^{\circ}$. As to biological assays, the PVC-PAAs coated with bronopol and benzalkonium chloride were inefficient towards Staphylococcus aureus as they did not reduce the number of adhering specimens, and the modification with chlorhexidine exhibited a $50 \%$ activity. However, the adhesion reduction for the Escherichia coli strain was 60, 70, and $85 \%$ in the case of chlorhexidine, bronopol,, and benzalkonium chloride, respectively; interesting was the better biological activity of plasma-activated PVC, up to $80 \%$, towards this strain. Of the PVC-chitosan and PVC-chitosan/pectin, only the latter system showed biocidal effects against Staphylococcus aureus, about $30 \%$. And, they were active against Escherichia coli strains in 50 and $20 \%$, respectively. As to PVC-irgasan, it worked in the inhibition of bacterial growth against both strains but was ineffective in preventing the adherence and biofilm formation.

However, Alvarez-Lorenzo and Burillo and their group [54] treated pieces of PVC-made urinary catheter with oxidative irradiation using ${ }^{60} \mathrm{Co}-\mathrm{y}$ rays (doses of 5$15 \mathrm{kGy}$ ) to promote the graft polymerization of acrylic acid (PAA) and poly(ethylene glycol) methacrylate (PEGMA, $M=360 \mathrm{~g} / \mathrm{mol}$ ), conceived as the one shown in Scheme 1. The graft copolymers, PVC-g-PAA, PVC$g$-PPEGMA, and the binary grafts PVC-g-PAA- $g$ PPEGMA were obtained with grafting extents of 8$207 \%$. Graft copolymers were $10{ }^{\circ} \mathrm{C}$ more thermally stable than the bare PVC catheter; the PAA content in binary graft copolymers enhanced the thermal stability better than PPEGMA content. The swelling ratios of the different graft copolymers in water reached $51 \%$ beyond $7 \mathrm{~h}$ of contact and were dependent of PAA and PPEGMA contents; the greater the content, the better the swelling degree. The water contact angles $\theta_{\mathrm{w}}$ of the copolymers after $30 \mathrm{~s}$ of contact were lower than that of PVC, $65-97^{\circ}$ versus $98^{\circ}$ for untreated PVC catheter, as a result of the high hydrophilicity of the grafts PAA and PPEGMA. The Young's moduli of the graft copolymers are linked to the graft chains; graft copolymer with $16 \%$
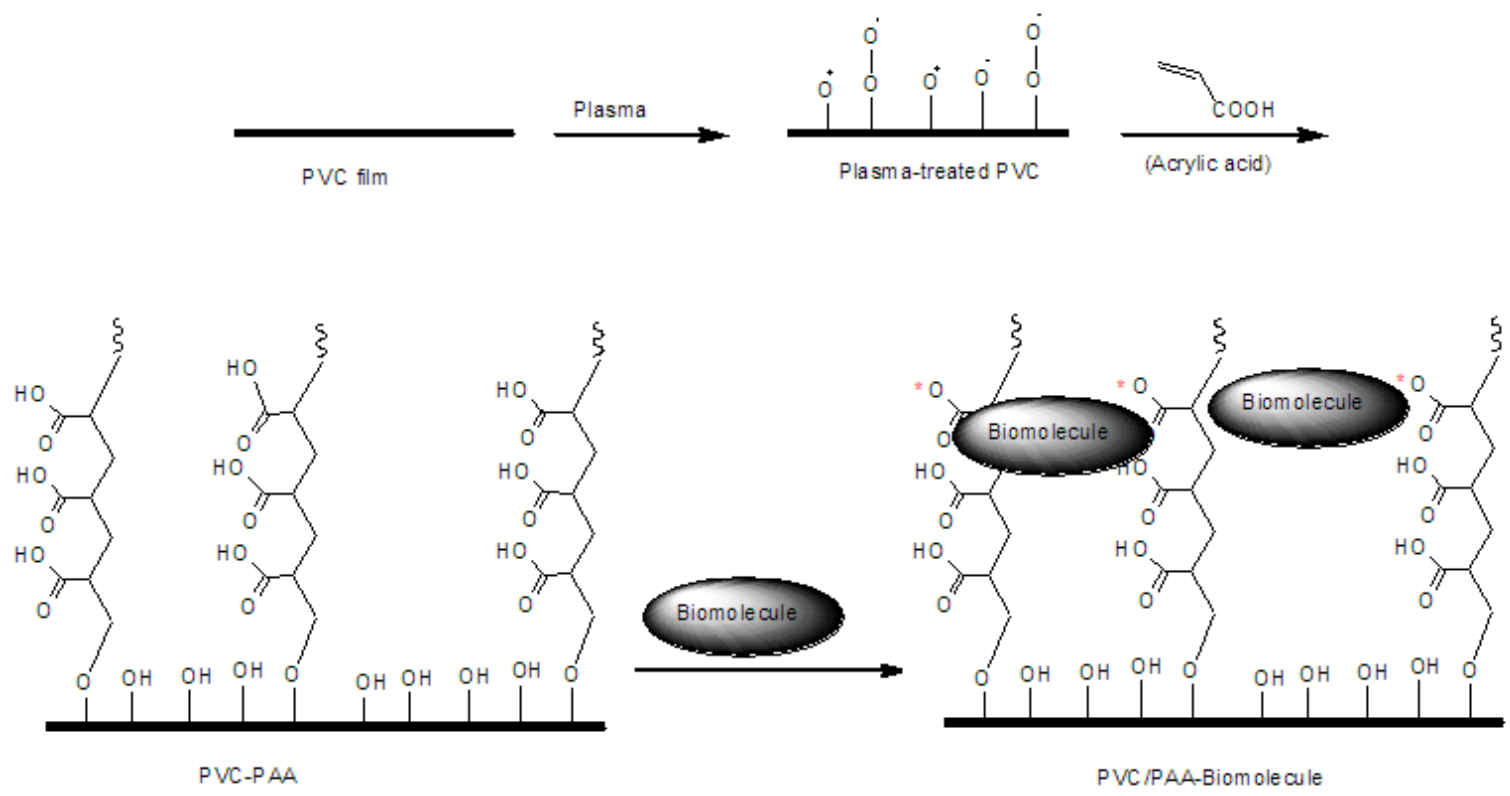

Scheme 1: Acrylic acid graft polymerization initiated by plasma-treated PVC surface and immobilization of biomolecules. Activated carboxyl groups are shown in red stars. 
PPEGMA chains had a Young's modulus of $10 \mathrm{MPa}$ and that for a graft copolymer with 25\% PAA had a Young's modulus of $64 \mathrm{MPa}$; the Young's modulus of PVC catheter was measured to be $18 \mathrm{MPa}$; the measured moduli are in agreement with the stiffness of the homopolymers PPEGMA $\left(T_{\mathrm{g}}<0{ }^{\circ} \mathrm{C}\right)$ and PAA $\left(T_{\mathrm{g}}\right.$ $\left.150{ }^{\circ} \mathrm{C}\right)$. For PVC-g-PAA-g-PPEGMA, the Young's modulus was $12 \mathrm{MPa}$, an in-between value. The different PVC-based graft copolymers exhibited good cytocompatibility with fibroblasts, from $90-107 \%$ for the cell viability during the first $24 \mathrm{~h}$ of incubation. The loading of ciprofloxacin, an antimicrobial agent, on the graft copolymers PVC-g-PAA and PVC-g-PAA-gPPEGMA was substantial $(0.13-0.28 \mathrm{mg} / \mathrm{g})$ compared with bare PVC $(0.025 \mathrm{mg} / \mathrm{g})$ and PVC-g-PPEGMA $(0.025-0.026 \mathrm{mg} / \mathrm{g})$ after $48 \mathrm{~h}$ of incubation; this difference in drug uptake was explained in term of the high interaction of the carboxylic acid functional group of PAA chains with the drug. The ciprofloxacin-loaded functionalized catheters inhibited the growth of Gram (+)-Escherichia coli and Gram (+)-Staphylococcus aureus. These catheters were still effective but to a lesser extent, for a second cycle against inhibition more Escherichia coli.

Recently, Korean investigators [55] applied the atom transfer radical polymerization (ATRP) technique for grafting poly(4-vinylpyridine) (P4VP) onto PVC matrix $\left(M_{\mathrm{w}}=97000 \mathrm{~g} / \mathrm{mol}\right)$ via the labile chlorine atoms. The highest grafting extent was in the range of 46 wt.\%. Such grafting altered the microphase structure of PVC, that is a microphase-separated nanostructure with $37.6 \mathrm{~nm}$ of domain spacing was formed for PVC-g-P4VP as revealed by transmission electron microscope (TEM) and small angle X-ray scattering (SAXS) analyses. The quaternization of PVC-g-P4VP with hexyl bromide afforded materials with a potential antimicrobial activity against Escherichia coli (E. coli), Staphylococcus aureus (S. aureus), Bacillus cereus (B. cereus), and Pseudomonas aeruginosa ( $P$. aeruginosa); about $100 \%$ of killing efficiency was observed after $24 \mathrm{~h}$ of contact.
A pyrimidine derivative was covalently incorporated onto PVC backbone by reaction of $N, N$-dimethyl- $N$ '-(6oxo-2-thioxo- $1 \mathrm{H}$-pyrimidine-4-yl)formamidine in THF at $60{ }^{\circ} \mathrm{C}$ for $5 \mathrm{~h}$ [56] as illustrated in Eq. 7. Nearly $50 \%$ of chlorine atoms of PVC were substituted. The thusfunctionalized PVC was experimented for antibacterial activity against Staphylococcus aureus, Bacillus cereus, Escherichia coli and Salmonella typhimurium, and for antifungal activity against Candida albicans and Aspergillus flavus. The antibacterial effects of modified PVC, using Cefoperazone as standard, were $78.57 \%$ (Gram+ Staphylococcus aureus), 92.86\% (Gram+ Bacillus cereus), $92.86 \%$ (Gram- Escherichia coli), and $71.43 \%$ (Gram- Salmonella typhimurium); those for native PVC were $0,78.57,71.43$, and $0 \%$, respectively. However, its antifuncal activity was found to be lower than that of the unmodified PVC. The effect of this pyrimidine functionalization was the relatively good photostability of the modified PVC and the solidity towards discoloration; a maximum decrease of its molecular weight $M_{\mathrm{w}}$ of only $6.16 \%$ occurred after $10 \mathrm{~h}$ of UV irradiation.

Functionalization of thermoplastic polymers with silanes and siloxanes was surveyed by Chruściel and E. Leśniak [57]. Polish researchers [58] reported the modification of PVC sheets by organosilanes after a plasma operation. The latter treatment generated hydroxyl groups on the PVC surface in an extent of $1.47 \mathrm{nmol} . \mathrm{cm}^{-2}$, which reacted with organosilanes, including $1 \mathrm{H}, 1 \mathrm{H}, 2 \mathrm{H}, 2 \mathrm{H}$-perfluorooctylmethyldimethoxysilane, isobutylmethyl dimethoxysilane, (3-glycidoxypropyl)trimethoxysilane, and 3(1-tertbutylamine-2hydroxy)propyloxypropyl diethoxymethylsilane, in the presence of tin (II) octoate as catalyst. Surface tensions of PVCs modified with the last two organosilanes were about twice that of virgin PVC sheet, whereas those for PVCs modified with the first two organosilanes were slightly higher. Polar forces, for the former modifications, were found to contribute largely to the surface tension, and, for the latter ones, the dispersive forces were predominant. These specimens were examined for antibacterial activity against Aeromonas hydrophila strain. Adhesion test
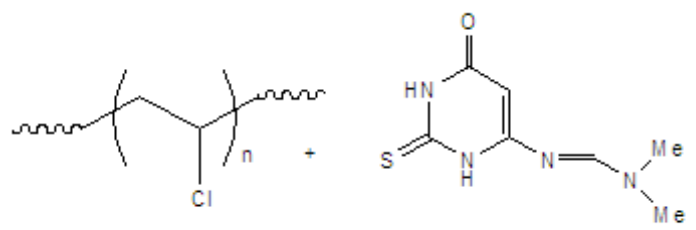

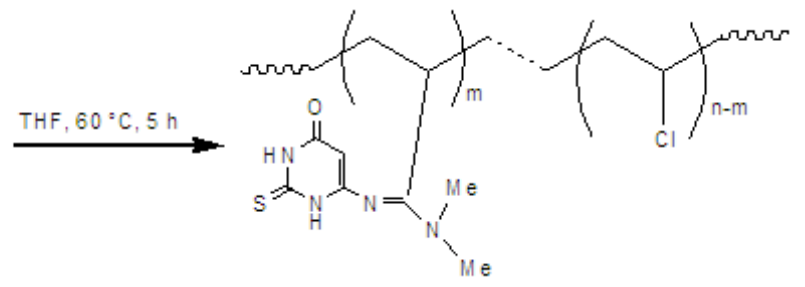




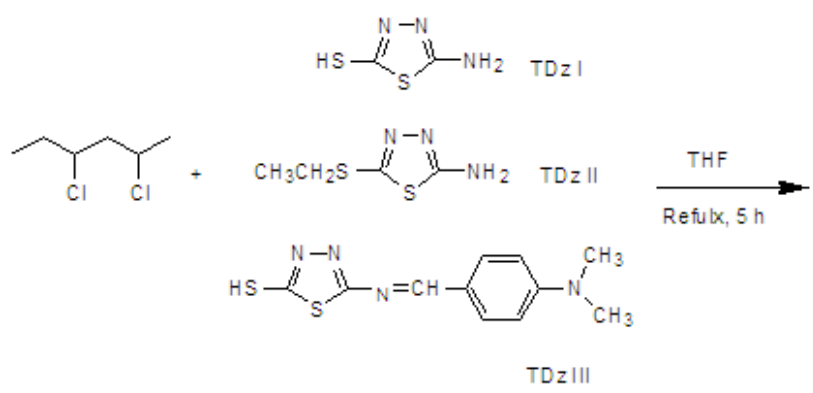

(8)
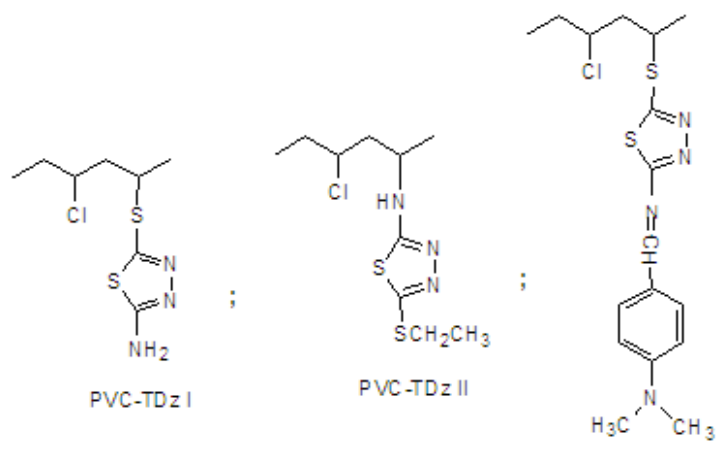

PVC-TDZ III showed that PVCs modified with the first three organosilanes were more efficient than PVC modified with the last one which behaved similarly to the pristine PVC.

A means of detection of Bacillus anthracis spores was conceived by Oztuna et al. [59] and realized by providing a coating of aminated PVC on quartz crystal microbalance (QCM) immunosensor; aminated PVC was obtained by refluxing a mixture of PVC and 1,3diaminopropane in DMF for $3 \mathrm{~h}$.

Thiadiazole-bearing units were appended to PVC chains through amino and mercapto bridges [60]. The substitution reaction on PVC was induced by 2-amino5-thiol-1,3,4-thiadiazole (TDz I), 2-amino-5-ethyl thio1,3,4-thiadiazole (TDz II), and 2[4-dimethyl amino benzylidine] 5-thiol- 1,3,4-thiadiazole (TDz III), in THF and in the presence of pyridine at reflux for $5 \mathrm{~h}$, to yield PVC-TDz I, PVC-TDz II, and PVC-TDz III, respectively,
(Eq. 8). The as-modified PVCs were yellow to brown powders, soluble in DMF, DMSO, methanol $(\mathrm{MeOH})$, and diethyl ether (DEE) (except for PVC-TDz III), and characterized with softening points of 250, 210 and 290 ${ }^{\circ} \mathrm{C}$, respectively. These PVC-TDz materials, particularly PVC-TDz III, exhibited good antimicrobial activity against Escherichia coli Staphylococcus arueus bacteria.

Kébir et al. [47, 61] realized the covalent functionalization of bioactive seaweed polysaccharide, methyl and hydroxyethylcellulose (MC, HEC) onto PVC backbone. Isothiocyanate functionality served as an intermediate means for binding these polysaccharides to PVC matrix through o-thiocarbamate linkage. PVC films $\left(M_{\mathrm{w}}=80000 \mathrm{~g} / \mathrm{mol}\right)$ were allowed to react with potassium thiocyanate in DMSO/water and in the presence of tetrabutylammonium hydroxide (TBAH) at $60{ }^{\circ} \mathrm{C}$ for $17 \mathrm{~h}$. For the grafting of MC and HEC with different molecular weights, PVC sheets were
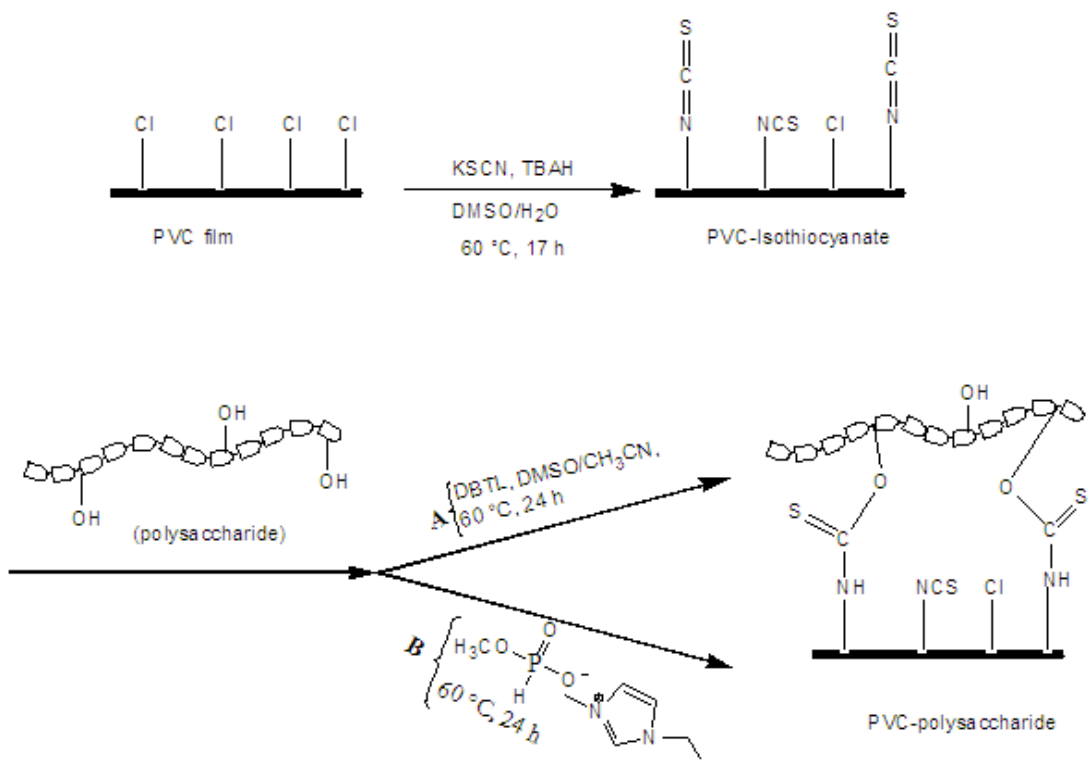
immersed for $24 \mathrm{~h}$ at $60{ }^{\circ} \mathrm{C}$ into a DMSO/acetonitrile solution containing the polysaccharide and dibutyltin dilaurate as catalyst (Eq. 9A). Static contact angles with water $\theta_{\mathrm{w}}$ and polarities of the PVC-MC $\left(M_{\mathrm{w}}\right.$ of MC $=88000 \mathrm{~g} / \mathrm{mol})$ and PVC-HEC $\left(M_{\mathrm{w}}\right.$ of HEC $=720000$ $\mathrm{g} / \mathrm{mol}$ ) were 60 and $65^{\circ}, 22.7$ and $14.6 \%$, respectively; those for PVC and PVC-isothiocyanate were 89 and $44^{\circ}, 2.3$ and $32.7 \%$, respectively. The grafted PVCpolysaccharides were more polar and more hydrophilic than pristine PVC sheet and less polar and less hydrophilic than PVC-isothiocyanate films. However, the grafting of seaweed polysaccharides (Laminarin 822, Ulvan 901, Ulvan 815, Ulvan 815, Fucan 812, Zosterin 900) onto PVC film via isothiocyanation was accomplished in 1-ethyl-3-methyl-imidazolium phosphate, an ionic liquid, and under the same temperature and time (Eq. 9B). The static contact angles with water $\theta_{\mathrm{w}}$ and polarities of these PVCseaweed polysaccharides varied in the range of $56-61^{\circ}$ and $19.5-26.3 \%$.

Monika et al. [62-64] investigated the biocompatibility of surface-modified medical grade PVC with thiosulfate TS $\left(\mathrm{S}_{2} \mathrm{O}_{3}{ }^{2-}\right)$, sulfite $\mathrm{S}\left(\mathrm{SO}_{3}{ }^{2-}\right)$, and thiourea TU $\left(\left(\mathrm{NH}_{2}\right)_{2} \mathrm{C}=\mathrm{S}\right)$ as ionomers. The modifications involved the reactions of the ionomers with PVC film in THF at $60-65{ }^{\circ} \mathrm{C}$ for $5-6 \mathrm{~h}$ and in the presence of $t$-butylammonium hydrogen sulfate (TBAHS), a phase transfer catalyst. The functionalized PVC films, PVC-TS, PVC-S, PVC-TU started to decompose at temperatures lower than that of PVC $\left(240{ }^{\circ} \mathrm{C}\right)$ that is 200,190 , and $219{ }^{\circ} \mathrm{C}$, respectively. Anchoring the ionomers onto PVC did not alter the morphology of the polymer but diminished its hydrophobicity, hence improving wettability, as the water contact angles were measured to be lower than that of PVC: 65,60 , and $55^{\circ}$ versus $82^{\circ}$. Lower hemolysis was found with the functionalized PVC films $(<3 \%)$ compared with bare PVC $(6 \%)$; hemolysis degree is taken as a blood compatibility estimation. However, the chemical modifications did not bring about a change in the adhesion of bacteria.

Brooks and his collaborators [65] adopted the surface-initiated atom transfer radical polymerization (SI-ATRP) to fashion polymer brushes from unplasticized poly(vinyl chloride) and $\mathrm{N}, \mathrm{N}$ dimethylacrylamide (DMA) monomer. As shown in Eq. 10, PVC surface underwent three successive modifications by reaction with 4-aminothiophenol, glycidol, and finally with 2-chloropropionyl chloride, affording an ATRP macroinitiator. DMA polymerization was initiated under ATRP conditions and the grown poly $(\mathrm{N}, \mathrm{N}$-dimethylacrylamide) (PDMA) brushes were characterized by molecular weights $M_{\mathrm{n}}$ of as low as 35 $000 \mathrm{~g} / \mathrm{mol}$ and as high as $2100000 \mathrm{~g} / \mathrm{mol}$ and with a polydispersity index of $1.24-1.92$. The graft density ranged from 0.05 to 1.13 chains $/ \mathrm{nm}^{2}$. The water contact angle $\theta_{\mathrm{w}}$ decreased dramatically to $0^{\circ}$ for PVC$g$-PDMA graft copolymers with high molecular weights and high graft density, suggesting a change in the interfacial energy. The PVC-g-PDMAs with increasing molecular weights and graft densities up to 0.5 chains $/ \mathrm{nm}^{2}$ lowered the platelet activation in plateletrich plasma (PRP).

\subsection{Enzyme/Protein Immobilization}

Polymeric materials have continued to serve as immobilizing supports for enzymes since the Merrifield's solid-state peptide synthesis breakthrough.
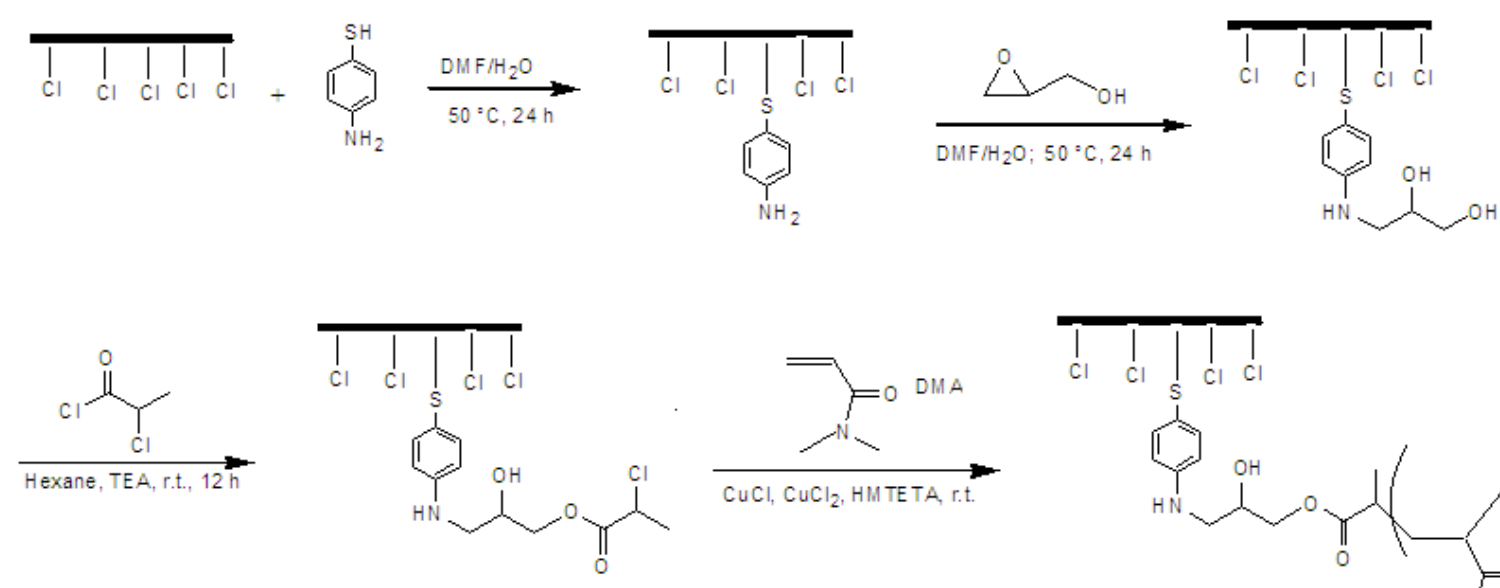

PVC-based ATRP macroinitiator

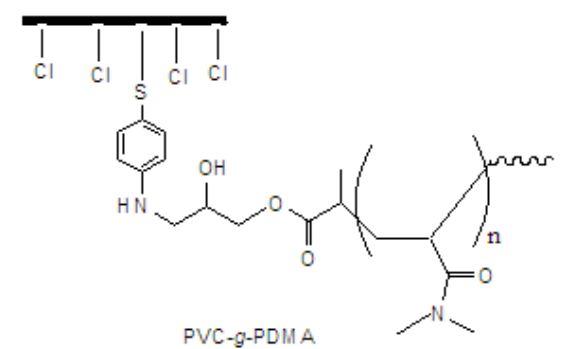


Specific applications require relevant polymers with adequate functionalizations towards immobilizing of enzymes. A sound review on this special issue was published in 2014 by Mohy Eldin and Mita [66]. In fact, Mohy Eldin and his co-workers [67-70] were able to covalently immobilize penicillin $G$ acylase and $\beta$ galactosidase onto PVC matrix via the amine functionalization as depicted in Scheme 2. The immobilized penicillin $G$ acylase was employed for the production of 6-aminopenicillanic acid (6APA) from penicillin hydrolysis. The PVC membrane, prepared by casting from a THF solution, was put in contact with aqueous solution of ethylenediamine at $80{ }^{\circ} \mathrm{C}$ for $1 \mathrm{~h}$. Immobilization of enzyme was performed after activation of the PVC- $\mathrm{NH}_{2}$ membrane with glutaraldehyde in phosphate buffer solution of a $\mathrm{pH}$ of 7.8 at $4{ }^{\circ} \mathrm{C}$ for $16 \mathrm{~h}$. It was claimed that glutaraldehyde enhanced the conformational flexibility and the enzymatic activity, and restricted the interactions among immobilized enzyme molecules. Optimal immobilization yield and penicillin $G$ acylase activity were observed for a temperature of $30^{\circ} \mathrm{C}$ and a time of $16 \mathrm{~h}$. The apparent kinetic parameters, Michaelis constant $K_{\mathrm{m}}$ and velocity $V_{\max }$ for the immobilized enzyme in the catalytic production of 6aminopenicillanic acid were 23 times higher and six times lower, respectively, than those of the free one. The results on $\beta$-galactosidase-immobilized PVC microspheres showed some promise in the industrial use for milk production; about $80 \%$ of lactose could be hydrolyzed within $6 \mathrm{~h}$ at $60{ }^{\circ} \mathrm{C}$ by virtue of using this immobilized enzyme. $K_{m}$ and $V_{\max }$ of the lactose hydrolysis using the immobilized $\beta$-galactosidase were, respectively, 2.36 and 1.63 times higher than those using the free form.

Zhou et al. [71] applied the same glutaraldehyde activation process for PVC- $\mathrm{NH}_{2}$ microspheres to immobilize trypsin-chymotrypsin, a mixed protease. The activity of the immobilized enzyme was found to increase with the amination degree; an optimal activity was seen for $\mathrm{PVC}-\mathrm{NH}_{2}$ with $\% \mathrm{~N}$ of about $0.03 \%$. And, a better glutaraldehyde activation happened under the following conditions: a glutaraldehyde concentration of $1.0 \%$, a pH of 3.0 , a contact time of $1 \mathrm{~h}$, and a reaction temperature of $40{ }^{\circ} \mathrm{C}$. The immobilized mixed trypsin/chymotrypsin with maximum activity $(1341 \mathrm{U} / \mathrm{g})$ was made under the following optimal conditions: a $\mathrm{pH}$ of 6.6 , a temperature of $23^{\circ} \mathrm{C}$, and a contact time of 2 h. The catalytic hydrolysis of casein using the trypsin/chymotrypsin-immobilized PVC followed Michaelis-Menten kinetics. The Michaelis constant $K_{\mathrm{m}}$ was greater than that for the free enzyme system, 23.65 against $19.33 \mathrm{~g} / \mathrm{L}$, and the corresponding $V_{\mathrm{m}}$ was lower, 1.36 against $1.96 \mathrm{U}$, under optimum conditions $\left(\mathrm{T}=55^{\circ} \mathrm{C}, \mathrm{pH}=7.5-8.2\right)$.

Koncki and his team [72] realized the covalent immobilization of alkaline phosphatase onto the inner wall of PVC tubing, conceived as a bioreactor. PVC tubing was coated with carboxylic acid-functionalized PVC layer by immersion into THF. 1-Ethyl-3-(3dimethylaminopropyl) carbodiimide hydrochloride was employed for attaching the phosphatase enzyme (coded as ALP, EC 3.1.3.1) onto the inner wall of PVC tubing. Such a thus-mounted bioreactor was tested for the hydrolysis of $p$-nitrophenyl phosphate. The
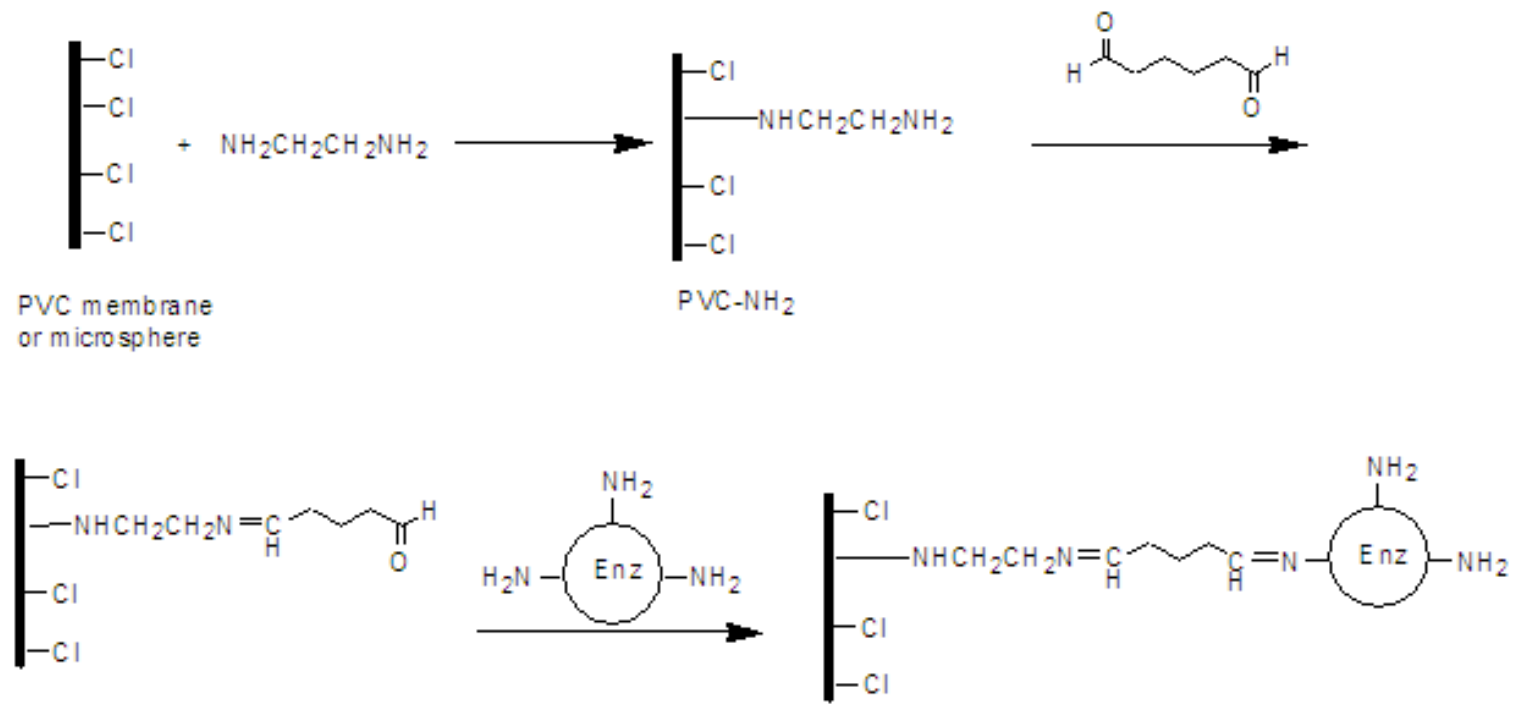

Enzyme-im mobilized PVC

Scheme 2: Required steps for immobilization of enzymes on PV surface. 
hydrolysis success was quantified in terms of $p$ nitrophenol formation, and the results revealed that the as-made bioreactor showed better performance than the uncoated PVC tubing. Also, the success of this operation was attributed to the use of 1-ethyl-3-(3dimethylaminopropyl) carbodiimide as an effective crosslinker for the enzyme immobilization.

The protein horseradish peroxidase (HRP) was covalently bound to DEHP-plasticized and unplasticized medical grade PVC sheets upon surface treatment with ion beam implantation (plasma) [73]. Such plasma operation caused wettability changes of the PVC materials; water angle contact $\theta_{\mathrm{w}}$ decreased when freshly beamed and increased after storage: 58 and $12.8^{\circ}$ for plasticized and unplasticized PVC, respectively, after $1600 \mathrm{~s}$, and 87 and $46.6^{\circ}$ after 4-5 days. The immobilized HRP was found to resist to sodium dodecyl sulfate washing, only $18 \%$ of the protein was leached, suggesting a strong binding of the enzyme to the polymer matrix. The enzymatic activity of the HRP-immobilized unplasticized PVC after a plasma treatment in the known 3,3,5,5'tetramethylbenzidine assay, that is the reduction of hydrogen peroxide to water, was found to drop with time, whereas that for plasticized one was maintained for two weeks if plasma treatment time was longer than $400 \mathrm{~s}$. The plasma treatment and the plasticization seemed to have a significant effect on the enzyme immobilization stability.

Arenas et al. [74] succeeded in covalently linking streptokinase coenzyme onto a graft copolymer PVC-gPEGMA grafted (poly(vinyl chloride)-g-poly(ethylene glycol)methacrylate). PEGMA grafting occurred on PVC irradiated with mercury lamp, at a temperature of 50,60 , or $70{ }^{\circ} \mathrm{C}$ for $23 \mathrm{~h}$; a maximum grafting efficiency of about $82 \%$ was achieved for a temperature of $70{ }^{\circ} \mathrm{C}$, PVC irradiation time of about $3 \mathrm{~h}$, and $1 \mathrm{M}$ of EGMA monomer. Such grafting would impart a good mechanical property of the system and a degree of hydrophilicity $\left(\theta_{w} \sim 68-72^{\circ}\right.$ against $\left.86^{\circ}\right)$. The immobilization course involved the use of 1-ethyl-3-(3dimethyl aminopropylcarbodiimide hydrochloride) and sulfo- $N$-hydroxysulfosuccinimide and UV light. The results of immobilized enzyme test for H-D-Val-LeuLys-pNA $\times 2 \mathrm{HCl}$ substrate were: $K_{\mathrm{m}}=0.14 \mu \mathrm{M}$ and $V_{\max }=29.8 \mu \mathrm{M} \mathrm{min}^{-1}$.

The chemistry using 1-ethyl-3-(3-dimethyl aminopropylcarbodiimide hydrochloride) and sulfo- $N$ hydroxysulfosuccinimide was applied for covalently immobilizing avidin, a biotin-binding protein, to electrospun nanofiber PVC membrane [75]. The avidinappended nanofiber membrane was functionalized with biotinylated quantum dot (QD) in view of quantifying fluorescently the avidin content. To this end, PVC with $1.8 \%$ of carboxylic acid group was transformed into electrospun nanofiber membrane to which avidin was linked, followed by QD attachment.

Gabriel et al. [76] performed a thorough study on the amination of surface of PVC films, using $20 \%$ of ethylene diamine in isopropanol at ambient temperature for different times. The maximum amination extent occurred for a period of time of $30 \mathrm{~min}$ for which a surface density of amino groups attained $10.5 \mathrm{l} / \mathrm{nm}^{2}$. The water contact angle $\theta_{\mathrm{w}}$ of this aminated PVC film was measured to be $75.8^{\circ}$ (that for untreated PVC film was $102.9^{\circ}$ ), hinting at a hydrophobicity lowering. The aminated PVC was taken as scaffold for covalently immobilizing the cell adhesive Asp-Gly-AspSer peptide (a RGD peptide), thus providing sites for cellular adhesion and proliferation of fibroblasts. Compared with untreated and PEGylated PVC surfaces, the RGD-immobilized PVC one demonstrated excellent attachment of fibroblasts; surface coverage of fibroblasts after three weeks was as follows: $1.3 \%$ on untreated surface, $0.43 \%$ on PEGylated surface, and $53 \%$ on RGD-modified surface. PEGylation, which provides greater hydrophilicity, prevented the cellular adhesion and acted as antifouling means. The latter fact has been medically valorized in blood contacting devices that may inhibit the adhesion of platelets [77]. Stachelek and his co-workers [78] applied a multistep methodology to covalently append a recombinant CD47 protein onto medial grade PVC surface via thiol groups of its lysine moiety (Figure 4). The as-made PVC-CD47 exhibited blood contacting properties, preventing the adhesion and activity of platelets and neutrophils, the cellular blood components.

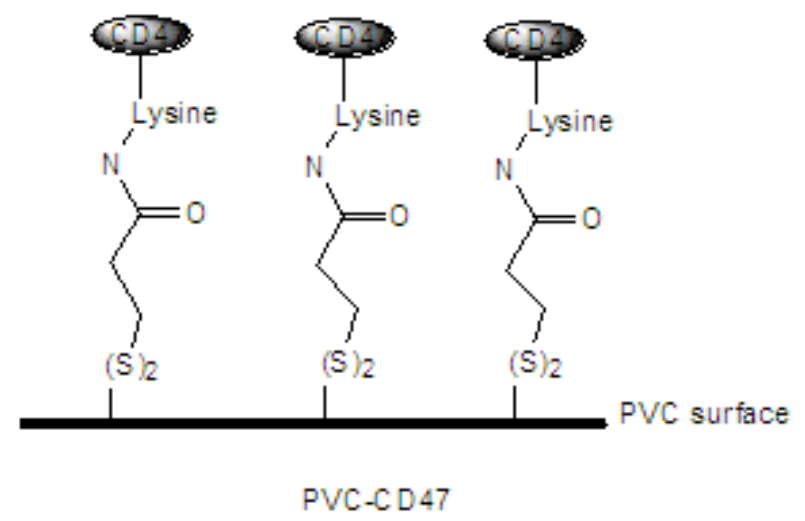

Figure 4: The immobilization of CD47 protein on PVC via lysine unit. 


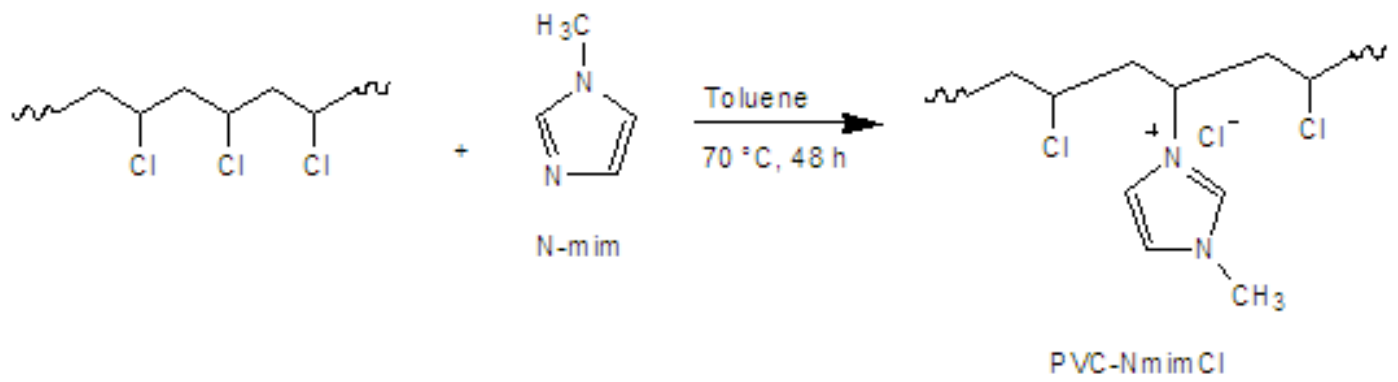

\begin{abstract}
Zhao Qiang et al. [79] grafted $\operatorname{poly}(N-$ vinylpyrrolidone) (PVP) and poly([2(methacryloyloxy)ethyl]dimethyl-(3-sulfopropyl) ammonium hydroxide (PMEDSAH) onto PVC surface via dopamine methacrylamide (DAMA) as a bridging spacer. The grafting polymerization of NVP and MEDSAH was conducted in the presence of AIBN and $(\mathrm{NH} 4)_{2} \mathrm{~S}_{2} \mathrm{O}_{3}$, respectively, at $60{ }^{\circ} \mathrm{C}$ for $6 \mathrm{~h}$. The covalent link between PVC surface and DAMA, and the graft copolymers, PVC-g-PVP, and PVC-g-PMEDSAH, were confirmed by IR and XPS analyses. The modifications reduced the hydrophobicity of the parent PVC; $\theta_{\mathrm{w}}$ 's were $\sim 75^{\circ}$ (PVC), $\sim 55^{\circ}$ (PVC-DAMA), and $\sim 30^{\circ}$ (PVC-PVP). The antifouling properties of the modified PVC were demonstrated by fibrinogen adsorption test; fibrinogen adsorption levels were 0.76 , 0.24 , and $0.19 \mu \mathrm{g} / \mathrm{cm}^{2}$ for PVC, PVC-g-PVP, and PVC$g$-PMEDSAH, respectively, a $68-75 \%$ antifouling efficiency of the modified PVCs.
\end{abstract}

The grafted amphiphilic copolymer poly(vinyl chloride)-graft-poly(oxyethylene methacrylate) (PVC-gPPEOM), synthesized as shown below (Eq. 37), was experimented in protein, bacteria, and cell adhesion [80]. Hydrophilicity, which is due to PEG segments, increased with PEOM content; the water contact angle of the copolymer with these molecular weights was $51.35^{\circ}$ against that for PVC $\left(113.43^{\circ}\right)$. The adhesion of BSA, Escherichia coli (E. coli), Staphylococcus aureus ( $S$. aureus), Bacillus cereus (B. cereus), and mouse embryonic fibroblast (MEF) cells was reduced by coating the tested surface with graft copolymer PVC-gPPEOM; the BSA adsorption dropped from 170 to to 22 $\mathrm{mg} / \mathrm{g}$.

Chinese workers [81] covalently immobilized $\mathrm{N}$ methylimidazole (N-mim) on surface and bulk of PVC, through a nucleophilic substitution mechanism, to end up with hydrophilic ionic liquid-PVC hybrids, PVC$\mathrm{NmimCl}$. The operation consisted of reacting $\mathrm{N}$ methylimidazole with PVC in toluene at $70{ }^{\circ} \mathrm{C}$ for $48 \mathrm{~h}$ (Eq. 11). Degrees of immobilization reached 2.8 and
$15.1 \%$ on surface and bulk, respectively. Selective adsorption of proteins by bulk PVC-NmimCl with $10.8 \%$ grafted N-mim; almost $95 \%$ adsorption of basic proteins (lysozyme, cytochrome c, hemoglobin), whereas that for acidic ones (immunoglobulin G, bovine albumin serum, transferrin) was insignificant (0$4 \%)$. The protein adsorption efficiency was found to drop at a $\mathrm{pH}$ higher than the isoelectric point of the particular protein, and an insignificant change in adsorption was observed at an ionic strength higher than $0.1 \mathrm{~mol} / \mathrm{L}$.

\section{FUNCTIONALIZATIONS FOR MORE CHEMISTRY}

\subsection{Click Chemistry}

Photoinduced CuAAC click chemistry was applied for the synthesis of poly( $\varepsilon$-caprolactone)-grafted PVC (PCL-g-PVC) [82]. Azidation of PVC $\left(M_{n}=57800\right.$ $\mathrm{g} / \mathrm{mol}$ ) took place with sodium azide in DMF-water at $60{ }^{\circ} \mathrm{C}$ for $48 \mathrm{~h}$ (Eq. 12); the yield was $86.3 \%$ and $10 \%$ of chlorine atoms were substituted by azide groups. Click chemistry between poly( $\varepsilon$-caprolactone)-alkyne $\left(M_{\mathrm{n}}=8000 \mathrm{~g} / \mathrm{mol}\right)$ and $\mathrm{PVC}-\mathrm{N}_{3}$ proceeded in the presence of $\mathrm{CuBr}_{2}, \quad \mathrm{~N}, \quad \mathrm{~N}, \quad \mathrm{~N}^{\prime}, \quad \mathrm{N}^{\prime \prime}, \quad \mathrm{N}^{\prime \prime}$ pentamethyldiethylenetriamine (PMDETA), and 2dimethoxy-2-phenyl acetophenone (DMPA), in DMF and irradiation for overnight; the yield of the grafted copolymers was about $81 \%$ and the grafting efficiency was $89 \%$. The glass transition temperatures $T_{\mathrm{g}}$ 's of $\mathrm{PVC}^{-\mathrm{N}_{3}}$ and the graft copolymer (PCL-g-PVC) were measured to be 87 and $76{ }^{\circ} \mathrm{C}$, respectively, along with the melting point $T_{\mathrm{m}}$ of grafted $\mathrm{PCL}$ detected at $47^{\circ} \mathrm{C}$; PCL could have acted as a macromolecular plasticizer for PVC.

Taking advantage of the existence of polyene sequences ( 10-30 conjugated double bonds) in PVC formed during its processing, Iván et al. [83] were able to thiolate PVC through a thiol-ene click reaction (Eq. 13). The thiolation of PVC proceeded in THF with thiolacids, thiol-esters, or thiol-alcohols via radical initiation using AIBN inifer. 


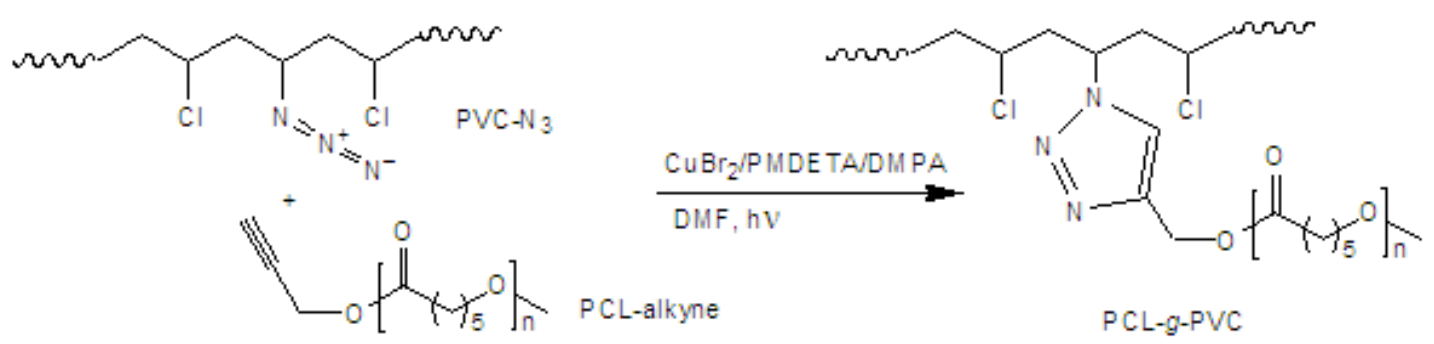

(12)

Akat and Ozkan [84] prepared a macrophotoinitiator using click reaction between azidated PVC and 2(prop-2-yn-1-yloxy)-9H-thioxanthen-9-one in the presence of copper (II) bromide, 2,2'-bipyridine, and in DMF at room temperature for $24 \mathrm{~h}$. The as-made PVCthioxanthone (Figure 5) was characterized by an absorption band at $\lambda_{\max }=340-400 \mathrm{~nm}$, corresponding to the thioxanthone moiety, and was thermally stable up to a temperature of $250{ }^{\circ} \mathrm{C}$. The PVC-thioxanthone was efficient in photoinitiating the polymerization of vinyl monomers, namely methyl methacrylate (MMA), methyacrylic acid (MAA), styrene (St), and $N$ vinylpyrrolidone (NVP) in DMSO and in the presence of triethylamine as hydrogen donor. Of these monomers styrene, unexpectedly, could not be photopolymerized under the cited conditions. The average mass molars $M_{\mathrm{n}}$ of the corresponding polymers were: $19500 \mathrm{~g} / \mathrm{mol}$ (PMMA), $80877 \mathrm{~g} / \mathrm{mol}$ (PMAA), and $101200 \mathrm{~g} / \mathrm{mol}$ (PNVP). The PVC-thioxanthone proved to be useful in photocuring bifunctional monomers such as 1,1,1-tris(hydroxymethyl)-propan-triacrylate, resulting in a crosslinked network, a technique widely applied in UVcurable varnishes.

\subsection{Poly(vinyl chloride)-supported Catalysts}

\subsubsection{Poly(vinyl chloride)-supported Metals}

Polymer-supported catalysts are still assisting chemical reactions whenever the related advantages in their use are sought for. Nowadays, not only does the novelty lie on the outcome of the reactions but also on the use of the supported metals in their nanoparticle form. The uses of polymer-supported transition metal catalysts in some coupling reactions were reviewed [85].

Copper- and solvent free Sonogashira and Heck coupling reactions were promoted by PVC-supported palladium complexes as investigated by Bakherad's school [86-89]. Bidentate nitrogen- and sulfurcontaining chelating ligands, phenyldithiocarbazate, 4amino-3-methyl-5-mercaptotriazole, 4-amino-6-methyl3-thio-1,2,4-triazine-5-one, and 1,5-diphenyl-3thiocarbazone (dithizone), were covalently bound to PVC matrix, followed by complexing $\mathrm{Pd}^{\prime \prime}$ as sketched in Scheme 3. Such functionalizations occurred generally in DMF at $80{ }^{\circ} \mathrm{C}$ for $20-30 \mathrm{~h}$ and the complexing reactions were accomplished with $\mathrm{PdCl}_{2}(\mathrm{PhCN})_{2}$ in
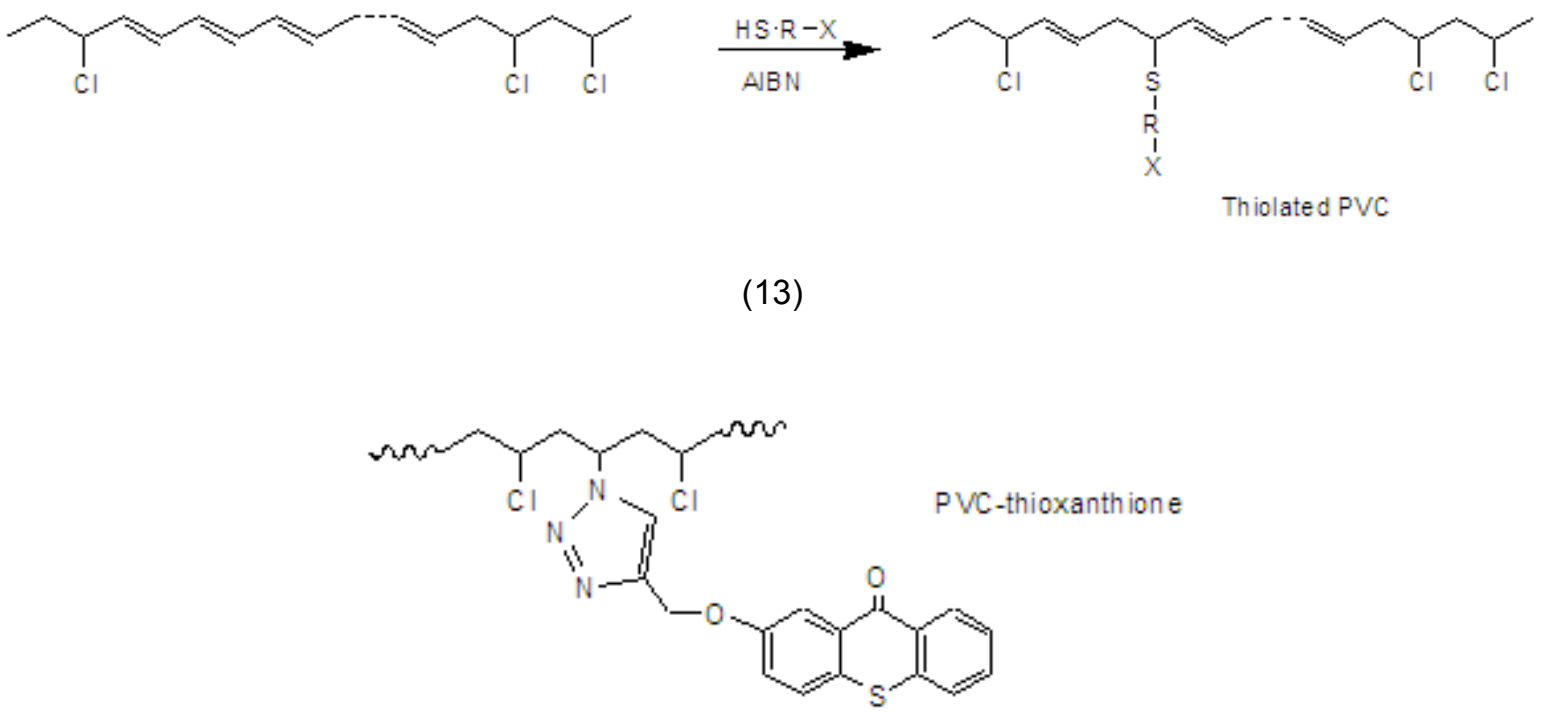

Figure 5: Chemical structure of PVC-thioxanthone. 
$\mathrm{DMF} / 80{ }^{\circ} \mathrm{C}$ or EtOH/reflux for $15-20 \mathrm{~h}$. The PVCchelator-Pd" complexes (A, B, C, D) were found to contain palladium in amounts of $2.2-4.9 \% \mathrm{~g} / \mathrm{g}$ as evidenced by inductively coupled plasma atomic emission spectroscopy (ICP-AES), and nitrogen contents (indirect measure of degree of substitution) in the range of $2.5-4.6 \%$. The PVC-chelator-Pd" complexes were bright yellow and stable in an aerobic ambiance. The catalytic activities of these complexes in Sonogashira and Heck coupling reactions shown in
Eqs. 14 and 15 depended on the base used. For the complexes $\mathbf{A}$ and $\mathbf{B}$, the best yields of Sonogashira reaction obtained were $97-99 \%$ when using ethanolamine (for complex A), $\mathrm{Et}_{3} \mathrm{~N}$ (for complex $\mathbf{B}$ and D), and piperidine (for complex $\mathbf{C}$ ) as bases. The retention of catalytic activities of the PVC-chelator-Pd" complexes was excellent, and the yields dropped to only $93-94 \%$ after six runs, with a negligible palladium leaching (an utmost leaching of $10 \%$ ).
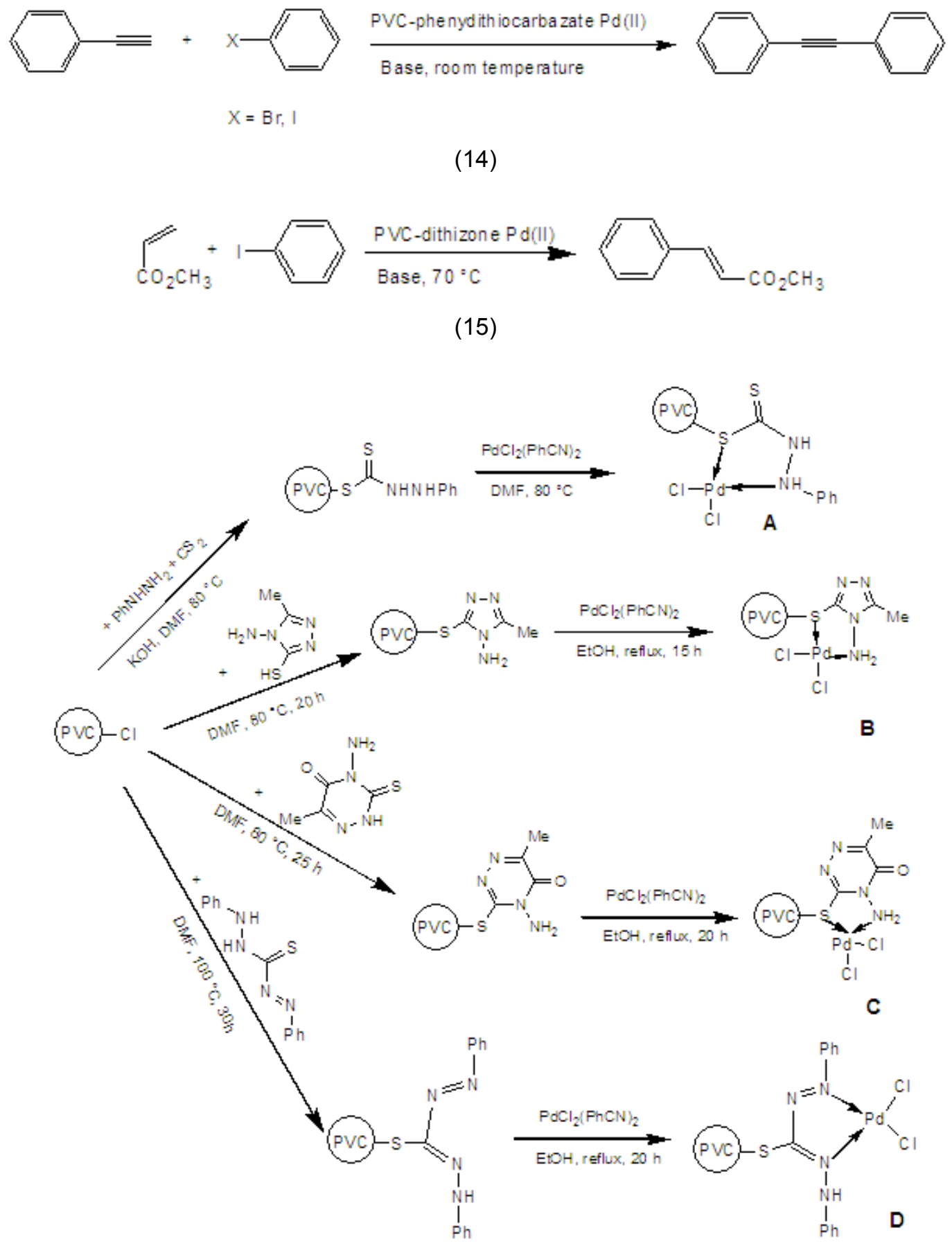

Scheme 3: Pathways for PVC-supported Pd complexes. 


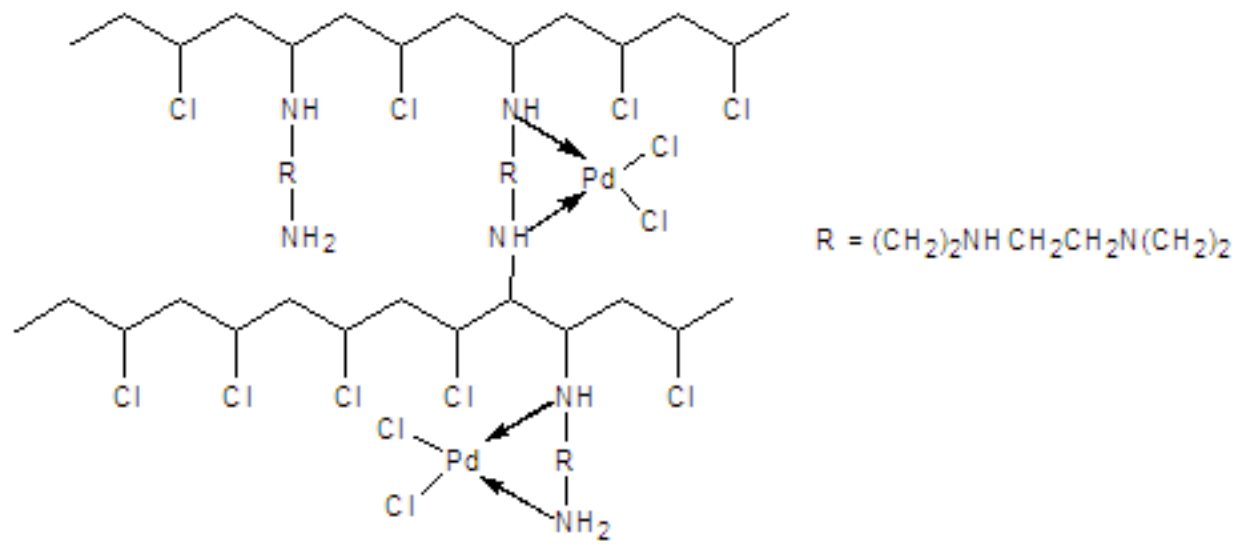

Figure 6: PVC-triethylenetetramine supported palladium complex.

Cui and his collaborators [90] realized a PVCtriethylenetetramine supported palladium complex (PVC-TETA-Pd) (Figure 6). Stirring the dispersion of $\mathrm{PVC}$ in triethylenetetramine at $80{ }^{\circ} \mathrm{C}$ for $3 \mathrm{~h}$ under aerobic conditions yielded PVC-TETA as a brown powder. Reaction of PVC-TETA with $\mathrm{PdCl}_{2}$ took place in acetone at $60{ }^{\circ} \mathrm{C}$ for $72 \mathrm{~h}$, affording PVC-TETA-Pd complex. The nitrogen content in this complex was 5 $\mathrm{mmol} / \mathrm{g}$ and $\mathrm{Pd}$ content was $0.32 \mathrm{mmol} / \mathrm{g}$. The complex was thermally stable up to $250^{\circ} \mathrm{C}$. The catalytic activity of PVC-TETA-supported Pd" in Heck coupling reaction, involving bromobenzene and styrene, was high as revealed by the quantitative yield obtained $(99.8 \%)$ at a temperature of $120{ }^{\circ} \mathrm{C}$ for $8 \mathrm{~h}$ under nitrogen atmosphere and in the presence of $(n-\mathrm{Bu})_{3} \mathrm{~N}$ as a base. Other bases such as $\mathrm{Et}_{3} \mathrm{~N}, \mathrm{Na}_{2} \mathrm{CO}_{3}, \mathrm{NaHCO}_{3}$, and $\mathrm{NaOAc}$, were experimented and, under identical conditions, the yields were $80.1,74.4,95.2$, and $99.7 \%$, respectively.

Zhang and his collaborators [91] aminated the chlorinated PVC (CPVC) in form of nanofiber mats made by electrospinning technique, with ethylenediamine (EDA), 1,3-propylenediamine (PDA), diethylenetriamine (DETA), tetraethylenepentamine (TEPA). These amine units served as ligands for supporting $\mathrm{Pd}^{0}$ (Figure 7 ). The immobilization extents of $\mathrm{Pd}^{0}$ were insignificant on the bare CPVC nanofber mat and about $3 \mathrm{wt} . \%$ on the aminated ones. Both amination and immobilization of $\mathrm{Pd}^{0}$ did not modify the morphology of the CPVC nanofber mat. However, the mechanical properties of the aminated CPVCs were enhanced; the tensile strength for CPVC-PDA was higher than that of CPVC nanofiber mat, 11 versus 6.5 MPa. These aminated CPVC-nanofiber mat-supported palladium compounds were examined for their catalytic activity in Heck coupling reactions between aromatic halides and acrylates (Eq. 16). The conversions and the yields in organic solvent and water were quantitative, mostly higher than $90 \%$. Also, the activity catalytic of these polymer-supported $\mathrm{Pd}^{0}$ could be retained after the fifth run.

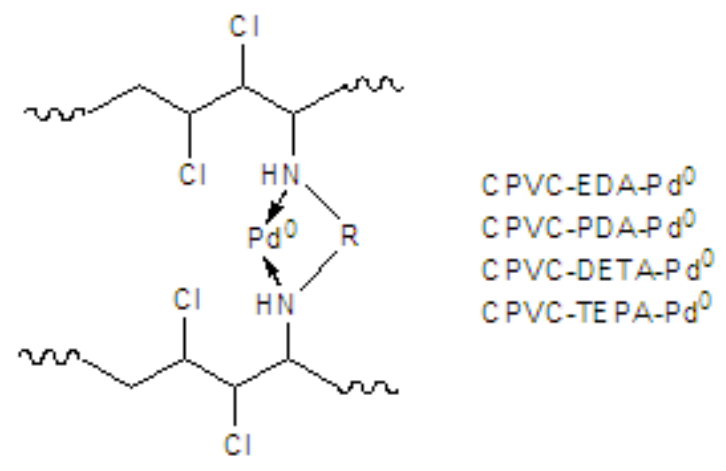

CPVC-Polyamine-Pd $\mathrm{d}^{\mathrm{O}}$

Figure 7: Immobilzed $\mathrm{Pd}^{0}$ on $\mathrm{PVC}$ crosslinked by polyamines.

Zhou and Li [92] were able to immobilize palladium nanoparticles onto pyridinium-functionalized PVC (PVC-Py) as traced in Eq. 17. Such PVC modification was realized in water using sodium hydroxide and an excess of pyridine and at a temperature of $80^{\circ} \mathrm{C}$. An in situ reduction of ethanolic solution of palladium chloride in the presence of PVC-Py afforded the immobilized palladium nanoparticles $\mathrm{Pd}^{0}, \mathrm{PVC}-\mathrm{Py}-\mathrm{Pd}^{0}$. The latter system was thermally stable up to a temperature of 174 ${ }^{\circ} \mathrm{C}$. The catalytic activity PVC-Py- $\mathrm{Pd}^{0}$ in the SuzukiMiyaura cross-coupling reaction of aryl halides and arylboronic acid (Eq. 18) was affected by the nature of base employed in this reaction and time. In general, the yields were moderate to excellent and the best one $(99 \%)$ was observed with potassium carbonate and a time of $1 \mathrm{~h}$ for nitrobromobenzene/phenylboronic acid. Retention of catalytic activity of PVC-Py- $\mathrm{Pd}^{0}$ was demonstrated to occur for six runs. 

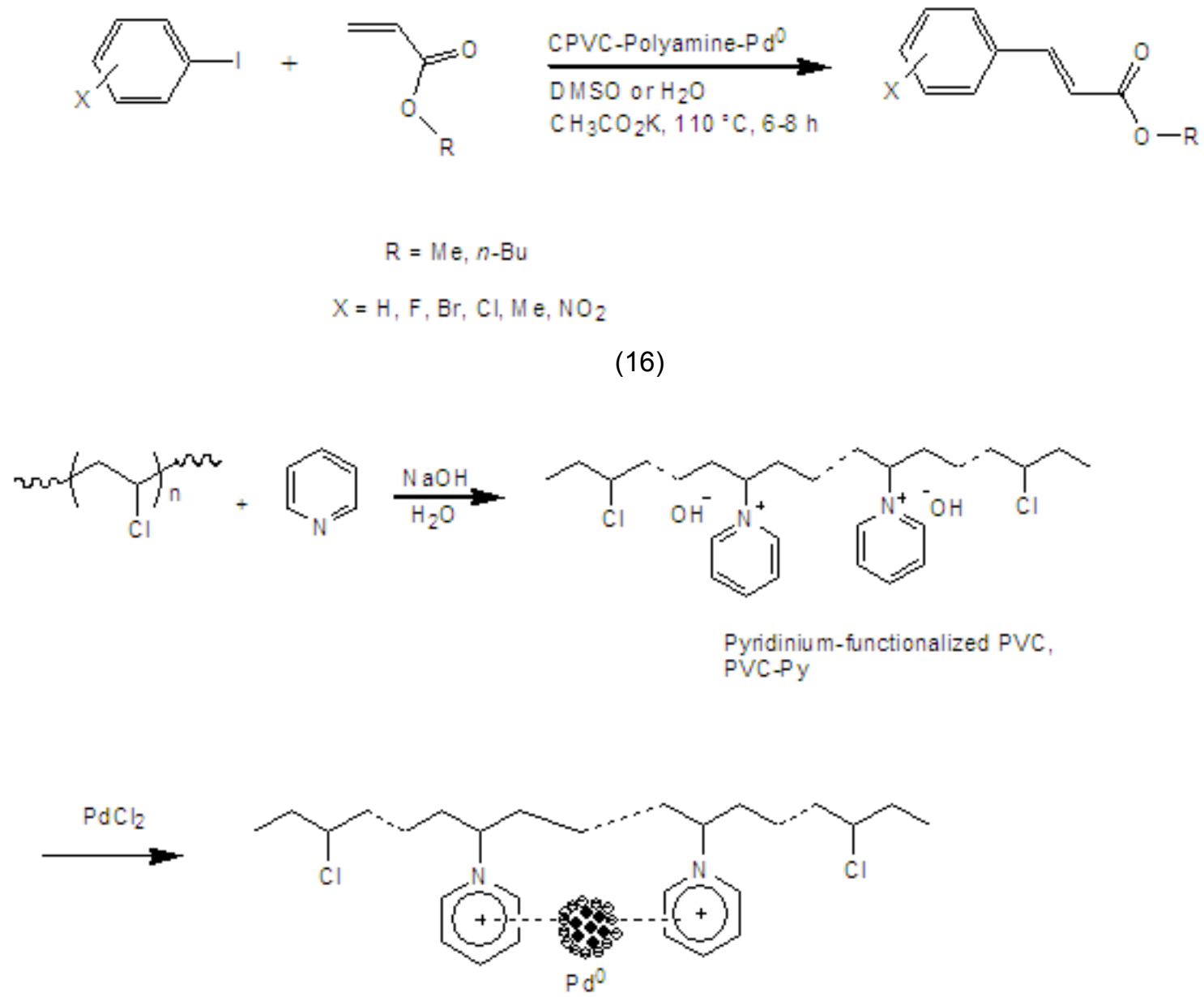

Pyridn ium -functionalized PVC - supported palladiunm nanoparticles, PVC -Py-P d

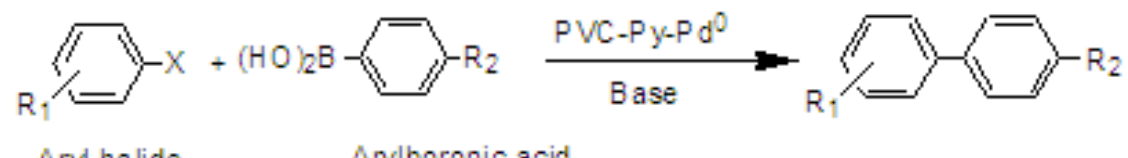

Aryl halide Arylboronic acid

Covalent modification of PVC with 2mercaptobenzothiazole (MBT) provided a polymer metal complex with a bidendate ligand [93]. The functionalization reaction was run in ethanol and in the presence of sodium hydroxide, at $50{ }^{\circ} \mathrm{C}$ for $12 \mathrm{~h}$ (Eq. 19). Nanoparticles of palladium $(40-60 \mathrm{~nm})$ were complexed to the modified PVC, PVC-MBT, by reaction with $\mathrm{PdCl}_{2}$ in ethanol at reflux for $24 \mathrm{~h}$. The resin PVCMBT-Pd ${ }^{0}$, obtained with a palladium content of 0.195 $\mathrm{mmol} / \mathrm{g}$, was thermally stable up to $\sim 223{ }^{\circ} \mathrm{C}$. This polymer complex catalyzed efficiently the SuzukiMiyaura coupling reaction between iodobenzene and phenylboronic acid, and the yields depended on the solvent, the base, the temperature, and the catalyst concentration. Of the screened solvents, alcohols $(\mathrm{MeOH}, \mathrm{EtOH}, \mathrm{PrOH})$ led to moderate to good yields (43-84\%) after short reaction times, and dioxane, THF, $\mathrm{DMF}$, toluene, acetonitrile $(\mathrm{MeCN})$, and DMSO were poor to ineffective media ( 0 to $6 \%$ yield). The appropriate base, temperature, and catalyst concentration as far as the yield of the reaction is important, were potassium carbonate, $80{ }^{\circ} \mathrm{C}, 0.1$ $\mathrm{mmol} / \mathrm{g}$, respectively, to give the maximum yield $(84 \%)$ for a reaction time of $5 \mathrm{~min}$. However, the yields of a 

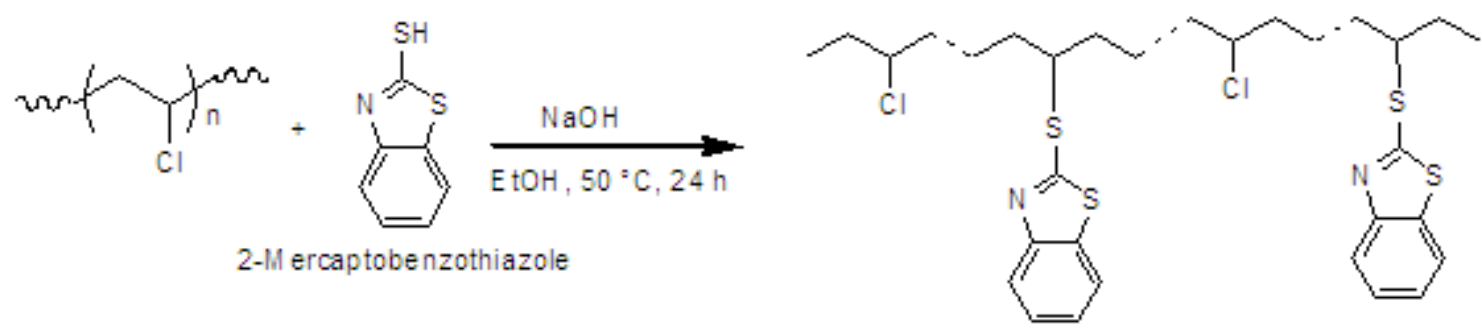

2-M ercapto benzothia zole-fun ctiona lized PVC, PVC-MBT
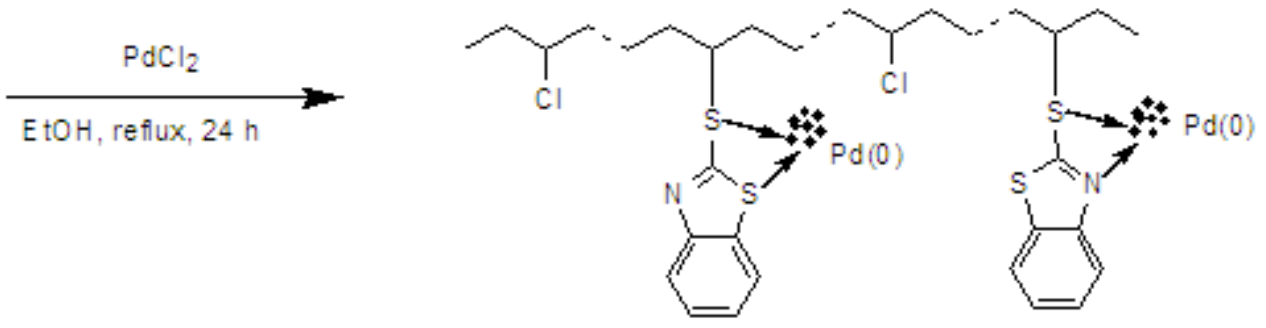

2-1M ercaptobenzothiazole-functionalized PVC-supported palladium nanoparticles, PVC-MBT-P ${ }^{0}$

(19)

number of Suzuki-Miyaura coupling reactions between suitably substituted iodobenzene and derivatives of phenylboronic acid were quantitative (up to $99 \%$ ) under the following conditions: PVC-MBT-Pd ${ }^{0}(0.001 \mathrm{mmol}$ of palladium), $\mathrm{K}_{2} \mathrm{CO}_{3}$ as a base, $95 \%$ ethanol as a solvent. PVC-MBT-Pd ${ }^{0}$ could retain its catalytic activity after a number of cycles; the yield of the reaction between 4-iodoanisole with phenyl boronic acid decreased from $98 \%$ to only $97 \%$ after the fifth cycle.

Hemantha and Sureshbabu [94] described a simple protocol to make PVC-supported $\mathrm{Pd}^{0}$ nanoparticles without a prior functionalization of $\mathrm{PVC}$ with a chelating agent. A dispersion of $\mathrm{PVC} / \mathrm{PdCl}_{2}$ in ethanol was treated, after a reflux, with $\mathrm{NaHB}_{4}$ to reduce $\mathrm{Pd}^{\prime \prime}$ to $\mathrm{Pd}^{0}$ for few minutes. $\mathrm{Pd}^{0}$ nanoparticles were formed within a size of $20 \mathrm{~nm}$ and their loading capacity in the resin was about $12.8 \%$ as estimated by ICP-OES. The resin $\mathrm{PVC}-\mathrm{Pd}^{0}$ was of value as catalyst in the reduction of a range of functional groups (nitro, azide, aldehyde, ketone, $\alpha, \beta$-unsaturated ester, and propargyl) and in the deprotection of some commonly used blocking groups in peptide chemistry. In general, the reduction required only 25 to $60 \mathrm{~min}$ (compared to $3-4 \mathrm{~h}$ with conventional catalyst $\mathrm{Pd} / \mathrm{C}$ for the hydrogenation of $p$ nitroaniline) with quantitative yields $(92-100 \%)$. The PVC-supported $\mathrm{Pd}^{0}$ nanoparticles were effective in the deprotection of peptide protectors such as carboxybenzyl (Cbz or Z), benzyl ester and benzyl ether; the deprotection of a number of protected peptide using $\mathrm{PVC}-\mathrm{Pd}^{0}$ occurred during hydrogenation with high yields, $68-100 \%$, within a period of time of $25-$ $110 \mathrm{~min}$.

Kajal's group [95] anchored four Schiff bases by reacting the PVC-bound ethylenediamine (PVC-EDA) with salicylaldehyde, vanillin, veratraldehyde, and camphor, in ethanol at reflux for $24 \mathrm{~h}$ (Eq. 20). The resulting PVC-supported Schiff bases were the platforms for making copper and nickel complexes by reaction with $\mathrm{CuCl}_{2}$ and $\mathrm{NiCl}_{2}$ in water at room temperature (Eq. 21). These PVC-supported transition metals were thermally stable up to $160-200{ }^{\circ} \mathrm{C}$. Their catalytic potency was experimented in the synthesis of $\beta$-amino alcohols by ring opening of epoxides (cyclohexene oxide, styrene oxide, 2-butene oxide, epichlorohydrin) with amines (aniline and methylated anilines), such as the one depicted in Eq. 22. The yields for the reaction between cyclohexene oxide and aniline were higher with nickel-based catalysts (60$94 \%)$ than those with copper-based ones (35-70\%). The ring opening reaction of the different epoxides with different anilines in the presence of PVC-supported nickel through Schiff base of salicylaldehyde afforded the corresponding $\beta$-amino alcohols in quantitative yields (80-93\%). A negligible loss of catalytic activity of 


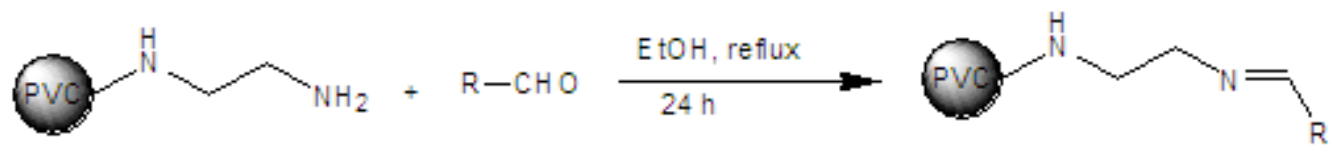

PVC-supported Schiff base

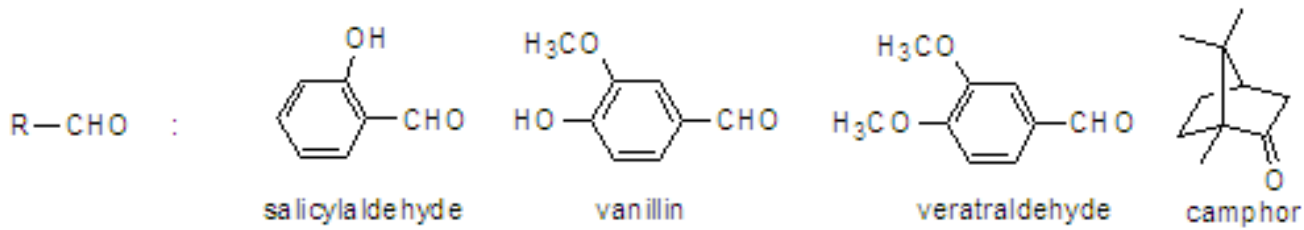

(20)
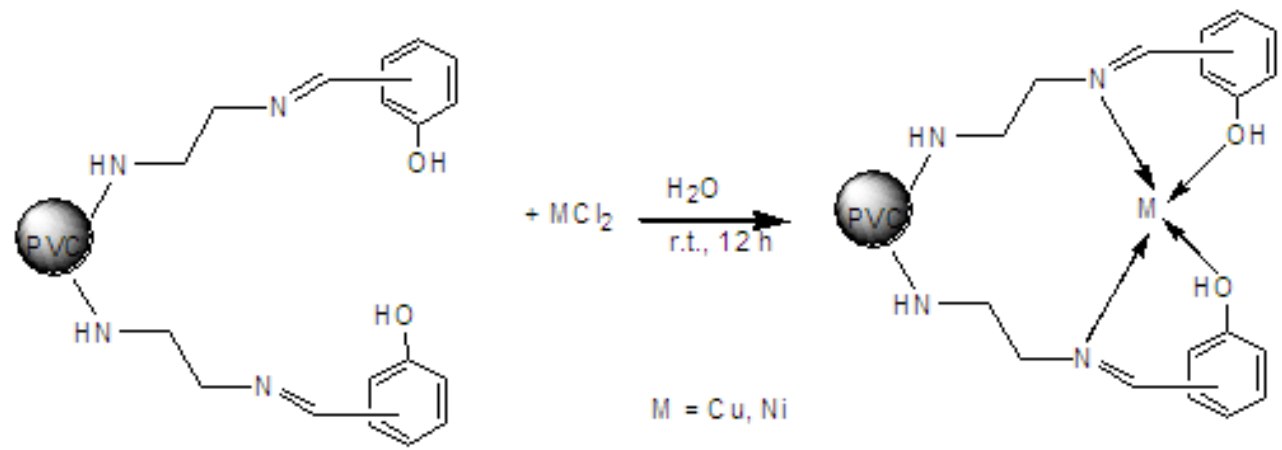

PVC-Schiff base-M (II) complex

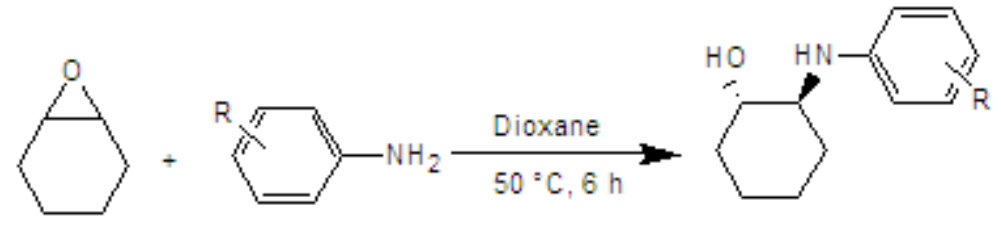

the latter catalyst was observed for the same reaction after four cycles; the yield dropped from 93 to $92 \%$.

\subsubsection{Poly(vinyl chloride)-supported Organo- catalysts}

Poly(vinyl chloride)-supported pyrrolidine-thiourea (Figure 8) was synthesized and valorized as catalyst in the direct asymmetric aldol reaction between cyclohexanone and arylaldehydes in aqueous medium (Eq. 23) [96]. PVC was functionalized with tetraethylenepentamine, followed by reaction with the product of the reaction of the synthesized Fmoc-Lproline with $\mathrm{SO}_{2} \mathrm{Cl}_{2} / \mathrm{NH}_{4}$ SCN/PEG 400 (Fmoc = fluorenylmethyloxycarbonyl). The aldol reaction between cyclohexanone and $p$-nitrobenzaldehyde in the presence of the PVC-supported pyrrolidine-thiourea occurred efficiently both in organic and aqueous media; the yields were 70,63 , and $58 \%$ in petroleum ether, water/DMSO, and water, respectively, with an enantioselectivity (enantiomer excess, ee) of 90, 69, and $94 \%$, respectively. It was claimed that such reaction happened at the interface between the PVC resin and the aqueous phase. Also, the thiourea group of the catalyzing site played a major role in the activity and selectivity of the aldol reaction. The catalytic activity of the PVC-supported organocatalyst was retained after three runs as revealed by the good yields and high stereoselectivities.

Amination of PVC was also undertaken by Sreekumar and his co-workers [97] using an excess 


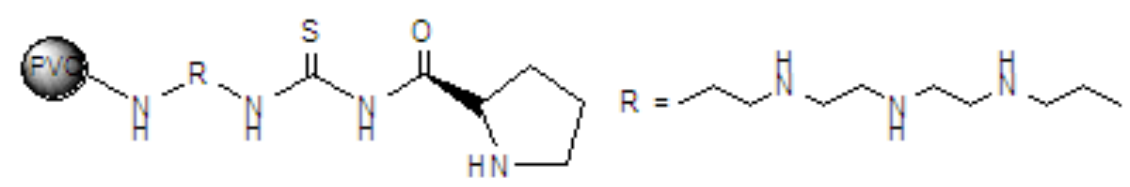

Figure 8: PVC-supported pyrrolidine-thiourea.

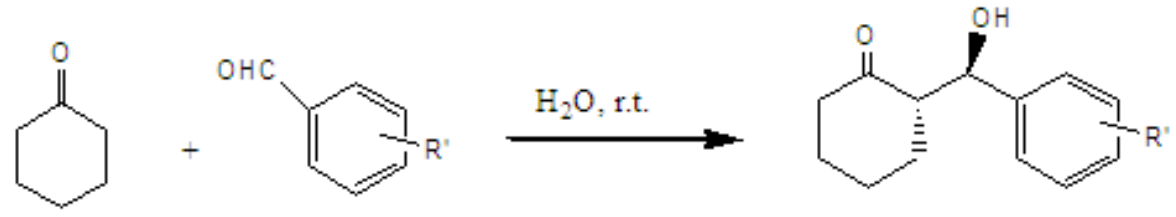

amount of ethylene diamine and at $30{ }^{\circ} \mathrm{C}$ and for $2 \mathrm{~h}$. The light yellow PVC- $\mathrm{NH}_{2}$ was found to contain 5 mmoles of $\mathrm{NH}_{2}$ groups per gram of resin, and to be less stable than pristine $\mathrm{PVC}$, a decomposition temperature $T_{\mathrm{d}}$ of 200 against $250{ }^{\circ} \mathrm{C}$. The PVC-NH ${ }_{2}$ was evaluated as effective polymer-supported catalyst for a number of Knoevenagel condensation reactions in water and in solventless conditions (Eq. 24). When run in water, the reactions afforded yields in the range of 95 to $100 \%$ within 20 to $30 \mathrm{~min}$, whereas the yields for the neat reactions were $100 \%$ within shorter times ( 3 to $8 \mathrm{~min}$ ), with the exception of the reaction of acetophenone with ethyl cyanoacrylate (yield $98 \%$ within $8 \mathrm{~min}$ ). It was claimed that this PVC-supported catalyst could be recycled five times without a substantial loss of its catalytic activity.

\subsection{PVC-Graft Copolymerization}

PVC underwent several modifications to produce graft copolymers as cited above/below. Controlled radical polymerization (CRP), including ATRP, RAFT, and NMP, has been of a great interest in polymer synthesis and polymer modification. Behaving as alkyl halide, PVC is considered a suitable starting material for designing macroinitiator for these CRP techniques. Öztürk and his group [98] applied RAFT technique to promote the grafting of poly(2-vinylpyridine) (P2VP) onto PVC. As illustrated in Eq. 25, RAFT macroinitiator was realized by reacting PVC with potassium salt of ethyl xanthogenate in THF at room temperature. About 72 of chlorine atoms per PVC chain were substituted by ethyl xanthogenate groups. The graft polymerization of 2-vinylpyridine was run in the presence of the RAFT macroinitiator in DMF and in the presence of AIBN at $90{ }^{\circ} \mathrm{C}$. A 2VP conversion of as high as $67.35 \%$ could be reached for a reaction time of $200 \mathrm{~min}$. A molecular weight $M_{\mathrm{n}}$ of $15000 \mathrm{~g} / \mathrm{mol}$ and a polydispersity index PDI of 1.84 of the PVC-g-P2VP copolymer were measured; the P2VP chain length varied with monomer/initiator ratio. Thermal analysis revealed a $T_{\mathrm{g}}$ of the graft copolymer of about $140{ }^{\circ} \mathrm{C}$, a $T_{\mathrm{g}}$ higher than both of those of PVC and P2VP, 80 and $95{ }^{\circ} \mathrm{C}$, respectively.

Poly(vinyl chloride) in its chlorinated form, CPVC, has gained a foothold in diverse applications as per its properties [99]; it is endowed with mechanical<smiles>[X]CC#N</smiles>
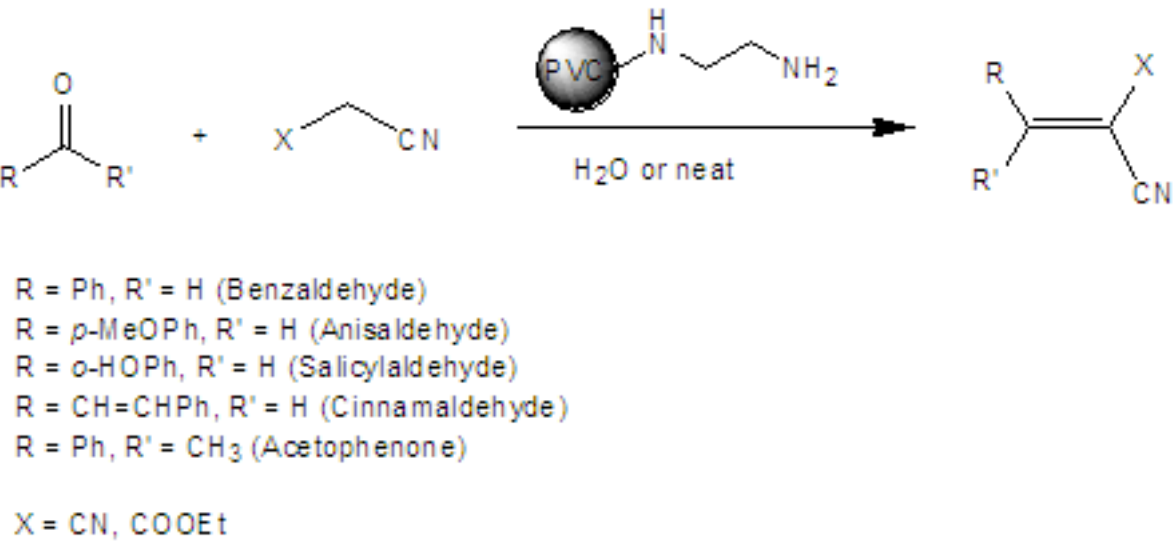

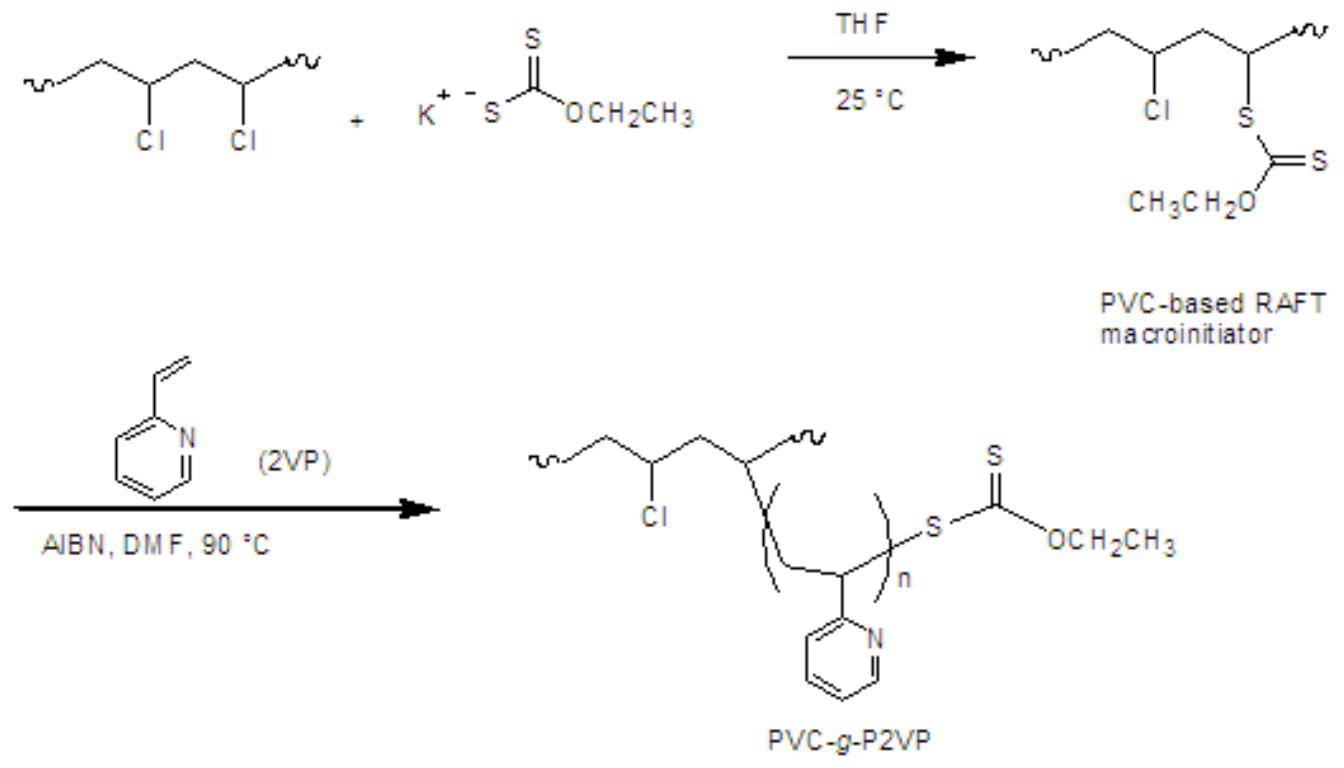

(25)

performance, flame retardancy, and heat resistance better than PVC. Its uses in hot and cold water pipes and industrial liquid handling are but the results of the latter property. The chlorine content in CPVC is high and ranged from 63 to $69 \%$, compared with that of PVC (56.7\%). Although, the synthesis of CPVC has been largely tackled, novel and improvement methodologies are progressively emerged. For example, Cheng and his group [100, 101] adopted cold plasma as free radical initiator in the gas-solid chlorination process, instead of the commonly employed UV-assisted method, and avoiding the use of fluorine gas as initiator.

Grafting of maleic anhydride (MAH) onto polymer matrixes was thoroughly reviewed by Rzayev [102]. In the aim at upgrading the mechanical strength, the softening point, and the thermal stability of chlorinated PVC (CPVC), Zhao and his collaborators [103, 104] modified CPVC by grafting with polymer of maleic anhydride (PMAH) through an in situ chlorinating graft copolymerization. For this purpose, a mixture of $\mathrm{PVC} /$ maleic anhydride in acetone was flushed with chlorine gas for $15 \mathrm{~min}$ at a temperature of $50-60{ }^{\circ} \mathrm{C}$ (Eq. 26). Chlorination of PVC and MAH grafting polymerization proceeded via radical initiation, with a concomitant polyene formation. The obtained CPVC- $g$ PMAH was found to contain $66 \%$ of chlorine atoms and had a grafting degree of $2.58 \mathrm{wt} . \%$ and a molecular weight $M_{\mathrm{w}}$ of $1.6 \times 10^{5} \mathrm{~g} / \mathrm{mol}$ (that for CPVC was $1.1 \times 10^{5} \mathrm{~g} / \mathrm{mol}$ ). Compared to CPVC, the tensile and impact strengths of CPVC-g-PMAH increased by 14.5 and $34.6 \%$, respectively. The polar PMAH grafts engendered higher toughness and rigidity, and a very slight increase in $T_{\mathrm{g}}\left(101.19{ }^{\circ} \mathrm{C}\right.$ for the graft copolymer against $101.7 \%$ for CPVC). The Vicat softening temperature of CPVC-g-PMAH was $130{ }^{\circ} \mathrm{C}, 15{ }^{\circ} \mathrm{C}$ higher than that of CPVC and $44^{\circ} \mathrm{C}$ higher than that of PVC. Maximum weight loss for CPVC-g-PMAH happened at $291.6{ }^{\circ} \mathrm{C}$, whereas that for CPVC occurred at $285.5{ }^{\circ} \mathrm{C}$, indicating that the graft copolymer is relatively more stable than CPVC.

Hammiche et al. $[105,106]$ were able to graft maleic anhydride polymer (PMAH) onto PVC matrix under radical initiation. The ensued functionalized PVC-gPMAH, with a proposed structure shown in Eq. 27, was conceived as a compatibilizer (or coupling agent) for the formulation of PVC/alfa composites and PVC/alfa composites. The grafting reaction was run in xylene at $140{ }^{\circ} \mathrm{C}$ for $1 \mathrm{~h}$ using benzoyl peroxide (BPO) as radical initiator. Grafting level of PMAH units onto PVC macromolecules was about $2.32 \%$ after $1 \mathrm{~h}$ of reaction and increased to 3.8 after $3 \mathrm{~h}$. It was claimed that the use of PVC-g-PMAH in the proposed PVC/alfa composite rendered the surface more homogeneous with less cavities, suggesting an improved affinity between the polymeric binder and the alfa composite, hence a better interfacial adhesion. Overall, positive effects of PVC-g-PMAH on the mechanical properties of the composite were noted: a greater hardness, a $21 \%$ increase in tensile strength, a $53 \%$ increase in elongation at break, and a moderate increase of the Young's modulus as expected. In addition, the thermal stability of the composite was also enhanced of about $16 \%$ by using PVC- $g$-PMAH. 


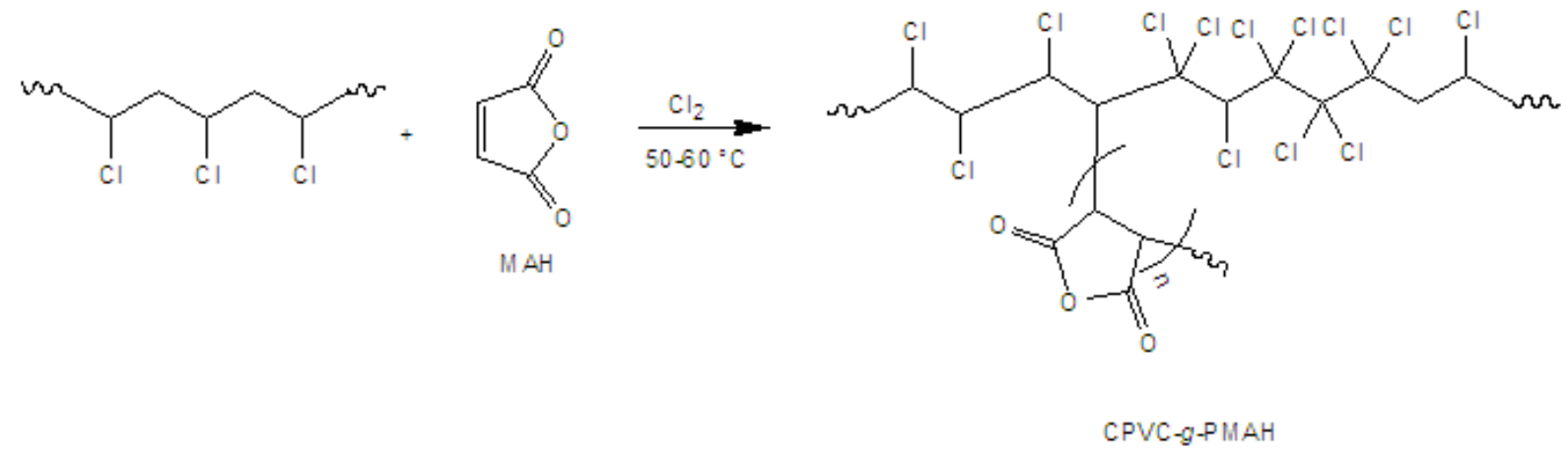

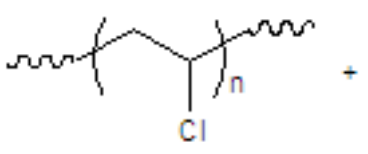<smiles>O=C1C=CC(=O)O1</smiles>

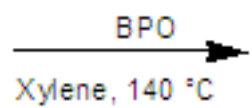

M AH

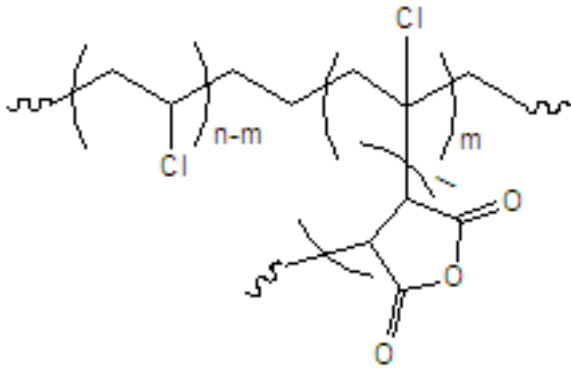

PVC-g-PMAH

\subsection{Miscellaneous Functionalizations}

As far as green chemistry is of a great interest, Pant and Kumar [107] provided an ecofriendly route to achieve amidated PVC. They made PVC react with ethylene glycol carbamate at $180{ }^{\circ} \mathrm{C}$ for $2 \mathrm{~h}$ (Eq. 28); ethylene glycol carbamate, a green amidation reagent, was formed by reaction of ethylene glycol and urea in the presence of zinc oxide as a catalyst at $180{ }^{\circ} \mathrm{C}$ for $20 \mathrm{~min}$. The success of such functionalization was confirmed by energy dispersive X-ray (EDX) analysis.

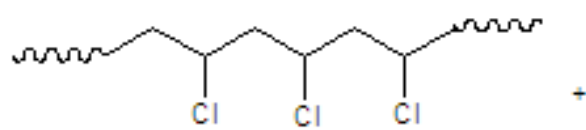

Triazolyl group was appended onto PVC matrix via sulfide functionality by reacting PVC with sodium salt of 3-thiol-1,2,4-triazol (3TTA) in cyclohexanone (Eq. 29) [108]. Thermal process of the reaction beyond $80{ }^{\circ} \mathrm{C}$ and the microwave-assisted process at times longer than $30 \mathrm{~min}$ did not imply significant functionalization extents. The highest conversion degree for the former process was nearly $23 \%$ at $60{ }^{\circ} \mathrm{C}$ and two days and that for the latter one was about $46 \%$ at $80{ }^{\circ} \mathrm{C}$ and for $30 \mathrm{~min}$. In the thermal process, both substitution and elimination mechanisms occurred as suggested by the

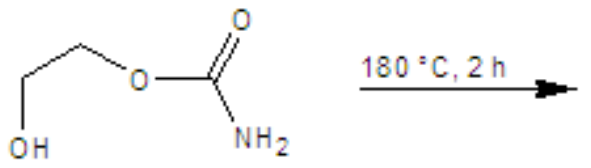

E thyle ne glycol carbamate<smiles>NOCC(Cl)CC(CC(Cl)CON)C(N)=O</smiles> 

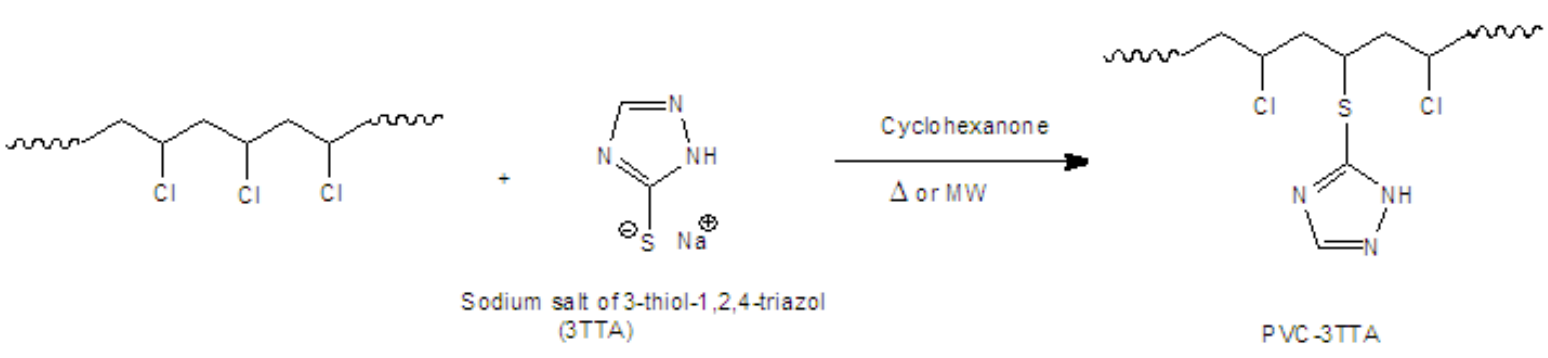

(29)

bimodal curve of the elution profile from GPC measurement (gel permeation chromatography). Molecular weights $M_{\mathrm{w}}$ of the PVC-3TTA's were lower than that of virgin PVC: $28900 \mathrm{~g} / \mathrm{mol}$ (thermal process), $35600 \mathrm{~g} / \mathrm{mol}$ (microwave-assisted process) against $56991 \mathrm{~g} / \mathrm{mol}$; the polydispersity index (microwave-assisted process) was higher than that of PVC, 3.8 against 1.7. However, their $T_{g}$ 's were measured to be greater than that of PVC: $89.8{ }^{\circ} \mathrm{C}$ (thermal process), $95.7{ }^{\circ} \mathrm{C}$ (microwave-assisted process), $84.3{ }^{\circ} \mathrm{C}$ (PVC), hinting at the plausible interactions between polymeric chains via hydrogen bonds established by this triazolyl functionality. Untreated PVC was found to be more thermally stable than the modified ones; PVC started to degrade at a temperature of about $250{ }^{\circ} \mathrm{C}$, the functionalized PVC's started at $175-180^{\circ} \mathrm{C}$.

The cinnoline derivative, 5-methoxycinnoline, was affixed onto PVC backbone through thioether and hydrazine bridges upon treating PVC with 4-mercapto 5-methoxy cinnoline (cinnoline-1) and 4-hydrazine-5methoxy cinnoline (cinnoline-2), respectively, in THF in the presence of traces of pyridine and at reflux for $5 \mathrm{~h}$ (Eq. 30) [109]. The as-modified PVC's, PVC-cinnoline1 and PVC-cinnoline-2, were yellow and brown, respectively. A simultaneous functionalization with both cinnolines was attempted and afforded a brown material. The authors claimed that precipitation of the modified polymers took place after the reaction time, whereas their UV-visible analyses were conducted in THF. No extent of modification was advanced.

\section{FUNCTIONALIZATION BY CARBON ALLOTROPES}

Carbon nanoparticles, including carbon nanotubes, graphene, and fullerenes, have gained special attention because of their salient and unique properties. To cite but the latest and unexpected application is the water desalination [110]. As soon as they emerged, investigations on their functionalizing ability towards polymeric materials and their vulnerability to the modifications by molecular or macromolecular species have been embarked on [111- 116]. And, numerous interesting applications have been duly conceived, particularly in medicine. PVC and its dehydrochlorinated (DHPVC) form were tagged with fullerene $C_{60}$ under normal procedure (AIBN as initiator) and atom transfer radical addition methodology (ATRA) in THF at $80{ }^{\circ} \mathrm{C}$ for $24 \mathrm{~h}$ (Eq. 31)[117]. The grafted $C_{60}$ extents on PVC were 5.66 and $2.77 \%$ for ATRA and AIBN methods, respectively; that for grafted onto DHPVC using AIBN was $4.65 \%$. All $\mathrm{PVC}-\mathrm{C}_{60}$ 's obtained by both procedures were soluble in THF, whereas only DHPVC- $\mathrm{C}_{60}$ 's produced using AIBN were soluble. Dehydrochlorination and fullerenation provoked a change in the glass transition temperature of PVC $\left(T_{\mathrm{g}}=78{ }^{\circ} \mathrm{C}\right): 72^{\circ} \mathrm{C}$ (DHPVC), 78 ${ }^{\circ} \mathrm{C}$ (DHPVC-C 60 using AIBN), $86{ }^{\circ} \mathrm{C}$ (PVC-C 60 using ATRA), $82{ }^{\circ} \mathrm{C}$ (PVC- $\mathrm{C}_{60}$ using AIBN). The higher $T_{\mathrm{g}}$ 's

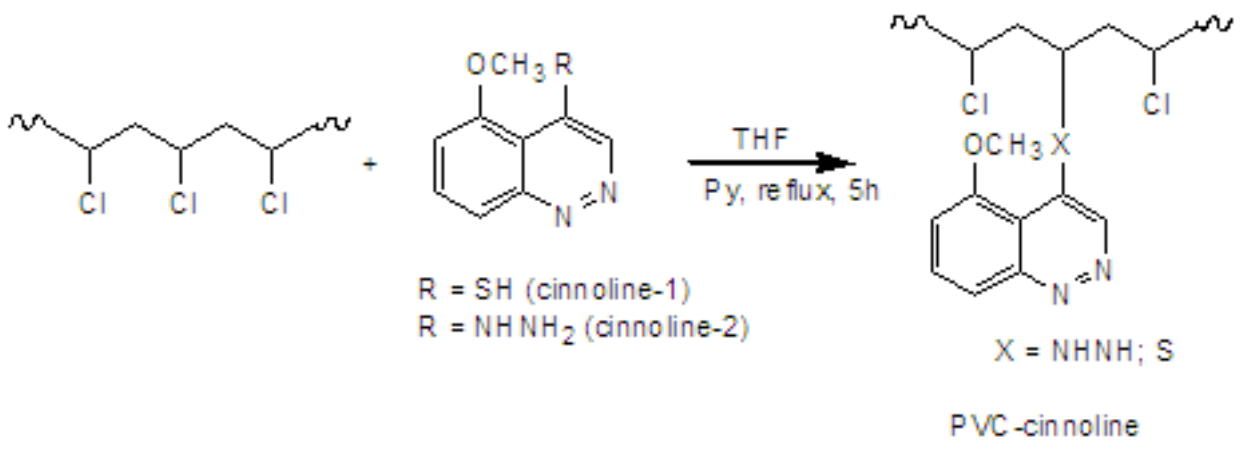




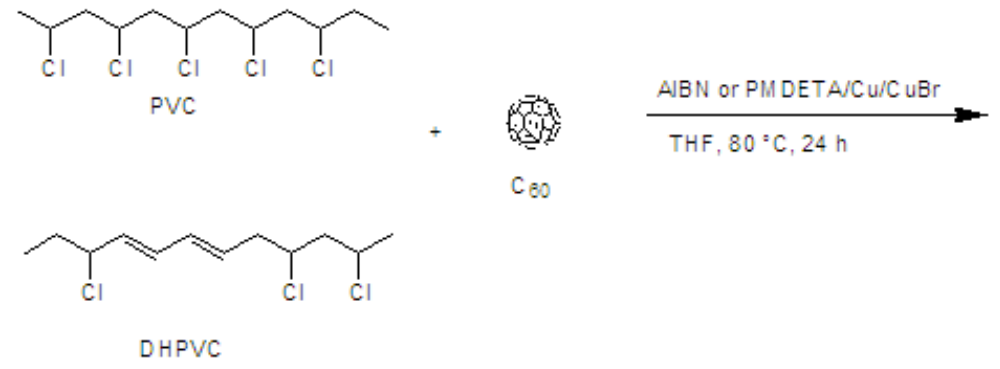

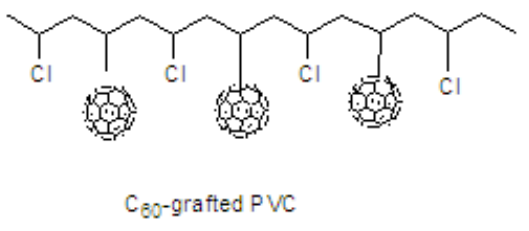

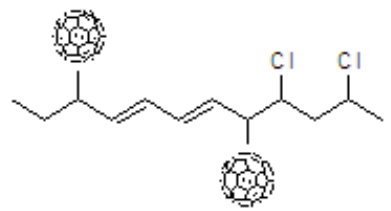

C60-grafted DHPVC after fullerenation was ascribed to the imparted rigidity by the higher $\mathrm{C}_{60}$ content. Another effect of the fullerenation method was on the thermal stability of the materials; while the thermal stability of $\mathrm{PVC} \mathrm{C}_{60}$ obtained via AIBN was more stable than PVC, the one obtained by ATRA was less stable. The electrical conductivities of the doped $\mathrm{C}_{60}$-grafted PVC's were larger than that of doped PVC $\left(\sigma=4 \times 10^{-8} \mathrm{~S} \mathrm{~cm}^{-1}\right)$ : $1.73 \times 10^{-5} \mathrm{~S} \mathrm{~cm}^{-1}$ for ATRA process and $1.18 \times 10^{-5} \mathrm{~S}$ $\mathrm{cm}^{-1}$ for AIBN process. However, the conductivities of doped $\mathrm{C}_{60}$-grafted DHPVC's were lower $\left(\sigma=1.38 \times 10^{-5}\right.$ $\left.\mathrm{S} \mathrm{cm}^{-1}\right)$ than that of the doped DHPVC $\left(\sigma=1.81 \times 10^{-5}\right.$ $\mathrm{S} \mathrm{cm}^{-1}$ ). In general, the conductivity of the $\mathrm{C}_{60}$-grafted $P V C$ and $\mathrm{C}_{60}$-grafted DHPVC increased linearly with $\mathrm{C}_{60}$ content. Inasmuch as being an electron donor, $\mathrm{C}_{60^{-}}$ grafted DHPVC was lately reported to be a basic component in a system destined for bulk heterojunction solar (BHJ) cells design, [118]; the power conversion efficiency of the BHJ solar cell using $[6,6]-$ phenyl- $\mathrm{C}_{61}$ butyric acid methyl ester (PCBM) as an electron acceptor alone increased from 0.5 to $1.34 \%$, after the adjunction of $\mathrm{C}_{60}-g$-DHPVC.

Wu and Liu [119] applied the Friedel-Crafts alkylation to graft PVC onto the surface of multi-walled carbon nanotubes (MWCNT), providing PVC as alkylating agent. The reaction involved the use of anhydrous aluminum chloride as catalyst in the dispersed medium containing PVC and MWCNT in chloroform/THF system (Eq. 32); the reaction was run at $60{ }^{\circ} \mathrm{C}$ for a varying reaction time. The grafting efficiency fluctuated between 117 and $246 \%$ for a reaction time ranging between 6 and $30 \mathrm{~h}$. The thermal analysis showed that 38 to $49 \%$ weight loss occurred at $400{ }^{\circ} \mathrm{C}$, while those of PVC and MWCNT were 67 and $5 \%$, respectively. The two characteristic Raman bands of MWCNT, the graphitic bands, appeared in the PVC-
$g$-MWCNT at $1290 \mathrm{~cm}^{-1}$ (D-band, assigned to $\mathrm{sp}^{2}$ hybridization) and $1600 \mathrm{~cm}^{-1}$ (G-band assigned $\mathrm{sp}^{3}$ bonded carbon atoms) with an intensity ratio $I_{D} / I_{G}$ of 1.68 , a ratio higher than that in unmodified MWCNT (0.74), hinting at extra $\mathrm{sp}^{3}$-hybridized carbons, that is the success of such alkylation. PVC grafting had helped the dispersion of MWCNT in organic solvents; indeed, PVC-g-MWCNT was found to be easily and homogeneously dispersed in polar solvents such as THF, while MWCNT was not.

Salavagione et al. [120] linked MWCNT to PVC via a thiophenol spacer. MWCNT, carboxylated by an ozonation protocol, was esterified with thiophenolated PVC (PVC-SPhOH) in cyclohexanone under $N, N$ dicyclohexylcarbodiimide (DCC)/4-(dimethylamino) pyridine (DMAP) chemistry as illustrated in Eq. 33. The thiophenolation of PVC was carried out with 4hydroxythiophenol in the presence of $\mathrm{K}_{2} \mathrm{CO}_{3}$ in cyclohexanone at $40{ }^{\circ} \mathrm{C}$; the maximum thiophenolation degree was in the range of $15 \%$ after a reaction time of 40 min. The thiophenolated PVC with this degree of modification displayed a $T_{\mathrm{g}}\left(101^{\circ} \mathrm{C}\right)$ higher than that of virgin PVC $\left(78.8{ }^{\circ} \mathrm{C}\right)$, indicating that the thiophenol group increased the stiffness of the polymer. The modification occurred stereoselectively in the isotactic triad of the PVC polymer; the isotactic triad content dropped from 0.210 in the unmodified PVC to 0.162 in the modified one, whereas the syndiotactic triad content rose from 0.292 to 0.337 . The obtained graycolored (PVC-SPhOH)-g-MWCNT contained about 1.3 wt.\% of MWCNT, and was soluble in THF, cyclohexanone, 1,2-dichlorobenzene, and DMF. The (PVC-SPhOH)-g-MWCNT was found to be more thermally stable than the parent PVC; while the latter one started to degrade at $265{ }^{\circ} \mathrm{C}$, the former one did at $290^{\circ} \mathrm{C}$. 

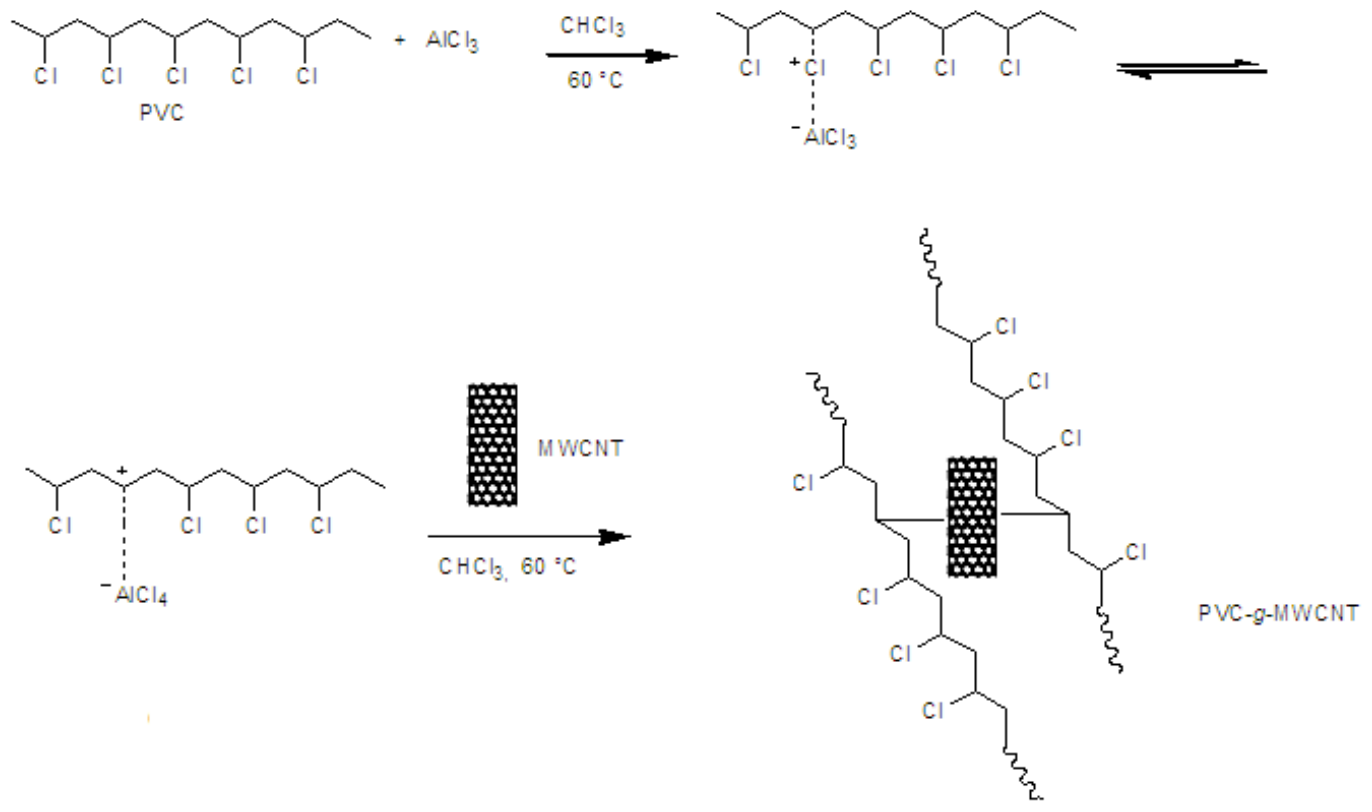

(32)<smiles>CCC(Cl)CC(Cl)CC(Cl)CC(CC(C)Cl)Sc1ccc(O)cc1</smiles><smiles>C#CC(C#C)(C#CC(=O)Oc1ccc(SC(CC(C)Cl)CC(Cl)CC(Cl)CC(Cl)CC)cc1)C(=O)O</smiles>
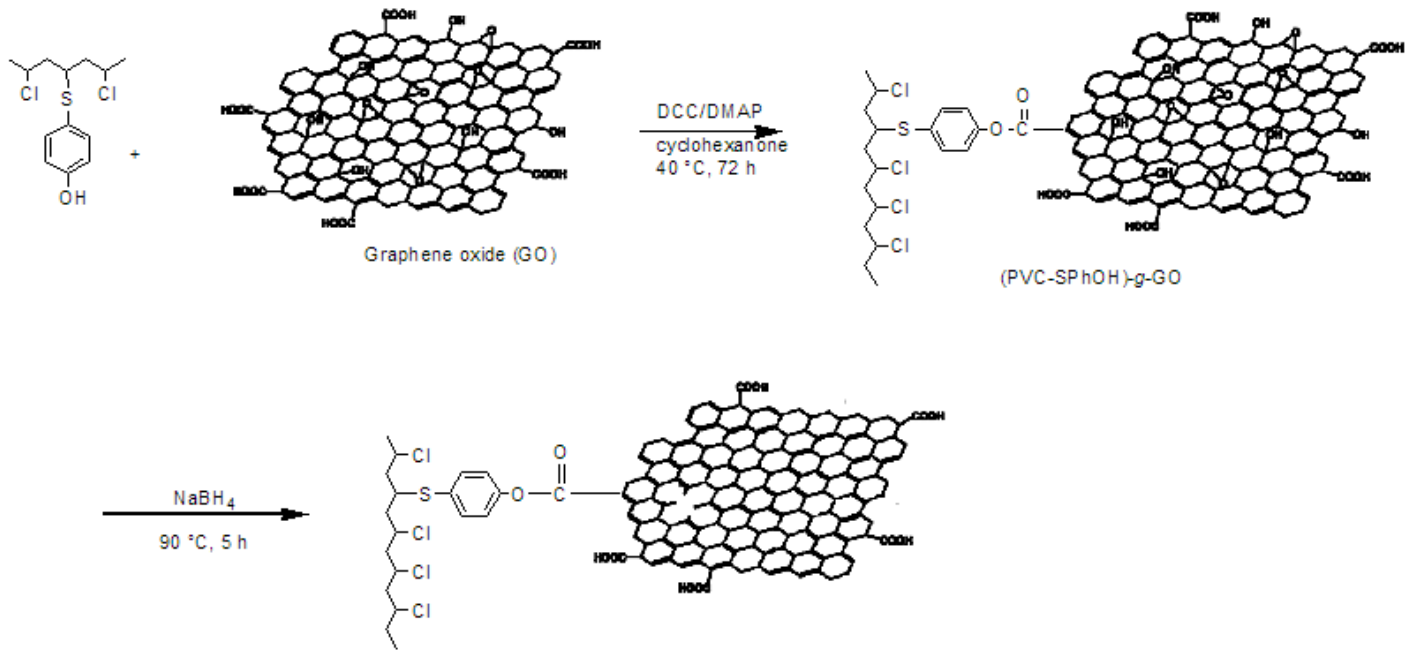

(34) 
By applying the same experimental protocol (Eq. 34), Salavagione and Martínez [121] succeeded in binding stereoselectively graphene oxide $(\mathrm{GO})$ to $\mathrm{PVC}$ to produce the nanocomposite (PVC-SPhOH)-g-GO; the isotactic sequence increased from 1.14 for the parent PVC to 1.32 for the modified one, PVC-SPhOH. (PVC-SPhOH)- $g$-GO underwent reduction by means of $\mathrm{NaBH}_{4}$ to afford (PVC-SPhOH)-g-RGO. The $T_{\mathrm{g}}$ of the (PVC-SPhOH)-g-RGO containing 1.4 wt.\% RGO was about $25{ }^{\circ} \mathrm{C}$ higher than that of the untreated PVC, 106.7 versus $81.8{ }^{\circ} \mathrm{C}$, implying the greater rigidity conferred by the RGO entities. The thermal degradation of (PVC-SPhOH)-g-RGO was observed at $265{ }^{\circ} \mathrm{C}$, while that for PVC was at $290{ }^{\circ} \mathrm{C}$, and such stability decreasing was imputed to the stereoselective substitution. The storage moduli for PVC-SPhOH, (PVC-SPhOH)-g-RGO (1.4 wt.\% RGO), (PVC$\mathrm{SPhOH}$ )-g-GO, and (PVC-SPhOH)-g-MWCNT (1.3 wt. \% MWCNT) were measured as 1100, 2326, 2960, and $1830 \mathrm{MPa}$, respectively; the RGO units demonstrated improved interfacial interactions. The lower storage modulus of (PVC-SPhOH)-g-RGO compared with that of (PVC-SPhOH)-g-GO was reasoned to be due to the higher formation of hydrogen bonding of $\mathrm{OH}$ groups of the nucleophile with oxygenated groups in GO. On the opposite, PVC macromolecules were grafted on graphene sheets using $n$-BuLi as initiator, to design graphene-based nanocomposites [122].

\section{FUNCTIONALIZATION FOR PVC WASTE RECYCLING}

Plastic wastes are valorized in many applications such as wood composites [123], concrete mixes [124], and fuel in the co-pyrolysis of biomass [125]. One way to manage PVC wastes was through its nucleophilic modifications [126]. Towards this objective, Grause's group [127-134] tackled several nucleophilic modifications of the polymer (Eq. 35).
Thiocyanation reaction was conducted on two PVC grades, flexible and rigid ones, in ethylene glycol under phase transfer catalysis (tetrabutylammonium bromide,

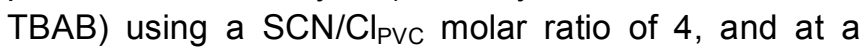
temperature range of $150-190{ }^{\circ} \mathrm{C}$ [128]. Both substitution and elimination occurred to certain extents and their ratio was function of reaction time, temperature and TBAB concentration. For both PVC grades, all these factors accelerated the dehydrochlorination rate. It was insignificant at $150{ }^{\circ} \mathrm{C}$ but was about $93-97 \%$ at $190{ }^{\circ} \mathrm{C}$ after $6 \mathrm{~h}$ in the absence of TBAB, and increased to $50 \%\left(150{ }^{\circ} \mathrm{C}\right.$ and after $12 \mathrm{~h}$ ) and nearly $100 \%\left(190{ }^{\circ} \mathrm{C}\right.$ and after $\left.3 \mathrm{~h}\right)$ in the presence of TBAB. The substitution yields were improved in the presence of TBAB, particularly at 150 ${ }^{\circ} \mathrm{C}$ : from 3.2 to $24.6 \%$ for the flexible PVC, and from 0.9 to $23.2 \%$ for the rigid one. The substitution/elimination ratios were found to slightly rise in the presence of the phase transfer agent. Lower temperatures were found to favor substitution. In other places [129-132], it was reported that modifications of rigid and flexible PVC with hydroxide, azide, and thiocyanate using ethylene glycol as solvent at $190{ }^{\circ} \mathrm{C}$ resulted in $\sim 20 \%$ substitution and $\sim 40-80 \%$ elimination. However, the iodide ion promoted almost only elimination ( $70 \%$ for rigid PVC and $\sim 20 \%$ for flexible PVC). The explanation was advanced in terms of nucleophilicity of the nucleophiles; the similar results with hydroxide, azide, and thiocyanate could be due to their close nucleophilicities, around of 4.0-4.77 based on the Swain-Scott equation. The behavior of iodide ion, a stronger nucleophile (nucleophilicty of 5.04), was due to its elimination by zipper mechanism, favoring the dehydrochlorination.

The impact of solvent on the substitution/elimination ratio in the thiocyanation of PVC was undertaken [130]. It was revealed that DMF favored the substitution mechanism and DMSO favored the elimination one. However, addition of THF to DMSO in $1: 2$ ratio
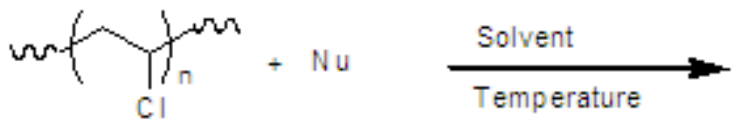

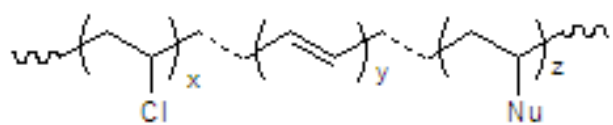

$$
\begin{aligned}
& \mathrm{Nu}=\mathrm{OH}^{-}, \mathrm{SCN}^{-}, \mathrm{I}^{-}, \mathrm{N}_{3}^{-}, \mathrm{S}^{2-}, \mathrm{S}_{3}^{2-} \\
& \text { Solvent = } \mathrm{H}_{2} \mathrm{O}, \text { DMF, D MSO, TH F-DM SO, E thyle ne glycol } \\
& \text { diethylene glycol, triethyle ne glycol }
\end{aligned}
$$




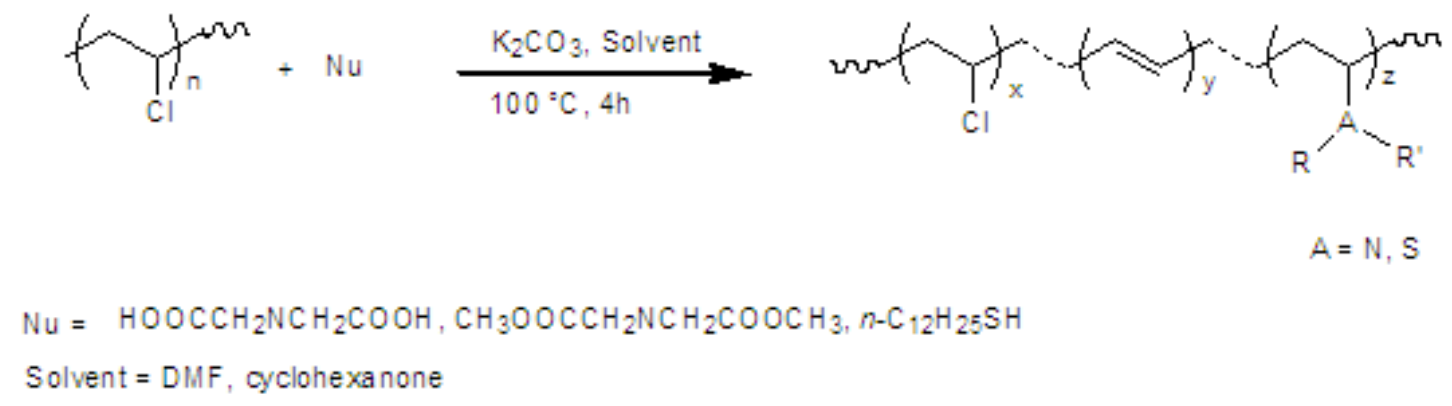

enhanced the substitution at ambient temperature. In DMF solution, higher temperatures were positive for increasing substitution yields. Thiocyanation of PVC at elevated temperatures led to the polyene formation, resulting in colored materials from white up to black, and to the isomerization of thiocyanate $-\mathrm{S}-\mathrm{C} \equiv \mathrm{N}$ to isothiocyanate $-\mathrm{N}=\mathrm{C}=\mathrm{S}$; indeed, an $\mathrm{IR}$ absorption band at around $2100 \mathrm{~cm}^{-1}$, attributed to thiocyanate group, was observed when working at $150{ }^{\circ} \mathrm{C}$, and shifted to $2050 \mathrm{~cm}^{-1}$ at $190^{\circ} \mathrm{C}$, a band assigned to isothiocyanate group.

Other functionalizations of PVC realized by Yoshioka and his team [133] were those using iminodiacetic acid (IDA), iminodiacetic acid dimethylester (IDADM), and as $n$-dodecanethiol (DT) as modifying agents. The course of reactions required potassium carbonate as base, dimethyl formamide (DMF) and cyclohexanone as solvents, and a temperature of $100{ }^{\circ} \mathrm{C}$ (Eq. 36). The outcome of these undertakings was that no modification occurred with iminodiacetic acid, probably due to its acidic character. However, the reaction with its dimethyl ester IDADM gave a high degree of elimination (43\%) and a low degree of substitution (3.8\%), and the IDADM-bound PVC was found to be insoluble in common solvents, presumably due to the high elimination extent. Spectral analysis along with the white color of IDADM-bound PVC would suggest the formation of isolated double bonds. The thiolation of PVC with $n$-dodecanethiol (DT) was successful in cyclohexanone, yielding about $17 \%$ of substitution and $10 \%$ of elimination according to elemental analysis and no elimination had taken place according to NMR analysis. The thus-modified PVC's were less thermally stable than the virgin PVC; while PVC started to degrade at nearly $270^{\circ} \mathrm{C}$, IDADM-PVC started to decompose drastically at about $170{ }^{\circ} \mathrm{C}$ and DT-bound PVC at about $240{ }^{\circ} \mathrm{C}$.

A thorough study of the reaction of PVC with sodium sulfide was carried out in water and in ethylene glycol at 80 and $150-190{ }^{\circ} \mathrm{C}$, respectively [127] (Eq.
35). Maximum dechlorination reached $2.5 \%$ after $3 \mathrm{~h}$ in water and $19.1 \%$ after $8 \mathrm{~h}$ in ethylene glycol. In the latter system and at $190{ }^{\circ} \mathrm{C}$, both substitution and elimination took place, and therefore, the formation of double bonds, thiol groups and crosslinks consisting of sulfide. The yield and the maximum substitution extent for $\mathrm{S}^{2-} / \mathrm{Cl}_{\mathrm{PVC}}$ molar ratio of 1 were near 71 and $39 \%$, respectively. The yields of dechlorination increased with temperature up to $170{ }^{\circ} \mathrm{C}$ and dropped beyond; the yield at $170{ }^{\circ} \mathrm{C}$ was nearly $57 \%$ for a $\mathrm{S}^{2-} / \mathrm{Cl}_{\mathrm{PVC}}$ molar ratio of 2 . Effect of diol medium on the dechlorination rates for a reaction time of $10 \mathrm{~h}$ was: $57.2 \%$ (ethylene glycol), $76.2 \%$ (diethylene glycol), and $56.4 \%$ (triethylene glycol). The use of tetrabutylammonium bromide (TBAB) as phase-transfer catalyst increased the dechlorination rate; at $170{ }^{\circ} \mathrm{C}$ and for a $\mathrm{S}^{2-} / \mathrm{Cl}_{\mathrm{PVC}}$ molar ratio of 2 , the dechlorination rate reached about $53 \%$ after $2 \mathrm{~h}$. In a continuing work on plastic waste recycling, Yoshioka et al. [134] lately reported the nucleophilic modification of PVC via reaction with sodium trisulfide $\mathrm{Na}_{2} \mathrm{~S}_{3}$ in ethylene glycol, diethylene glycol, or triethylene glycol, at $150-190{ }^{\circ} \mathrm{C}$ as shown in Eq. 35. On the contrary to what the authors expected, the ensued crosslinking between PVC chains was secured by monosulfide as observed with $\mathrm{Na}_{2} \mathrm{~S}$ and not by polysulfide. As advanced, monosulfide and polysulfide radical anions in such solvents could have been formed and were involved in the reaction mechanism as proposed in Scheme 4. The dechlorination was almost complete $(99 \%)$ after $36 \mathrm{~h}$ at $190{ }^{\circ} \mathrm{C}$ and in ethylene glycol, yielding $88.7 \%$ substitution for $\left[\mathrm{Na}_{2} \mathrm{~S}_{3}\right][\mathrm{PVC}]$ ratio of 3 . The dechlorination rate was initially higher in triethylene glycol and diethylene glycol, but the use of triethylene glycol favored the elimination pathway.

\section{FUNCTIONALIZATION FOR LIGHT-RELATED APPLICATIONS}

Kim's research group [135] anchored hydrophilic segments of polymer of poly(ethylene oxide) 


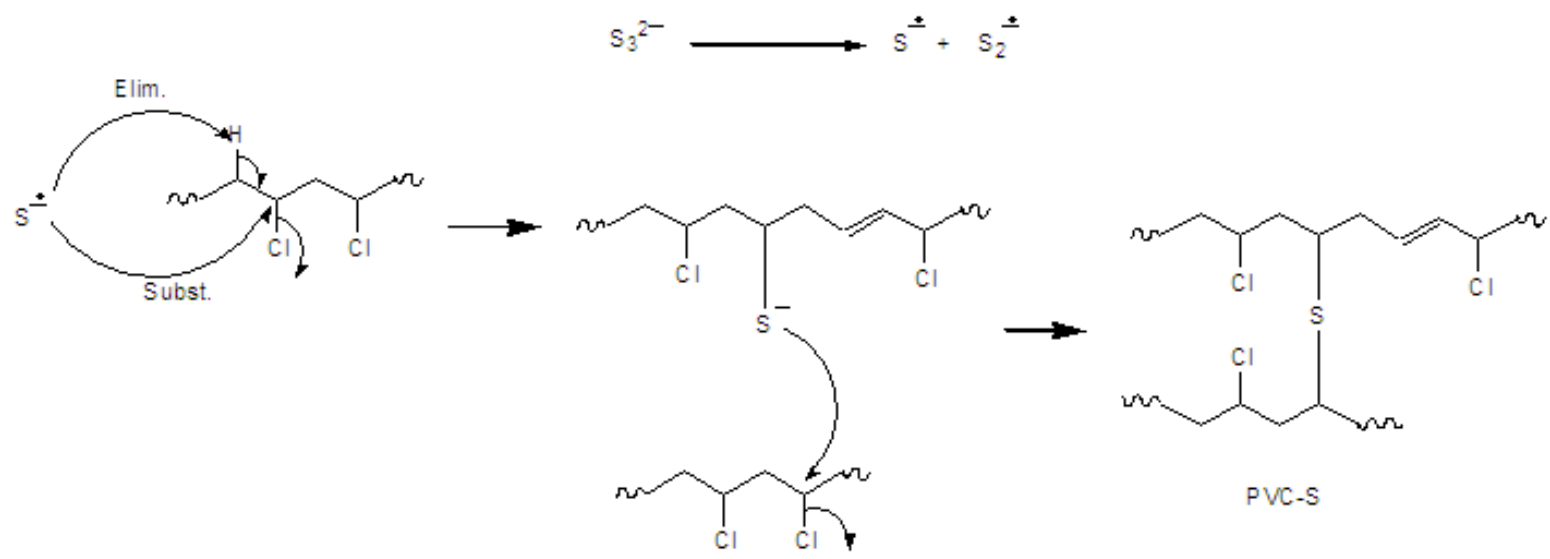

Scheme 4: Proposed mechanism for the vulcanization of PVC with $\mathrm{S}_{3}{ }^{2-}$.

monomethacrylate) (PEOM) of different lengths onto PVC matrix $\left(M_{\mathrm{w}}=43,000 \mathrm{~g} / \mathrm{mol}, M_{\mathrm{n}}=22,000 \mathrm{~g} / \mathrm{mol}\right)$ through grafting copolymerization by means of atom transfer radical polymerization (ATRP) as illustrated in Eq. 37. The molecular weight of the copolymer was function of the amount of PEOM used; molecular weights of $M_{\mathrm{w}} \sim 156,000 \mathrm{~g} / \mathrm{mol}, M_{\mathrm{n}} \sim 61,400 \mathrm{~g} / \mathrm{mol}$ were measured. Two $T_{\mathrm{g}}$ 's were detected at -58 and $70{ }^{\circ} \mathrm{C}$, assigned to the PPEOM and PVC chains, respectively; those of homopolymers were $-69{ }^{\circ} \mathrm{C}$ (PPOEM) and 83 ${ }^{\circ} \mathrm{C}$ (PVC). PVC-g-PPEOM was a platform for designing dye-sensitized solar cells (DSSC) [135-139]. To this end, polyelectrolyte prepared by mixing PVC-g-PPEOM with Lil/iodine/PEG500 in 1-methyl-3-propylimidazolium iodide MPII (an ionic liquid), was coated on $\mathrm{TiO}_{2}$ electrode sensitized with $\mathrm{Ru}(2,2-$ bipyridyl-4,4dicarboxylato) ${ }_{2}(\mathrm{NCS})_{2}$ dye. WAXS (wide angle x-ray scattering) and FTIR analyses of the polyelectrolyte confirmed the existence of coordinative interactions between Li ions and PPEOM chains. The $T_{\mathrm{g}}$ of PPEOM chain was affected by Lil treatment; it increased to -44 ${ }^{\circ} \mathrm{C}$, whereas that of PVC chain was not altered. The addition of the ionic liquid MPII to PVC-g-PPEOM-Lil restored the $T_{\mathrm{g}}$ of PPEOM chain to its original value ($59{ }^{\circ} \mathrm{C}$ ) and lowered that of PVC chain to $65^{\circ} \mathrm{C}$. And, the addition of PEG500 reduced both $T_{\mathrm{g}}$ 's to -64 and $48{ }^{\circ} \mathrm{C}$, respectively; MPII and PEG500 acted as effective plasticizers. The plasticizing character of the latter two additives affected positively the ionic conductivity of the material up to $1.2 \times 10^{-4} \mathrm{~S}_{\mathrm{cm}} \mathrm{cm}^{-1}$ (for PEG500). The best DSSC performance with an energy conversion efficiency $\eta$ of $5 \%$ at $100 \mathrm{~mW} / \mathrm{cm}^{2}$ was observed using PVC-g-PPEOM/(Lil+MPII)/PEG polyelectrolyte and giving the following current-voltage parameters: $V_{\mathrm{OC}}$ (open-circuit voltage) $=0.72 \mathrm{~V}, J_{\mathrm{SC}}$ (short-circuit current) $=11.3 \mathrm{~mA} / \mathrm{cm}^{2}, F F$ (fill factor) $=$ 0.61 .
The same school extended their investigation on dye-sensitized solar cells employing poly(vinyl chloride)-g-poly(2-(dimethylamino)ethyl methacrylate) (PVC-g-PDMAEM) [140] and poly(vinyl chloride)-graftpoly( $N$-vinyl pyrrolidone) (PVC-g-PVP) (Figure 9) [141], synthesized under identical conditions as those reported by ZhaoQiang et al. [79]. The molecular weights of these graft copolymers were higher than that of virgin PVC. Elsewhere [142], the graft copolymer PVC-g-PDMAEM was achieved differently, starting with isopropylthioxanthone (ITX)-grafted PVC, and leading to a copolymer with higher molecular weight and with $15-28.6$ mol.\% of PDMAEM chain; interestingly, the graft copolymer with more than $15 \mathrm{~mol} \%$ of PDMAEMA segments was claimed to be able to assemble into stable core-shell micelles in water at $\mathrm{pH}=3$.

The energy conversion efficiency $\eta$ for DSSC made of PVC-g-PDMAEM-coated $\mathrm{TiO}_{2}$ and a polyelectrolyte consisting of $\mathrm{PEODME} / \mathrm{SiO}_{2} / \mathrm{MPII} / \mathrm{I}_{2}$ (PEODME = poly(ethyleneglycol dimethyl ether)), was $3.2 \%$ at 100 $\mathrm{mW} / \mathrm{cm}^{2}$ with the following current-voltage characteristics: $V_{O C}=0.72 \mathrm{~V}, J_{\mathrm{SC}}=9.1 \mathrm{~mA} / \mathrm{cm}^{2}, F F=$ 0.48 . The photovoltaic characteristics of DSSC made of PVC-g-PVP-coated $\mathrm{TiO}_{2}$ and a polyelectrolyte consisting of PEODME $/ \mathrm{SiO}_{2} / \mathrm{MPII} / \mathrm{l}_{2}$ were: $\eta=1.05 \%$ at $100 \mathrm{~mW} / \mathrm{cm}^{2}, V_{\mathrm{OC}}=0.75 \mathrm{~V}, J_{\mathrm{SC}}=2.87 \mathrm{~mA} / \mathrm{cm}^{2}, F F=$ 0.49 .

Five aminated PVC's (Figure 10) were synthesized by chemical modification of PVC with dicyclohexylamine, dipropylamine, ethylenediamine, isobutylamine, and tert-butyamine in THF at reflux for 4-6 $h$ [143]. The resulting PVC-amines were pale yellow to brown in color and were obtained in moderate yields, $51-73 \%$. The optical properties of these aminated PVC's were measured using UV-visible analysis. According to Tauc equation $\alpha h u=\mathrm{A}\left(h \cup-E_{\mathrm{g}}\right)^{1 / 2}$, the 

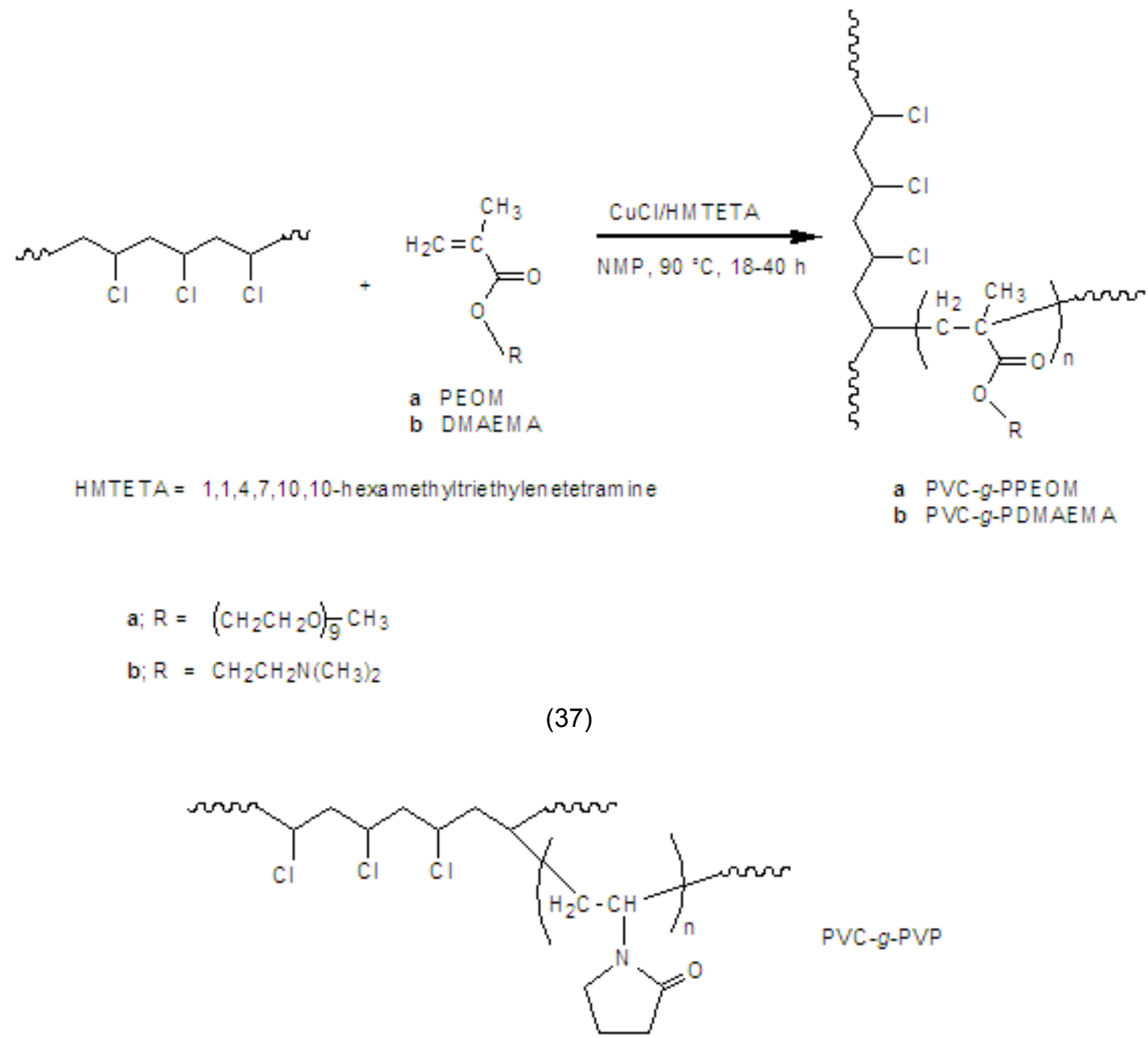

Figure 9: Poly(vinyl chloride)-graft-poly(N-vinyl pyrrolidone), PVC-g-PVP.

energy band gaps $E_{g}$ drawn from the plots of $(\alpha h u)^{2}$ versus $(h u)$ were in the range of 4.33-5.38 eV against $5.77 \mathrm{eV}$ for PVC.

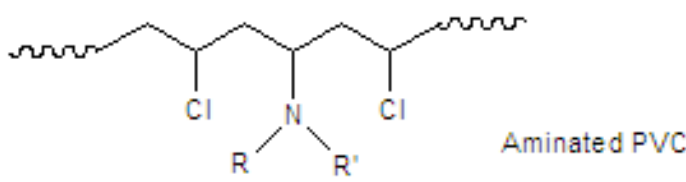

$R=R^{\prime}=$ cyclohexyl; $R=R^{\prime}=$ propyl; $R$ = ethylam in $e^{\prime} R^{\prime}=H$;

$\mathrm{R}=$ iso-butyl, $\mathrm{R}^{\prime}=\mathrm{H} ; \mathrm{R}=$ tert-butyl, $\mathrm{R}^{\prime}=\mathrm{H}$

Figure 10: Aminated PVCs.

Witwit [144] reported the functionalization of PVC with the synthesized 4-[(5-mercapto-1,3,4-thiadiazol-2yl)diazenyl]phenol (MTDZDZnPhOH), an azochromohore ligand. The reaction was run in THF at reflux and in the presence of trace of pyridine for four hours as depicted in Eq. 38. The brown thus-modified PVC-MTDZDZnPhOH, softened at a temperature of 249-253 ${ }^{\circ} \mathrm{C}$. Complexes of $\mathrm{Sn}^{\prime \prime}, \mathrm{Zn}^{\prime \prime}$, and $\mathrm{Cu}^{\prime \prime \prime}$ with
PVC-MTDZDZnPhOH were obtained as colored precipitates: yellow, reddish brown, and dark green, respectively. Their softening points were larger than that of chelating PVC and were in the order of their atomic weights of the metals: 288,267 , and $273{ }^{\circ} \mathrm{C}$, respectively. The energy gap shifts $E_{g}$ for unmodified PVC, modified PVC, and the PVC complexes were assessed by plotting $(\alpha h v)^{2}$ versus $h v$, and were found as follows $E_{\mathrm{g}}(\mathrm{eV})$ : $5.79 \quad(\mathrm{PVC}), 2.91 \quad$ (PVCMTDZDZnPhOH), 2.33 (PVC-MTDZDZnPhOH-Sn"), $2.30 \quad$ (PVC-MTDZDZnPhOH-Zn"), 2.00 (PVCMTDZDZnPhOH-Cu"). Two bipolaron bands were detected for the chelating PVC and the PVC complexes: one attributed to the transition from valence band to bonding bipolaron band and the other to the transition from valence band to anti-bonding bipolaron band. In another place [145], it was disclosed the synthesis of PVC modified with pyridine-4carbohydrazide $(\mathrm{PyCHz})$ under the same experimental protocols as in Eq. 38, followed by complexation with 

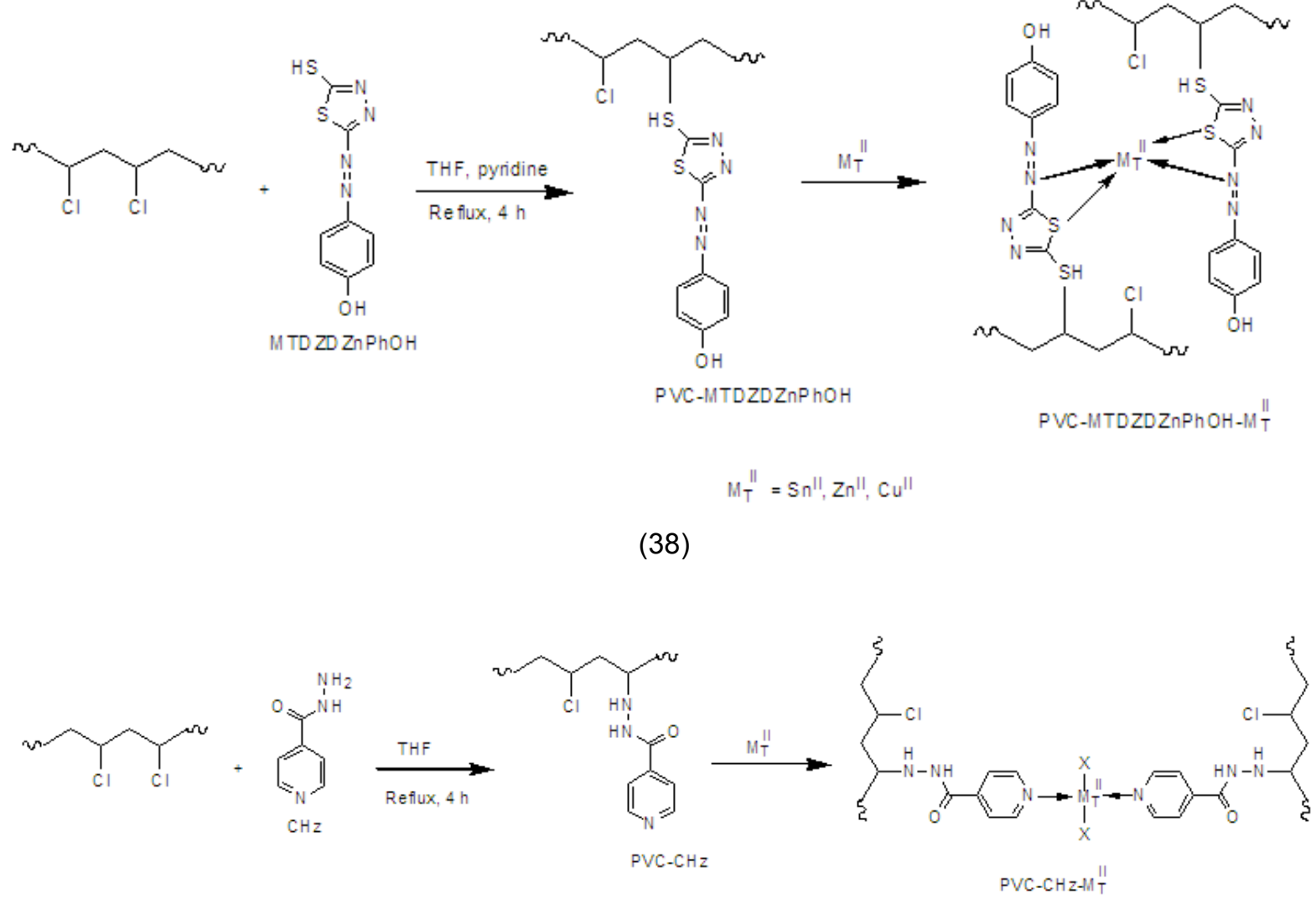

(39)

transition metals $\mathrm{M}_{T}^{\prime \prime}\left(\mathrm{Sn}^{\prime \prime}, \mathrm{Zn}^{\prime \prime}, \mathrm{Cu}^{\prime \prime}, \mathrm{Ni}^{\prime \prime}, \mathrm{Cd}{ }^{\prime \prime}\right)$ (Eq. 39). The PVC complexes were colored from pale yellow to yellow, brown, and green, and softened or decomposed at temperatures higher than $270{ }^{\circ} \mathrm{C}$. UVvisible spectra of the PVC complexes revealed absorption bands assigned for different $\Pi \rightarrow \pi^{*}$, charge transfer and $d$ - $d$ transitions. For all PVC complexes, two energy band gaps were observed $\left(E_{g 1}, E_{g 2}\right)$ and were (eV): PVC-PyCHz-Sn": 3.31, 3.73; PVC-PyCHz$\mathrm{Zn}^{\prime \prime}:$ 2.89, 3.02; PVC-PyCHz-Cu": 2.95, 3.19; PVC-
PyCHz-Ni": 3.24, 3.32; PVC-PyCHz-Cd": 2.97, 3.21. The energy gaps for PVC-PyCHz were 3.62 and 3.73 $\mathrm{eV}$ and that for bare PVC was $5.79 \mathrm{eV}$.

PVC bearing pendent groups that contain 1,3,4thiadiazole (TDz) and phthalyl (Pht) moieties (Figure 11) showed interesting optical properties [146]. Only one band energy gap was detected for all polymers and was measured as $E_{g}(\mathrm{eV}): 4.84$ (PVC), 4.31 (PVCTHDPht I), 4.17 (PVC-THDPht II), 4.38 (PVC-THDPht
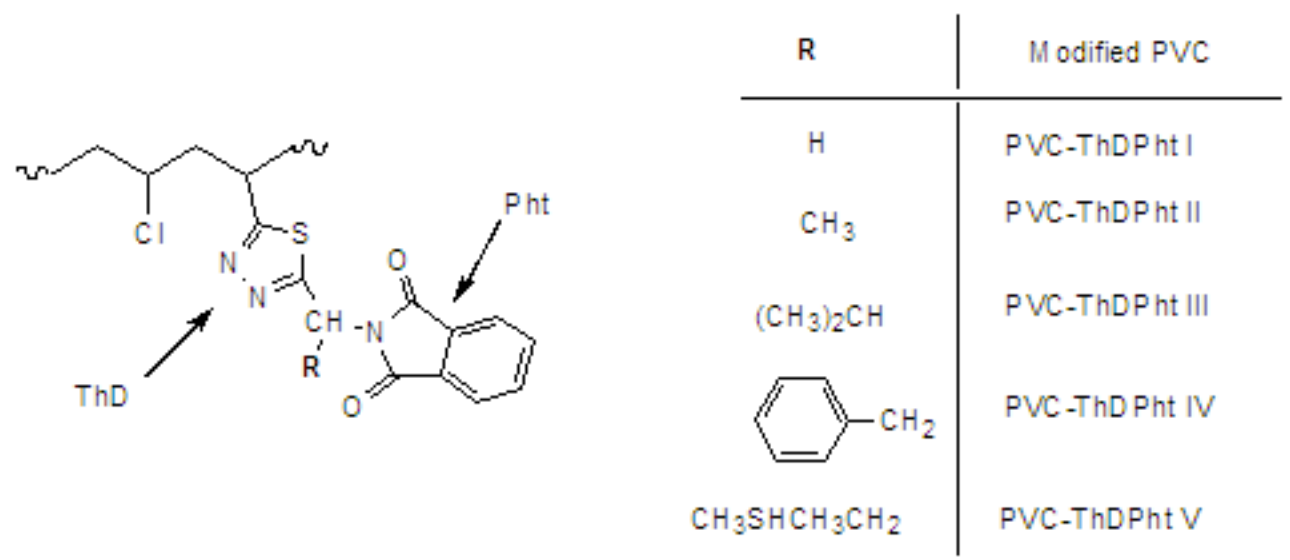

Figure 11: PVC with pendent 1,3,4-thiadiazole and phthalyl groups. 


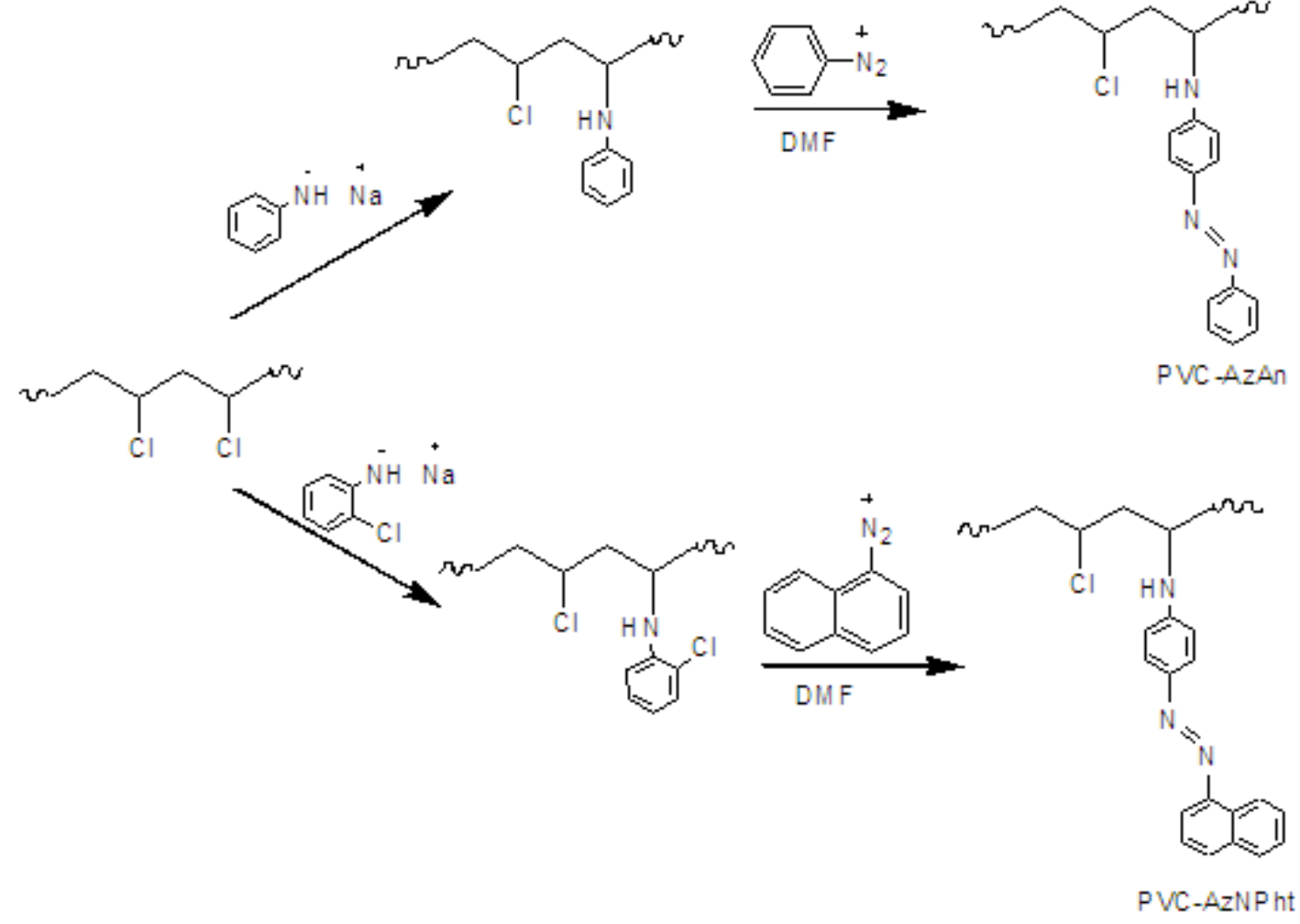

III), 4.35 (PVC-THDPht IV), 4.13 (PVC-THDPht V). The shifting in the energy gaps observed for modified PVCs was assigned to the formation of polarons, probably caused by the presence of the heteroatoms, nitrogen and sulfur atoms.

Photoresponsive materials were accomplished by covalently affixing azo-chromphore-containing moieties via diazonium coupling, using benzene diazonium salt (diazonium salt of aniline) and naphthalene diazonium salt (diazonium salt of $\alpha$-naphthylamine) onto PVC matrix [147]. The different steps to achieve these materials are outlined in Eq. 40. PVC underwent prior functionalizations by reacting with sodium aniline and o-chloroaniline salts in DMF at $60{ }^{\circ} \mathrm{C}$ for $8 \mathrm{~h}$, followed by reaction with the diazonium salts, to afford PVCAzAn and PVC-AzNPht. The thermal stability of the latter modified PVCs was lower than PVC; weight loss occurred at temperatures lower than $150{ }^{\circ} \mathrm{C}$, whereas that of PVC started at $265{ }^{\circ} \mathrm{C}$. Their absorption bands in UV-visible spectra appeared at 389 and $441 \mathrm{~nm}$, respectively.

Benzothiazole and benzimidazole units, UV absorbing groups and photostabilizers, were covalently bound to PVC backbone by reaction of the latter polymer with 2-aminobenzothiazole (ABTz), 2mercaptobenzothiazole (MBTz), and 2- aminobenzimidazole ( $A B I z)$ in THF and in the presence of pyridine at reflux for $3 \mathrm{~h}$ (Eq. 41) [148]. PVC-ABTz and PVC-MBTz were white and yellow in color and with softening points of $\sim 93.5$ and $\sim 104.5{ }^{\circ} \mathrm{C}$, respectively; PVC-ABIz, PVC-ABTz/MBTz, and PVC-ABTz/ABIz were brown with softening points of $\sim 164, \sim 143$, and $\sim 134{ }^{\circ} \mathrm{C}$, respectively. The photodegradation of untreated PVC and the modified ones was quantified by molecular weight measurement and by estimation of the carbonyl index $\left(I_{\mathrm{C}=\mathrm{O}}\right)$, the hydroxyl index $\left(I_{\mathrm{OH}}\right)$ and the polyene index $\left(I_{\mathrm{c}=\mathrm{c}}\right)$ of the irradiated samples; the indexes would give an insight into the extents of scission, carbonyl formation, hydroxyl formation, and polyene formation, respectively, after irradiation of the polymeric film. Upon irradiation, the quantum yields of the chain scission $\left(\Phi_{\mathrm{cs}}\right)$ of the modified PVC were found lower than that for PVC $\left(5.12 \times 10^{-7}\right)$, and were in this increasing order: $\Phi_{\mathrm{cs}}(\mathrm{PVC}-\mathrm{ABTz})=1.11 \times 10^{-7}>$ $\Phi_{\text {cs }}($ PVC-MBTz $)=1.36 \times 10^{-7}>\Phi_{\text {cs }}($ PVC-ABIz $)=$ $1.39 \times 10^{-7}>\Phi_{\mathrm{cs}}(\mathrm{PVC}-\mathrm{ABT} / \mathrm{MBTz})=1.59 \times 10^{-7}>\Phi_{\mathrm{cs}}$ $(\mathrm{PVC}-\mathrm{ABTz} / \mathrm{ABI})=2.82 \times 10^{-7}$. The indexes $I_{\mathrm{C}=\mathrm{O}}, I_{\mathrm{OH}}$, $I_{\mathrm{C}=\mathrm{C}}$ were lower than those for $\mathrm{PVC}$ after irradiation time of $250 \mathrm{~h}$, particularly those for PVC-ABTz, PVC-MBTz, and PVC-ABIz. In addition, their molecular weights did not change as abruptly as for PVC, especially the latter three modified PVCs. All these findings would hint at the photostabilizing effect of the benzothiazole and benzimidazole groups. 


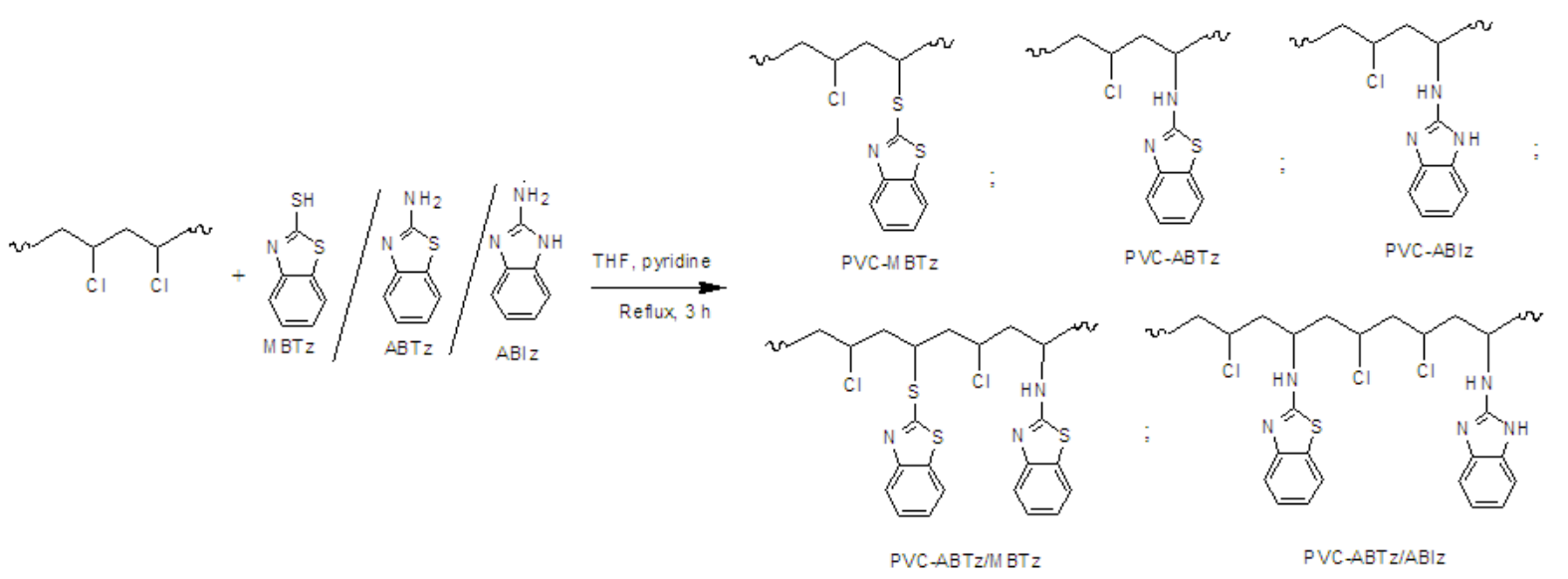

(41)

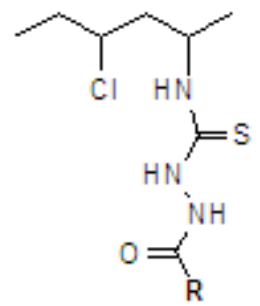

PVC-TSC Z<smiles>[R]c1nnc(SC(C)CC(Cl)CC)[nH]1</smiles>

PVC-TAZ

$\mathrm{R}=$

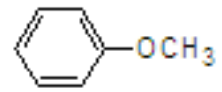

Figure 12: PVC functionalized with thiosemicarbazide, thiadiazole, and triazole.

PVC with thiosemicarbazide (TSCz), thiadiazole (TDzTAz), and triazole (TAz) functionalities were prepared under the conditions as indicated in Eq. 41 and were studied for the photosolidity [149]. After irradiation of their specimens for $250 \mathrm{~h}, \mathrm{PVC}$ and the modified PVCs (Figure 12), PVC-TSCz, PVC-TAz, PVC-TDzTAz, presented variations of indexes $I_{\mathrm{C}=\mathrm{O}}, I_{\mathrm{OH}}$, $I_{\mathrm{c}=\mathrm{c}}$ as given in Table 2. One can understand the photostability of the modified PVCs according to the variations of molecular weight and the indexes $\mathrm{IOH}_{\mathrm{OH}}$ and $I_{\mathrm{c}=\mathrm{c}}$; however, and to one's surprise, the variations of
$I_{\mathrm{C}=0}$ would suggest that $\mathrm{PVC}$ is more stable to photolysis than the modified ones.

\section{FUNCTIONALIZATIONS FOR DESALINATION}

A core-shell polymeric sorbent for removal of boric acid $\left(\mathrm{H}_{3} \mathrm{BO}_{3}\right)$ was conceived by grafting poly(glycidyl methacrylate) onto crosslinked PVC matrix, applying ATRP strategy [150]. The approach was to realize the graft polymerization of glycidyl methacrylate (GMA) onto dehydrochlorinated PVC (DHPVC) in the

Table 2: Variation of the Different Indexes after Irradiation of PVC and its Modifications

\begin{tabular}{|c|c|c|c|c|}
\hline & PVC & PVC-TSCz & PVC-TAz & PVC-TDzTAz \\
\hline \hline$\Delta I_{\mathrm{C}=\mathrm{O}}$ increase (\%) & 627 & 650 & 1100 & 2050 \\
\hline$\Delta \mathrm{I}_{\mathrm{OH}}$ increase (\%) & 251 & 123 & 82 & 65 \\
\hline$\Delta \mathrm{I}_{\mathrm{C}=\mathrm{c}}$ increase (\%) & 116 & 62 & 24 & 26 \\
\hline$\Delta M_{\mathrm{v}}$ decrease (\%) & 44 & 37.5 & 24 & 21 \\
\hline
\end{tabular}



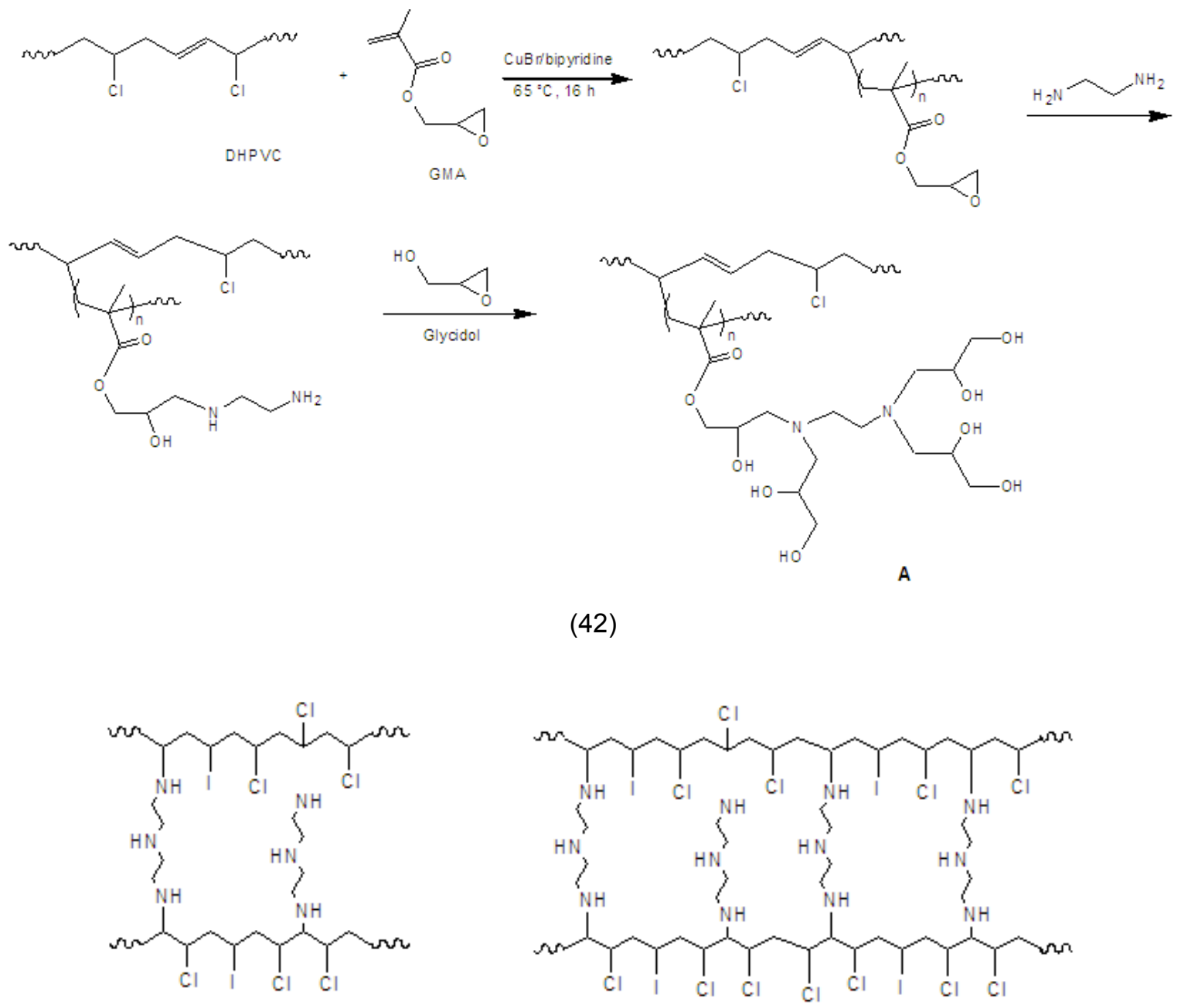

A

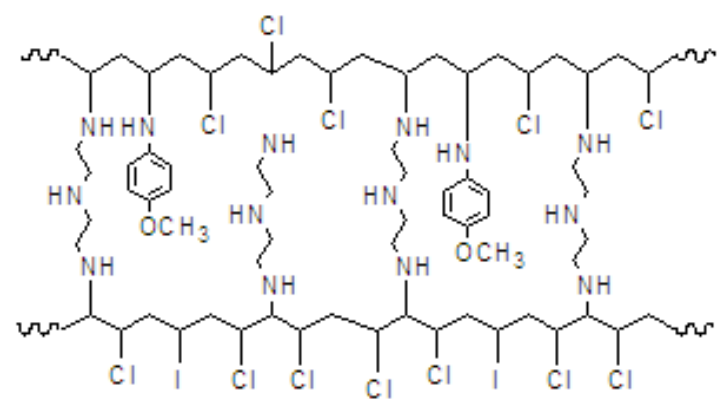

C

Figure 13: Functionalized PVC crosslinked with polyamines.

presence of $\mathrm{CuBr} / \mathrm{bipyridine}$ at $65{ }^{\circ} \mathrm{C}$ as traced in Eq. 42. The crosslinked DHPVC possessed labile allylic chlorines, which were the grafting initiation sites. A grafting percentage of as high as $200 \%$ was accomplished after $16 \mathrm{~h}$ of reaction. The GMA units of the copolymer underwent transformation with ethylenediamine followed by reaction with glycidol. The boron sorption capacity of the thus-made sorbent $\mathbf{A}$ reached $3 \mathrm{mmol} / \mathrm{g}$ at $\mathrm{pH}=8$; the mechanism sorption of boric acid by the sorbent was the chelation through the vicinal diol group. The capacity of the recycled sorbent was $2.48 \mathrm{mmol} / \mathrm{g}$.

Amination of PVC was managed by reaction with diethylenetriamine and $p$-aminoanisole in the presence of potassium iodide in dioxane or THF [151]. It was claimed that iodinated PVC was produced in situ, allowing facile substitution, providing that iodine atom is 


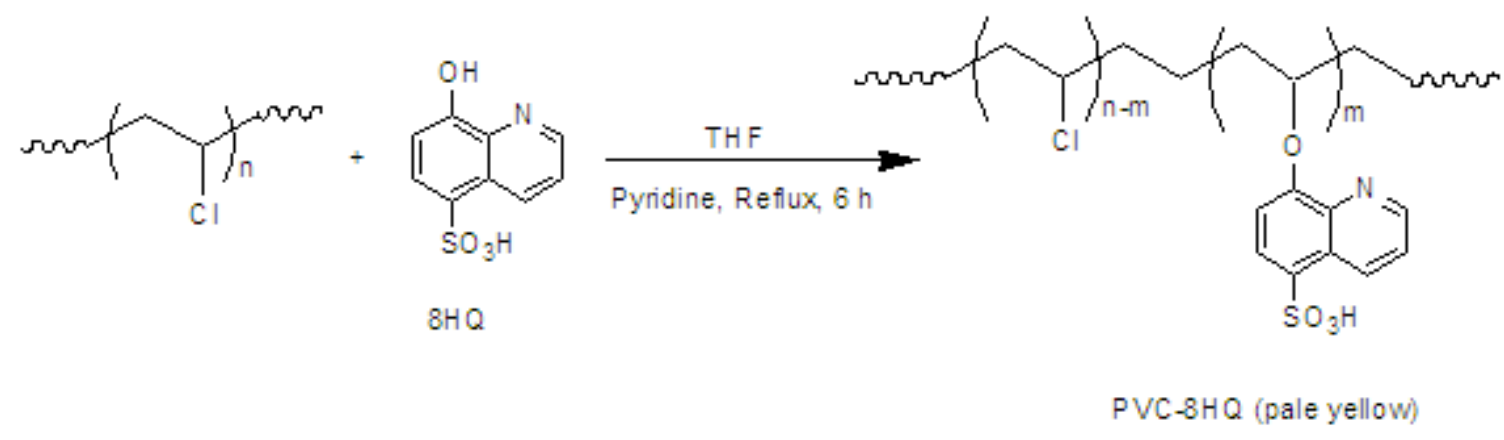

better leaving group than chlorine one. The reaction with diethylenetriamine in dioxane at $80{ }^{\circ} \mathrm{C}$ for $48 \mathrm{~h}$ afforded a yellow material with the proposed crosslinked structure $\mathbf{A}$ shown in Figure 13. The same reaction run in THF at $160{ }^{\circ} \mathrm{C}$ for $3 \mathrm{~h}$ yielded a brown material with the proposed crosslinked structure $\mathbf{B}$ as shown below (Figure 13). The PVC-amine prepared under the latter conditions was further functionalized with $p$-aminoanisole in THF at $150{ }^{\circ} \mathrm{C}$ for $3 \mathrm{~h}$ to end up with $C$ (Figure 13). The authors of this work seemed not to be aware of the polyene formation, particularly at high temperatures, giving rise to the brownish color of the modified PVC. The modified PVC's obtained were evaluated as potential sorbents for heavy metals. The removal levels of different metals by the modified PVCs A, B, and C were reported as follows: $\mathrm{Hg}_{2}{ }^{\prime \prime}(36,50$, $21 \%), \mathrm{Sn}^{\prime \prime}(33,87,12 \%), \mathrm{Pb}^{\prime \prime}(9,12,10 \%), \mathrm{Fe}^{\mathrm{III}}(27,75$, $8 \%), \mathrm{Cd}^{\prime \prime}(0,7.5,10.5 \%), \mathrm{Ni}^{\text {." }}(0,9,10 \%), \mathrm{Cu}^{\text {ll }}(0,16$, $30 \%)$.

A polymeric metal complex was devised by appending 8-hydroxyquinoline-5-sulphonic acid (8HQ), a chelating molecule, to PVC backbone as pictured in Eq. 43 [152]. $P V C$ complexes were realized by mixing a solution of PVC-8HQ in THF with the solution of transition metal $\left(\mathrm{M}_{\mathrm{T}}\right)$ in ethanol; the colored PVC-8HQ-M complexes $\left(\mathrm{M}_{\mathrm{T}}=\mathrm{Cr}^{\prime \prime \prime}, \mathrm{Co}^{\prime \prime}, \mathrm{Ni}^{\prime \prime}, \mathrm{Cu}^{\prime \prime}, \mathrm{Cd}^{\prime \prime}, \mathrm{Hg}^{\prime \prime}\right.$, and $\left.\mathrm{Pb}^{\prime \prime \prime}\right)$ were soluble in DMF and DMSO. Spectral evidence revealed the octahedral geometry for PVC-8HQ-Cr complex, square planar geometry for PVC-8HQ-Ni complex, tetragonal geometry for PVC-8HQ-Cu complex, and tetrahedral geometry for PVC-8HQ-Hg, PVC-8HQ-Pb, and PVC-8HQ-Cd complexes.

A PVC-based adsorbent was conceived by reaction of PVC-NH $\mathrm{N}_{2}$ with diacetone acrylamide via Michael addition [153]. The sorption of 4-chlorophenol by this PVC sorbent fitted Freundlich model, and obeyed a pseudo-second-order kinetics with a rate constant of $5.38 \mathrm{mg} /(\mathrm{mg} \cdot \mathrm{min})$ at $25{ }^{\circ} \mathrm{C}$. The adsorption capacity of the resin was $45.2 \mathrm{mg} / \mathrm{g}$ at this temperature.
To develop a palladium-free process for the electroless metal plating, a semi-interpenetrating polymer network (semi-IPN) hydrogel, consisting of chitosan/polyethylene glycerol) and glutaraldehyde as crosslinker, was covalently linked to an etched PVC surface $[154,155]$; the latter etching with $\mathrm{KMnO}_{4} / \mathrm{NaOH}$ helped creating polar groups, namely hydroxyl and carboxyl groups. The swelling of the PVC-(semi-IPN hydrogel) increased with glutaraldehyde content and decreased with increasing $\mathrm{pH}$. Optimal adsorption capacity of the PVC-(semi-IPN hydrogel) towards copper (II) nanoparticles (20-50 nm) was nearly 126 $\mathrm{mg} / \mathrm{g}$ under the optimal conditions: a $\mathrm{pH}$ of 5.5 , a glutaraldeyde quantity of $0.5 \mathrm{~mL}$, a copper(II) concentration of $100 \mathrm{mg} / \mathrm{L}$, a time of $60 \mathrm{~min}$. Such copper sorption by this PVC composite was found to be also depended on hydrogel morphology. Copper adsorption was believed to take place by a chelation mechanism mostly through the amino groups of chitosan. Such as-adsorbed copper ions would act as catalyst nuclei sites to initiate the electroless metal plating, and thus avoiding the common use of palladium. The surface resistance $R_{\mathrm{s}}$ detected of asplated nickel at $\mathrm{pH} 5.5$ and by using glutaraldehyde of $1 \mathrm{~mL}$ was around $0.52 \Omega \mathrm{sq}^{-1}$, a good value for a material to exhibit a better electromagnetic shielding property $\left(<10 \Omega \mathrm{sq}^{-1}\right)$. $R_{\mathrm{s}}$ rose with the amount of glutaraldehyde and reached $0.77 \Omega \mathrm{sq}^{-1}$ for $3 \mathrm{~mL}$ of glutaraldehyde. The $\mathrm{Cu}(\mathrm{II})$ adsorption results obeyed better the Langmuir model than the Freundlich one, hinting at the occurrence of a monolayer adsorption on the modified-PVC surfaces.

\section{FUNCTIONALIZATIONS FOR MISCELLANEOUS APPLICATIONS}

In the goal of setting resins for cation exchanger and chromatography, Singh and his co-workers [156] modified PVC with maleic anhydride after crosslinking with polyamines. Crosslinking was realized with ethylenediamine, diethylenetriamine, or ethanolamine, 


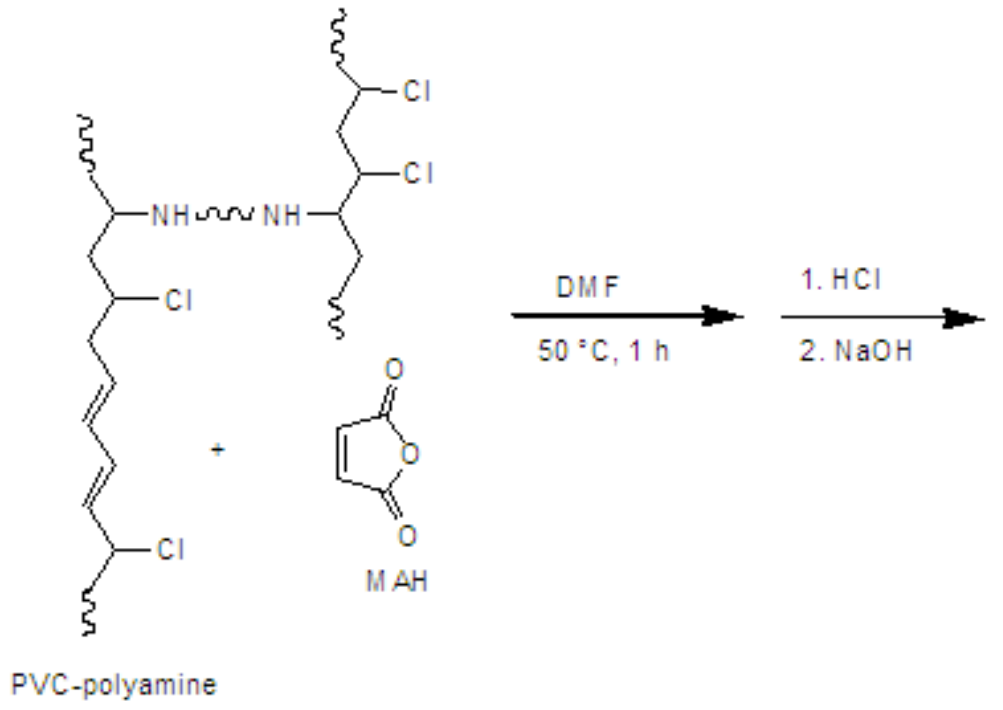

(44)

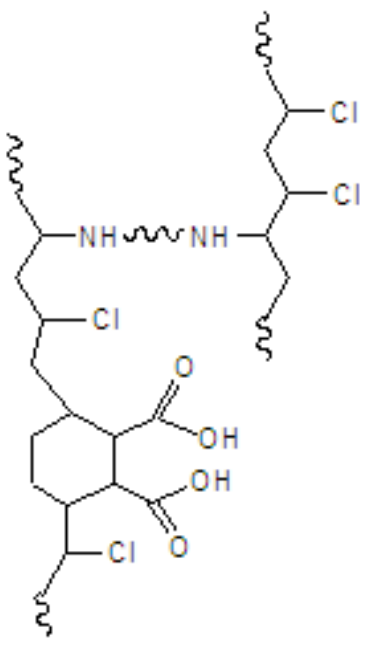

PVC-polyam in e-MAH in DMF at $80{ }^{\circ} \mathrm{C}$ for $4-5 \mathrm{~h}$, via a substitution mechanism; a crosslinking yield of $80 \%$ was attained, with a concomitant formation of conjugated polyene sequences under these conditions. The crosslinked PVC-polyamines were yellow to brown, indicating the existence of unsaturated sites, and were less thermally stable than the parent PVC. A further modification was devised by reacting the thus-crosslinked PVC with maleic anhydride $(\mathrm{MAH})$ through a Diels-Alder cycloaddition as depicted in Eq. 44. The PVCpolyamine-MAH resins were lighter in color, suggesting the decline in the number of conjugated double bonds. Greater swelling ratios of the PVC-polyamine-MAH resins in water, $0.1 \mathrm{HCl}, 0.1 \mathrm{NaOH}$, and $0.1 \mathrm{NaCl}$, were measured compared to those of $\mathrm{PVC}$ and crosslinked PVC-polyamines.

Russian workers [157] functionalized PVC $\left(M_{\mathrm{v}}=63\right.$ $000 \mathrm{~g} / \mathrm{mol}$ ) with pyrazole and 3,5-dimethylpyrazole by means of their sodium salts, in DMF, DMSO, or cyclohexanone at temperatures of $0-45{ }^{\circ} \mathrm{C}$. The thusmodified PVC's (Figure 14) were insoluble and yellow to black. The substitution degrees fluctuated between 4.30 and $15.88 \%$. Based on the residual chlorine, the modification degrees were found greater, suggesting the occurrence of intensive dehydrochlorination which was confirmed by the observed dark color. Pyrazolefunctionalized PVC's were found less thermally stable than the pristine PVC; while the latter one began to decompose at $170{ }^{\circ} \mathrm{C}$, the former ones started at 150 ${ }^{\circ} \mathrm{C}$. The conjugated polyene sequences conferred paramagnetic properties to the modified PVC's. Signals of a width 9 to $14 \AA$ in their EPR spectra corresponded to the concentrations of paramagnetic centers $10^{17}$

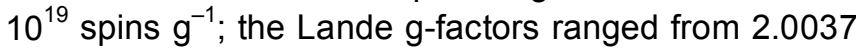
to 2.0044, values different from that of free electron (2.002319), which were assigned to spin-orbit interaction. Such deviation was reasoned in terms of interaction of the unpaired electron with nitrogen hetero atoms.

ATRP technique was employed to engineer PVC- $g$ PMMA and PVC-g-PSt with dielectric characteristics from PVC functionalized with diethanolamine (DEA) [158]. The macroinitiator for ATRP was made by acylating PVC-DEA with $\alpha$-bromoisobutyryl bromide (BIBB) in THF and in the presence of triethylamine (TEA) at room temperature (Eq. 45). The glass

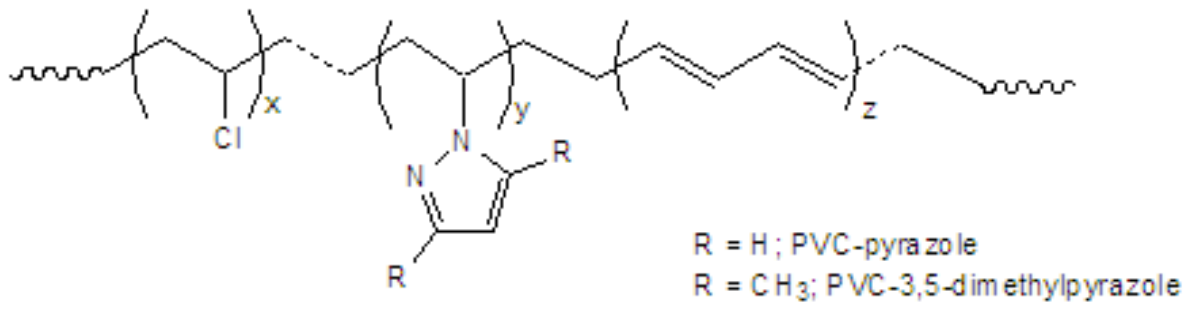

Figure 14: PVC modified with pyrazoles. 


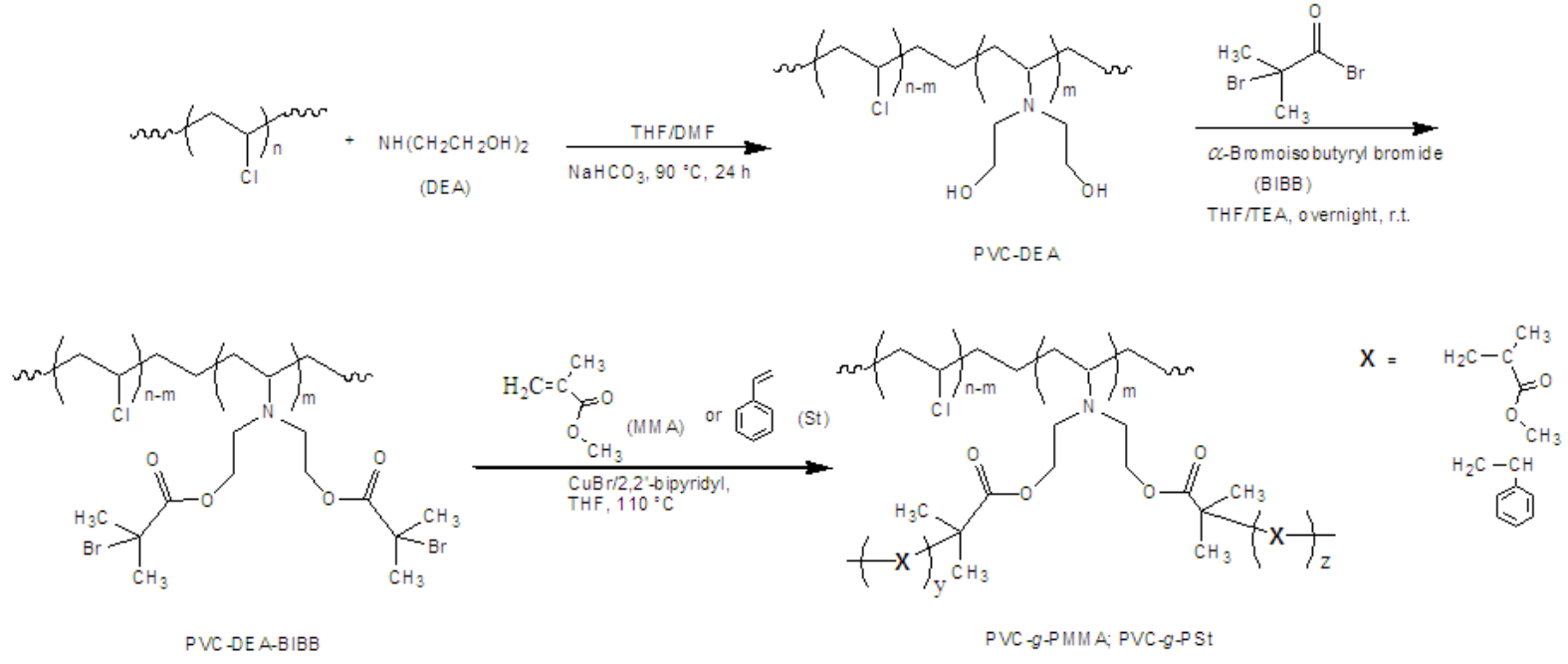

(45)

transition temperatures of PVC-DEA, PVC-DEA-BIBB, PVC-g-PMMA, and PVC-g-PSt were measured as 93, 91,120 , and $98^{\circ} \mathrm{C}$; that of parent PVC was found to be $91^{\circ} \mathrm{C}$. The higher $T_{\mathrm{g}}$ 's of the grafted copolymers were due to a drop in the chain mobility and the free volume, particularly for PVC-g-PMMA. Only one single glass transition was observed for both graft copolymers, hinting at the good compatibility of their segments. In general, the graft copolymers PVC-g-PMMA and PVC$g$-PSt exhibited better thermal stability than PVC, PVCDEA and PVC-DEA-BIBB; the latter two ones showed a thermal stability slightly lower than PVC. They started to degrade at the following temperatures: $243{ }^{\circ} \mathrm{C}$ (PVC), $220^{\circ} \mathrm{C}$ (PVC-DEA), $205^{\circ} \mathrm{C}$ (PVC-DEA-BIBB), $245{ }^{\circ} \mathrm{C}$ (PVC-g-PMMA, PVC-g-PSt). The dielectric constants $(\varepsilon)$ of the modified PVC's were in the range of $4.17-4.76$ measured at $1 \mathrm{kHz}$, values greater than that of PVC (3.22).

Lăzăroaie and his collaborators [159] presented sequential chemical modifications of PVC $(M=50300$ $\mathrm{g} / \mathrm{mol}$ ), involving amination, isocyanation, and PEGylation. Also, they investigated the transformation of $\mathrm{PVC}-\mathrm{NH}_{2}$ with acrylamide, and the graft copolymerization of PVC with 2-phenyl-2-oxazoline (PhOZ) via the iodinated PVC. PVC-amine was achieved with near $5 \%$ substitution, using EDA at 80 ${ }^{\circ} \mathrm{C}$ for $1 \mathrm{~h}$ under neat conditions. Isocyanation of PVC$\mathrm{NH}_{2}$ was accomplished in $4.5 \%$ conversion, and was affected by hexamethylene diisocyanate (HMDIC) in heptane at ambient temperature for $1 \mathrm{~h}$. A subsequent modification was the PEGylation of PVC- $\mathrm{NH}_{2}-\mathrm{HMDIC}$, employing PEG 400 and PEG 1500, in benzene at room temperature for only $15 \mathrm{~min}$. Michael addition was applied for the modification of $\mathrm{PVC}-\mathrm{NH}_{2}$ with acrylamide, affording $2 \%$ conversion when working with excess of aqueous acrylamide and at room temperature for $3 \mathrm{~h}$. A Conant-Finkelstein reaction on PVC using $\mathrm{Nal}$ in acetone at $50{ }^{\circ} \mathrm{C}$ for 1.5 yielded iodinated PVC-I with $33 \%$ conversion and molecular weight of $M=74500 \mathrm{~g} / \mathrm{mol}$. Ring-opening polymerization of 2-phenyl-2-oxazoline initiated by PVC-I, via nucleophilic substitution, took place in $\mathrm{CCl}_{4}$ and $70{ }^{\circ} \mathrm{C}$ for $11 \mathrm{~h}$, giving rise to grafted copolymer PVC-g-PPhOZ with a molecular weight of $M=113000$ $\mathrm{g} / \mathrm{mol}$ (Eq. 46).

Polystyrene (PSt) underwent Friedel-Crafts alkylation with $\mathrm{PVC}$ using $\mathrm{AlCl}_{3}$ to enhance the compatibility of PVC/PSt blend [160]; the obvious mechanism would have involved the PVC carbocation generated as the one shown in the above equation (Eq. 32). Such operation led to an improvement of the impact toughness of the blend and the melting temperature of the blending; indeed, the latter parameter dropped by $20{ }^{\circ} \mathrm{C}$. Also, an in-between $T_{\mathrm{g}}$ of the blend $\left(89^{\circ} \mathrm{C}\right)$ was detected; those of PSt and PVC were measured as 106 and $83^{\circ} \mathrm{C}$, respectively. Such modification led to enhanced mechanical properties of PVC: a tensile strength increase of about $22.6 \%$ and the impact strength increase of $35.9 \%$.

\section{CONCLUSIONS}

The above-outlined chemistry of poly(vinyl chloride) would inevitably instill into the chemist's mind that this material and the plethora of its functionalizations stand as valuable means for targeted applications and uses. Such a chemical diversity would let chemist expect a bright future for other undertakings of poly(vinyl 


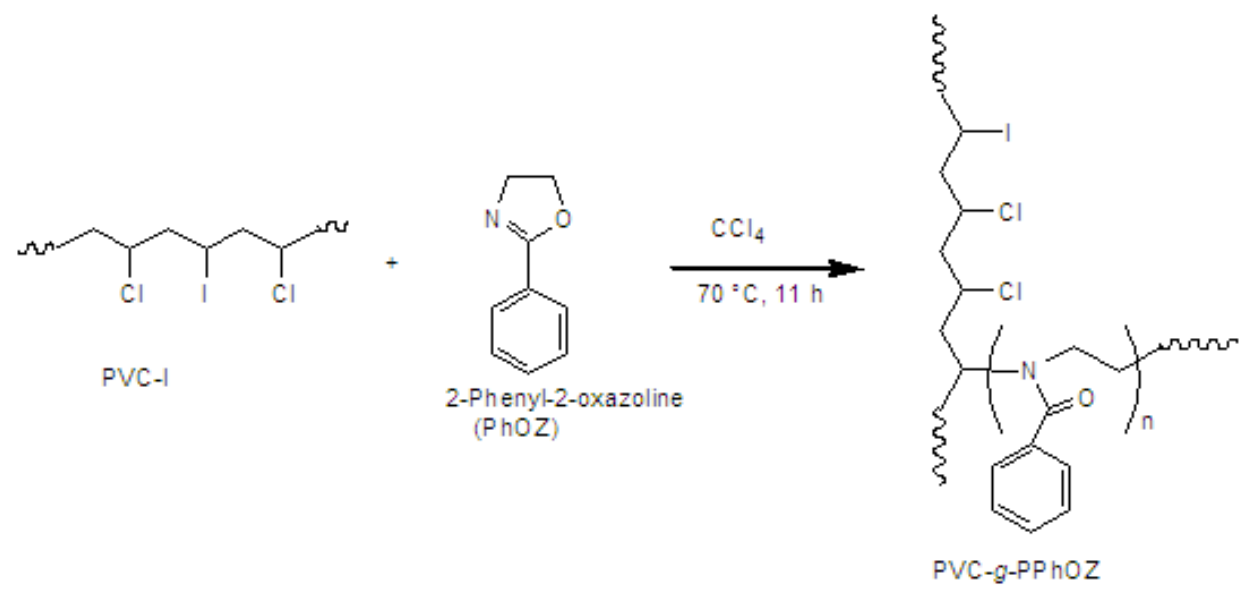

(46)

chloride). Adequately modified poly(vinyl chloride) would indubitably be an unshakable platform for cutting-edge technology. Indeed, the functionalizations of PVC intended for biological and medical end-uses are peculiarly regarded. Besides its good characteristics for designing separative and ionelectrode selective membranes, the other feature of PVC is its readily functionalizability by virtue of the novel chemistries, namely the click chemistry and the chemistry behind macroinitiator making as in living/controlled radical polymerization (LCRP), leading to PVC-graft copolymers. A definite remedy for migration of the external plasticizers from the bulk PVC could be effectively realized through covalent plasticization, thus annihilating any adverse effect of the plasticizer.

\section{REFERENCES}

[1] Vasita R, Shanmugam K, Katti DS. Improved biomaterials for tissue engineering applications: surface modification of polymers. Curr Top Med Chem 2008; 8: 341-53. http://dx.doi.org/10.2174/156802608783790893

[2] Asadinezhad A, Lehocký M, Sáha P, Mozetič M. Recent progress in surface modification of polyvinyl chloride. Materials 2012; 5: 2937-59. http://dx.doi.org/10.3390/ma5122937

[3] Li D, Xia Y. Electrospinning of nanofibers: reinventing the wheel?. Adv Mater 2004; 16: 1151-70. http://dx.doi.org/10.1002/adma.200400719

[4] Agarwal S, Wendorff JH, Greiner A. Use of electrospinning technique for biomedical applications. Polymer 2008; 49: 5603-21.

http://dx.doi.org/10.1016/j.polymer.2008.09.014

[5] Feng C, Li Y, Yang D, Hu J, Zhang X, Huang X. Well-defined graft copolymers: from controlled synthesis to multipurpose applications. Chem Soc Rev 2011; 40: 1282-95. http://dx.doi.org/10.1039/B921358A

[6] Braun D. Poly(vinyl chloride) on the way from the 19th century to the 21st century. J Polym Sci Part A Polym Chem 2004; 42: 578-86.

http://dx.doi.org/10.1002/pola.10906
[7] Endo K. Synthesis and structure of poly(vinyl chloride). Progr Polym Sci 2002; 27: 2021-54. http://dx.doi.org/10.1016/S0079-6700(02)00066-7

[8] Moulay S. Chemical modification of poly(vinyl chloride)-still on the run. Progr Polym Sci 2010; 35: 303-31. http://dx.doi.org/10.1016/j.progpolymsci.2009.12.001

[9] Kolb HC, Finn MG, Sharpless KB. Click chemistry: diverse chemical function from a few good reactions. Angew Chem Intern Ed 2001; 40: 2004-21. http://dx.doi.org/10.1002/15213773(20010601)40:11<2004::AID-ANIE2004>3.0.CO;2-5

[10] Moulay S, Touati A. Cycloaddition reactions in aqueous systems: a two-decade trend endeavour. C R Chim 2010; 13 : 1474-511. http://dx.doi.org/10.1016/i.crci.2010.05.025

[11] Pasini D. The click reaction as an efficient tool for the construction of macrocyclic structures. Molecules 2013; 18 : 9512-30. http://dx.doi.org/10.3390/molecules18089512

[12] Thirumurugan P, Matosiuk D, Jozwiak K. Click chemistry for drug development and diverse chemical-biology applications. Chem Rev 2013; 113: 4905-79. http://dx.doi.org/10.1021/cr200409f

[13] Moses JE, Moorhouse AD. The growing applications of click chemistry. Chem Soc Rev 2007; 36: 1249-62. http://dx.doi.org/10.1039/b613014n

[14] Evans RA. The rise of azide-alkyne 1,3-dipolar 'click' cycloaddition and its application to polymer science and surface modification. Aust J Chem 2007; 60: 384-95. http://dx.doi.org/10.1071/CH06457

[15] Fournier D, Hoogenboom R, Schubert US. Clicking polymers: a straightforward approach to novel macromolecular architectures. Chem Soc Rev 2007; 36: 1369-80. http://dx.doi.org/10.1039/b700809k

[16] Robb MJ, Hawker CJ. 'Click' chemistry in polymer science: CuAAC and thiol-ene coupling for the synthesis and functionalization of macromolecules. In: Schlüter AD, Hawker CJ, Sakamoto J, editors. Synthesis of polymers: new structures and methods. Weinheim: Wiley-VCH 2012; 2: 92371.

[17] Le Droumaguet B, Velonia K. Click chemistry: a powerful tool to create polymer-based macromolecular chimeras. Macromol Rapid Commun 2008; 29: 1073-89. http://dx.doi.org/10.1002/marc.200800155

[18] Moulay S. Review: poly(vinyl alcohol) functionalizations and its applications. Polym Plast Technol Eng. In press

[19] Stuart A, McCallum MM, Fan D, LeCaptain DJ, Lee CY Mohanty DK. Poly(vinyl chloride) plasticized with succinate 
esters: synthesis and characterization. Polym Bull 2010; 65: 589-98.

http://dx.doi.org/10.1007/s00289-010-0271-4

[20] Braslau R, inventor; The Regents of the University of California, assignee. Polyphthalate plasticizers that do not release endocrine disrupting compounds. United States patent US WO 2013/116818 A1.

[21] Reddy NN, Mohan YM, Varaprasad K, Ravindra S, Vimala K, Raju KM. Surface treatment of plasticized poly(vinyl chloride) to prevent plasticizer migration. J Appl Polym Sci 2010; 115: 1589-97.

http://dx.doi.org/10.1002/app.31157

[22] Navarro R, Perrino MP, Tardajos MG, Reinecke H. Phthalate plasticizers covalently bound to PVC: plasticization with suppressed migration. Macromolecules 2010; 43: 2377-81. http://dx.doi.org/10.1021/ma902740t

[23] Earla A, Braslau R. Covalently linked plasticizers: triazole analogues of phthalate plasticizers prepared by mild copperfree "click" reactions with azide-functionalized PVC. Macromol Rapid Commun 2014; 35: 666-71. http://dx.doi.org/10.1002/marc.201300865

[24] Braslau R, inventor; The Regents of the University of California, assignee. Polymer plasticizing agents that produce polymers that do not release endocrine disrupting compounds, United States patent US WO 2014/071347 A1.

[25] Yang P, Yan J, Sun H, Fan H, Chen Y, Wang F, Shi B. Novel environmentally sustainable cardanol-based plasticizer covalently bound to PVC via click chemistry: synthesis and properties. RSC Adv 2015; 5: 16980-85. http://dx.doi.org/10.1039/C4RA15527K

[26] Chang $Y$, Pan M, Yuan J, Liu Y, Wang X, Jiang P, Wang Y, Zhong G-J, Li Z-M. Morphology and film performance of phthalate-free plasticized poly(vinyl chloride) composite particles via the graft copolymerization of acrylate swelling flower-like latex particles. RSC Adv 2015; 5: 40076-87. http://dx.doi.org/10.1039/C5RA04747A

[27] Bierbrauer K, López-González M, Riande E, Mijangos C. Gas transport in fluorothiophenyl modified PVC membranes. J Membr Sci 2010; 362: 164-71. http://dx.doi.org/10.1016/j.memsci.2010.06.035

[28] Corrales M, Bierbrauer K, Sacristan J, Mijangos C. Surface modification of PVC membranes using fluorothiophenol compounds. Macromol Chem Phys 2010; 211: 1990-8. http://dx.doi.org/10.1002/macp.201000322

[29] Sacristan JJ, Mijangos C. Free volume analysis and transport mechanisms of PVC modified with fluorothiophenol compounds. A molecular simulation study. Macromolecules 2010; 43: 7357-67.

[30] Su Y, Zhao Q, Liu J, Zhao J, Li Y, Jiang Z. Improved oil/water emulsion separation performance of PVC/CPVC blend ultrafiltration membranes by fluorination treatment. Desalin Water Treat 2014, 1-11.

http://dx.doi.org/10.1080/19443994.2014.918903

[31] Zhu J, Su Y, Zhao X, Li Y, Zhao J, Fan X, Jiang Z. Improved antifouling properties of poly(vinyl chloride) ultrafiltration membranes via surface zwitterionicalization. Ind Eng Chem Res 2014; 53: 14046-55.

http://dx.doi.org/10.1021/ie5022877

[32] Pawlak M, Grygolowicz-Pawlak E, Bakker E. Ferrocene bound poly(vinyl chloride) as ion to electron transducer in electrochemical ion sensors. Anal Chem 2010; 82: 6887-94. http://dx.doi.org/10.1021/ac1010662

[33] Pawlak M, Mistlberger G, Bakker E. In situ surface functionalization of plasticized poly(vinyl chloride) membranes by 'click chemistry'. J Mater Chem 2012; 22: 12796-801.

http://dx.doi.org/10.1039/c2jm31118f

[34] Pawlak M, Grygolowicz-Pawlak E, Crespo GA, Mistlberger G, Bakker E. PVC-based ion-selective electrodes with enhanced biocompatibility by surface modification with "click" chemistry. Electroanalysis 2013; 25: 1840-46.

http://dx.doi.org/10.1002/elan.201300212

[35] Jarolímová Z, Crespo GA, Afshar MG, Pawlak M, Bakker E. All solid state chronopotentiometric ion-selective electrodes based on ferrocene functionalized PVC. J Electroanal Chem 2013; 709: 118-25.

http://dx.doi.org/10.1016/i.jelechem.2013.10.011

[36] Sohail M, De Marco R, Alam MT, Pawlak M, Bakker E. Transport and accumulation of ferrocene tagged poly(vinyl chloride) at the buried interfaces of solid-contact plasticized poly(vinyl chloride) based ion-selective membrane electrodes. Analyst 2013; 138: 4266-9.

http://dx.doi.org/10.1039/c3an00464c

[37] Pawlak M, Mistlberger G, Bakker E. Concanavalin A eelectrochemical sensor based on the surface blocking principle at an ion-selective polymeric membrane. Microchim Acta 2015; 182: 129-37. http://dx.doi.org/10.1007/s00604-014-1309-3

[38] Liu Y, Xue Y, Tang H, Wang M, Qin Y. Click-immobilized K+selective ionophore for potentiometric and optical sensors. Sens Actuators B 2012; 171-172: 556-62.

[39] Pietrzak M, Mroczkiewicz M, Malinowska E. Application of F--selective ionophores in carboxylated or aminated poly(vinyl chloride)-based membranes of ion-selective electrodes. Electroanalysis 2012; 24: 173-9.

http://dx.doi.org/10.1002/elan.201100445

[40] Merle G, Wessling M, Nijmeijer $K$. Anion exchange membranes for alkaline fuel cells: a review. J Membr Sci 2011; 377: 1-35.

http://dx.doi.org/10.1016/j.memsci.2011.04.043

[41] Couture G, Alaaeddine A, Boschet F, Ameduri B. Polymeric materials as anion-exchange membranes for alkaline fuel cells. Progr Polym Sci 2011; 36: 1521-57.

http://dx.doi.org/10.1016/j.progpolymsci.2011.04.004

[42] Hu J, Zhang C, Cong J, Toyod H, Nagatsu M, Meng Y. Plasma-grafted alkaline anion-exchange membranes based on polyvinyl chloride for potential application in direct alcohol fuel cell. J Power Sources 2011; 196: 4483-90.

http://dx.doi.org/10.1016/j.jpowsour.2011.01.034

[43] Kenaway E-R, Worley SD, Broughton R. The chemistry and applications of antimicrobial polymers: a state of the art review. BioMacromolecules 2007; 8: 1359-84. http://dx.doi.org/10.1021/bm061150q

[44] Muñnoz-Bonilla A, Fernández-Garcia M. Polymeric materials with antimicrobial activity. Progr Polym Sci 2012; 37: 281339. http://dx.doi.org/10.1016/j.progpolymsci.2011.08.005

[45] Siedenbiedel F, Tiller JC. Antimicrobial polymers in solution and on surfaces: overview and functional principles. Polymers 2012; 4: 46-71.

http://dx.doi.org/10.3390/polym4010046

[46] Lafarge J, Kébir N, Schapman D, Burel F. Design of selfdisinfecting PVC surfaces using the click chemistry. React Funct Polym 2013; 73: 1464-72. http://dx.doi.org/10.1016/j.reactfunctpolym.2013.08.001

[47] Bigot S, Louarn G, Kébir N, Burel F. Facile grafting of bioactive cellulose derivatives onto PVC surfaces. Appl Surf Sci 2013; 283: 411-6. http://dx.doi.org/10.1016/j.apsusc.2013.06.123

[48] Kameda T, Ono M, Grause G, Mizoguchi T, Yoshioka T. Antibacterial effect of thiocyanate substituted poly(vinyl chloride). J Polym Res 2011; 18: 945-7.

http://dx.doi.org/10.1007/s10965-010-9492-3

[49] Merchan M, Sedlarikova J, Vesel A, Sedlarik V, Pastorek M, Sáha P. Characterization of antibacterial, mechanical, and structural properties of polyvinyl chloride/silver nitrate composites prepared by thermoplastic compounding. Intern $\mathrm{J}$ Polym Anal Charact 2010; 15: 360-9. http://dx.doi.org/10.1080/1023666X.2010.500534 
[50] Merchan $M$, Sedlaříková J, Sedlařík $V$, Machovský $M$, Svobodová J, Sáha P. Antibacterial polyvinyl chloride/antibiotic films: the effect of solvent on morphology, antibacterial activity, and release kinetics. J Appl Polym Sci 2010; 118: 2369-78.

http://dx.doi.org/10.1002/app.32185

[51] Asadinezhad A, Novák I, Lehocký M, Sedlařík V, Vesel A, Junkar I, Sáha P, Chodák I. An in vitro bacterial adhesion assessment of surface-modified medical-grade PVC. Colloids Surf B 2010; 77: 246-56. http://dx.doi.org/10.1016/j.colsurfb.2010.02.006

[52] Asadinezhad A, Novák I, Lehocký M, Sedlařík V, Bílek F, Vesel A, Junkar I, Sáha P, Popelka A. Polysaccharides coatings on medical-grade PVC: a probe into surface characteristics and the extent of bacterial adhesion. Molecules 2010; 15: 1007-27. http://dx.doi.org/10.3390/molecules15021007

[53] Asadinezhad A, Novák I, Lehocký M, Sedlařík V, Vesel A, Junkar I, Sáha P, Chodák I. A physicochemical approach to render antibacterial surfaces on plasma-treated medicalgrade PVC: irgasan coating. Plasma Process Polym 2010; 7: 504-14.

http://dx.doi.org/10.1002/ppap.200900132

[54] Islas L, Alvarez-Lorenzo C, Magariños B, Concheiro A, Felipe del Castillo L, Burillo G. Singly and binary grafted poly(vinyl chloride) urinary catheters that elute ciprofloxacin and prevent bacteria adhesion. Intern J Pharm 2015; 488: 20-8.

http://dx.doi.org/10.1016/j.ijpharm.2015.04.036

[55] Patel M, Patel R, Chi WS, Kim JH, Sung J-S. Antibacterial behaviour of quaternized poly(vinyl chloride)-g-poly(4vinylpyridine) graft copolymers. Chinese J Polym Sci 2015; 33: $265-74$

http://dx.doi.org/10.1007/s10118-015-1577-3

[56] Rabie ST, El-Saidi MMT, Mohamed NR. Synthesis of biologically active and photostable rigid poly(vinyl chloride). J Biomed Mater Res Part A 2012; 100: 3503-10. http://dx.doi.org/10.1002/jbm.a.34279

[57] Chruściel JJ, Leśniak E. Modification of thermoplastics with reactive silanes and siloxanes. In: El-Sonbati A, editor. Thermoplastic elastomers 2012; Chap. 9: 155-92.

[58] Kregiel D, Berlowska J, Mizerska U, Fortuniak W, Chojnowski J, Ambroziak W. Chemical modification of polyvinyl chloride and silicone elastomer in inhibiting adhesion of aeromonas hydrophila. World $\mathrm{J}$ Microbiol Biotechnol 2013; 29: 1197-206. http://dx.doi.org/10.1007/s11274-013-1282-8

[59] Oztuna A, Nazir H, Baysallar M. Simultaneous Bacillus anthracis spores detection via aminated-poly(vinyl chloride) coated piezoelectric crystal immunosensor. J Coatings 2014; Vol. 2014, Article ID 256168, 8 pages. http://dx.doi.org/10.1155/2014/256168

[60] Naif OA. Modification of poly(vinyl chloride) via introducing of pendent thiadiazole derivatives and study of their biological activity. Al-Mustansiriyah J Sci 2012; 23: 39-54.

[61] Bigot S, Louarn G, Kébir N, Burel F. Click grafting of seaweed polysaccharides onto PVC surfaces using an ionic liquid as solvent and catalyst. Carbohydr Polym 2013; 98: 1644-49.

http://dx.doi.org/10.1016/j.carbpol.2013.07.079

[62] Monika S, Mishra RR, Jaiswal S, Kapusetti G, Misra N. Chemical modification of poly (vinyl chloride) sheet with thiourea for cell study. In: Bhardwaj S, Shekhawat MS, Suthar B, editors. Proceedings of international conference on recent trends in applied physics and material science, AIP Conf Proc 2013; 1536: 1157-8.

[63] Monika S, Kumar S, Misra N. Chemical modification of poly(vinyl chloride) by thiourea: influence of surface characteristics. Adv Sci Eng Med 2014; 6: 1167-70.

http://dx.doi.org/10.1166/asem.2014.1622
[64] Monika, Mahto SK, Das S, Ranjan A, Singh SK, Roy P, Misra $\mathrm{N}$. Chemical modification of poly(vinyl chloride) for blood and cellular biocompatibility. RSC Adv 2015; 5: 45231-8.

[65] Zou Y, Lai BF, Kizhakkedathu JN, Brooks DE. Inhibitory effect of hydrophilic polymer brushes on surface-induced platelet activation and adhesion. Macromol Biosci 2010; 10: 1432-43.

http://dx.doi.org/10.1002/mabi.201000223

[66] Mohy Eldin MS, Mita DG. Immobilized enzymes: strategies for overcoming the substrate diffusion-limitation problem. Curr Biotechnol 2014; 3: 207-17. http://dx.doi.org/10.2174/221155010303140918114737

[67] Mohy Eldin MS, El Enshasy HA, El Sayed M, El Sayed S, Haroun B, Hassan EA. Covalent immobilization of penicillin $G$ acylase onto chemically activated surface of poly(vinyl chloride) membranes for 6-penicillic acid production from penicillin hydrolysis process I. Optimization of surface modification and its characterization. J Appl Polym Sci 2012; 124 (S1): E27-E36. http://dx.doi.org/10.1002/app.35390

[68] Mohy Eldin MS, El Enshasy HA, Hassan ME, Haroun B Hassan EA. Covalent immobilization of penicillin $G$ acylase onto amine-functionalized PVC membranes for 6-APA production from penicillin hydrolysis process. II. Enzyme immobilization and characterization. J Appl Polym Sci 2012; 125: 3820-8.

http://dx.doi.org/10.1002/app.36690

[69] Mohy Eldin MS, Elaassar MR, Elzatahry AA, Al-Sabah MMB Hassan EA. Covalent immobilization of $\beta$-galactosidase onto amino-functionalized PVC microspheres. J Appl Polym Sci 2012; 125: 1724-1735. http://dx.doi.org/10.1002/app.35682

[70] Mohy Eldin MS, Elaassar MR, Elzatahry AA, Al-Sabah MMB. Covalent immobilization of $\beta$-galactosidase onto aminofunctionalized polyvinyl chloride microspheres: enzyme immobilization and characterization. Adv Polym Technol 2014; 33: 21379.

http://dx.doi.org/10.1002/adv.21379

[71] Li D-F, Ding H-C, Zhou T. Covalent immobilization of mixed proteases, trypsin and chymotrypsin, onto modified polyvinyl chloride microspheres. J Agric Food Chem 2013; 61: 1044753. http://dx.doi.org/10.1021/jf403476p

[72] Rozum B, Gajownik K, Tymecki $Ł$, Koncki R. Poly(vinyl chloride) tubing with covalently bound alkaline phosphatase and alternative approach for investigations of open-tubular bioreactors. Anal Biochem 2010; 400: 151-3. http://dx.doi.org/10.1016/j.ab.2010.01.016

[73] Kondyurin A, Nosworthy NJ, Bilek MMM. Effect of low molecular weight additives on immobilization strength, activity, and conformation of protein immobilized on PVC and UHMWPE. Langmuir 2011; 27: 6138-48. http://dx.doi.org/10.1021/la200376f

[74] Arenas E, Castillón FF, Farías MH. EDC and sulfo-NHS functionalized on PVC-g-PEGMA for streptokinase immobilization. Des Monom Polym 2012; 15: 369-78. http://dx.doi.org/10.1080/1385772X.2012.686685

[75] Marek P, Senecal K, Nida D, Magnone J, Senecal A Application of a biotin functionalized QD assay for determining available binding sites on electrospun nanofiber membrane. J Nanobiotechnol 2011; 9:48 (p.7). http://dx.doi.org/10.1186/1477-3155-9-48

[76] Gabriel M, Strand D, Vahl C-F. Cell adhesive and antifouling polyvinyl chloride surfaces via wet chemical modification. Artif Organs 2012; 36: 839-44.

http://dx.doi.org/10.1111/j.1525-1594.2012.01462.x

[77] Balakrishnan B, Jayakrishnan A. Chemical modification of poly(vinyl chloride) using poly(ethylene glycol) to improve 
blood compatibility. Trends Biomater Artif Organs 2005; 18 : 230-6.

http://dx.doi.org/10.1016/j.biomaterials.2004.09.032

[78] Finley MJ, Rauova L, Alferiev IS, Weisel JW, Levy RJ, Stachelek SJ. Diminished adhesion and activation of platelets and neutrophils with CD47 functionalized blood contacting surfaces. Biomaterials 2012; 33: 5803-11. http://dx.doi.org/10.1016/j.biomaterials.2012.04.051

[79] Jun D, XiaoLi L, Wei L, ZhaoQiang W, Hong C. One-step preparation of vinyl-functionalized material surfaces: a versatile platform for surface modification. Sci China Chem 2014; 57: 654-60. http://dx.doi.org/10.1007/s11426-014-5067-1

[80] Patel R, Patel M, Ahn SH, Sung YK, Lee H-K, Kim JH, Sung J-S. Bioinert membranes prepared from amphiphilic poly(vinyl chloride)-g-poly(oxyethylene methacrylate) graft copolymers. Mater Sci Eng C 2013; 33: 1662-70. http://dx.doi.org/10.1016/j.msec.2012.12.097

[81] Shu Y, Chen X-W, Wang J-H. Ionic liquid-polyvinyl chloride ionomer for highly selective isolation of basic proteins. Talanta 2010; 81: 637-42.

http://dx.doi.org/10.1016/j.talanta.2009.12.059

[82] Demirci G, Tasdelen MA. Synthesis and characterization of graft copolymers by photoinduced CuAAC click chemistry. Eur Polym J 2015; 66: 282-9. http://dx.doi.org/10.1016/j.eurpolymj.2015.02.029

[83] Iván B, Pálfi V, Szarka G. Novel functional polymers by terminal and pendant functionalizations via thiol-ene and thiol-polyene click reactions. Polym Prepr 2010; 51:715-6.

[84] Akat $H$, Ozkan $M$. Synthesis and characterization of poly(vinyl chloride) type macrophotoinitiator comprising sidechain thioxanthone via click chemistry. eXPRESS Polym Lett 2011; 5: 318-26.

http://dx.doi.org/10.3144/expresspolymlett.2011.32

[85] Karimi B, Behzadnia H, Farhangi E, Jafari E, Zamani A. Recent application of polymer supported metal nanoparticles in Heck, Suzuki and Sonogashira coupling reactions. Curr Org Synth 2010; 7: 543-67.

http://dx.doi.org/10.2174/157017910794328538

[86] Bakherad M, Keivanloo A, Bahramian B, Siavoshi M. Copper- and solvent-free Sonogashira reaction catalyzed by polyvinyl chloride-supported palladium(II) triazole complex. Letters Org Chem 2013; 10: 758-63. http://dx.doi.org/10.2174/15701786113109990048

[87] Bakherad M, Keivanloo A, Samangooei S, Omidian M. A phenyldithiocarbazate-functionalized polyvinyl chloride resin supported Pd(II) complex as an effective catalyst for solventand copper-free Sonogashira reactions under aerobic conditions. J Organomet Chem 2013; 740: 78-82.

http://dx.doi.org/10.1016/j.jorganchem.2013.04.058

[88] Bakherad M, Keivanloo A, Hadi A, Siavoshi M. Copper-free Sonogashira coupling reaction catalyzed by PVC-supported triazine palladium(II) complex under aerobic conditions. Asian J Org Chem 2014; 3: 1189-92.

http://dx.doi.org/10.1002/ajoc.201402125

[89] Bakherad M, Keivanloo A, Samangooei S. Poly(vinyl chloride)-supported Pd(II) complex as an efficient catalyst for Heck and Cu-free Sonogashira reactions under aerobic conditions. Chinese J Catal 2014; 35: 324-8. http://dx.doi.org/10.1016/S1872-2067(12)60746-3

[90] Zhang L, Xue M, Cui Y. Catalytic performance of PVCtriethylene-tetramine supported palladium complex for Heck reaction. J Appl Polym Sci 2010; 115: 2523-7.

http://dx.doi.org/10.1002/app.31182

[91] Shao L, Qi C, Zhang X-M. Aminated chlorinated polyvinylchloride nanofiber mat-supported palladium heterogeneous catalysts: preparation, characterization and application. RSC Adv 2014; 4: 53105-8.

http://dx.doi.org/10.1039/C4RA08469A
[92] Zhou B, Li Y-Q. Palladium nanoparticles immobilized on poly(vinyl chloride)-supported pyridinium as an efficient and recyclable catalyst for Suzuki-Miyaura cross-coupling reaction. E-J Chem 2011; 8: 1490-7.

http://dx.doi.org/10.1155/2011/313102

[93] Chen F, Huang M, Zhou B, Liu J, Li Y. Palladium nanoparticles immobilized on poly(vinyl chloride)-supported bidentate ligands: an easily prepared, air and moisture state catalyst for Suzuki-Miyaura reaction. http://www.paper.edu.cn/html/releasepaper/2013/04/450/

[94] Hemantha HP, Sureshbabu VV. Poly(vinyl chloride)supported palladium nanoparticles: catalyst for rapid hydrogenation reactions. Org Biomol Chem 2011; 9: 2597601.

http://dx.doi.org/10.1039/c0ob00962h

[95] Krishnan GR, Kajal KS, Sreekumar K. Synthesis of $\beta$-amino alcohols catalyzed by poly(vinyl chloride)-supported Schiff base metal complexes. Monatsh Chem 2012; 143: 637-42. http://dx.doi.org/10.1007/s00706-011-0628-x

[96] Li J, Yang G, Cui Y. Recyclable polyvinyl chloride-supported pyrrolidine-thiourea as a bifunctional organocatalyst for direct asymmetric aldol reaction in aqueous medium. J Appl Polym Sci 2011; 121: 1506-11.

http://dx.doi.org/10.1002/app.33676

[97] Krishnan GR, Niveditha KS, Sreekumar K. Aminated poly(vinyl chloride): an efficient green catalyst for Knoevenagel condensation. Indian J Chem 2013; 52B: 42831.

[98] Öztürk T, Göktaş M, Savaş B, Işıklar M, Atalar MN, Hazer B. Synthesis and characterization of poly(vinyl chloride-graft-2vinylpyridine) graft copolymers using a novel macroinitiator by reversible addition-fragmentation chain transfer polymerization. e-Polymers $2014 ; 14: 27-34$. http://dx.doi.org/10.1515/epoly-2013-0011

[99] Liu H, Zhang XM. Review on chlorinated polyvinyl chloride. Polyvinyl Chloride 2008; 36: 9-11.

[100] Lu W, Cao T, Wang Q, Cheng Y. Plasma-assisted synthesis of chlorinated polyvinyl chloride (CPVC) using a gas-solid contacting process. Plasma Process Polym 2011; 8: 94-9. http://dx.doi.org/10.1002/ppap.201000097

[101] Lu W, Cao T, Jin Y, Cheng Y. Process decoupling of plasma enhanced synthesis of chlorinated polyvinyl chloride (CPVC) particles in a circulating fluidized bed. In: 10th international conference on circulating fluidized beds and fluidization technology -CFB-10, Knowlton T, PSRI Editors, ECI Symposium Series, Volume RP7 (2013).

[102] Rzayev ZMO. Graft copolymers of maleic anhydride and its isostructural analogues: high performance engineering materials. Intern Rev Chem Eng 2011; 3: 153-215.

[103] Xu C, Wang S, Shao L, Zhao J, Feng Y. Structure and properties of chlorinated polyvinyl chloride graft copolymer with higher property. Polym Adv Technol 2012; 23: 470-7. http://dx.doi.org/10.1002/pat.1901

[104] Meng L, Xu C, Jing Z, Zhao J, Feng Y, Hu H. Preparation of anhydridized chlorinated polyvinyl chloride with enhanced properties and investigation of the factors affecting the chain structure of the graft copolymer. J Elast Plast 2015; 47: 13652.

http://dx.doi.org/10.1177/0095244313507801

[105] Hammiche D, Boukerrou A, Djidjelli H, Beztout M, Krim S. Synthesis of a new compatibilisant agent PVC-g-MA and its use in the PVC/alfa composites. J Appl Polym Sci 2012; 124 4352-61. http://dx.doi.org/10.1002/app.35422

[106] Hammiche D, Boukerrou A, Djidjelli H, Djerrada A. Effects of some PVC-grafted maleic anhydrides (PVC-g-MAs) on the morphology, the mechanical and thermal properties of (alfa fiber)-reinforced PVC composites. J Vinyl Addit Technol 2013; 19: 225-32. http://dx.doi.org/10.1002/vnl.21317 
[107] Pant D, Kumar S. Green chemical modification: an ecofriendly way to material management. Ind J Sci Res Tech 2014; 2: 58-61.

[108] Lamanna M, D'Accorso N. New copolymers with heterocyclic pendant groups obtained from PVC using microwaveassisted process. J Appl Polym Sci 2011; 121: 951-6. http://dx.doi.org/10.1002/app.33652

[109] Naif OA, AL-Bayati RI. Synthesis of some modified poly(vinyl chloride) containing cinnoline-deravitives. National J Chem 2010; 37: 74-85.

[110] Das R, Ali MdE, Abd Hamid SB, Ramakrishna S, Chowdhury ZZ. Carbon nanotube membranes for water purification: a bright future in water desalination. Desalination 2014; 336: 97-109. http://dx.doi.org/10.1016/j.desal.2013.12.026

[111] Prato M. [60]Fullerene chemistry for materials science applications. J Mater Chem 1997; 7: 1097-109. http://dx.doi.org/10.1039/a700080d

[112] Balasubramanian K, Burghard M. Chemically functionalized carbon nanotubes. Small 2005; 1: 180-92. http://dx.doi.org/10.1002/smll.200400118

[113] Kuilla T, Bhadra S, Yao D, Kim NH, Bose S, Lee JH. Recent advances in graphene based polymer composites. Progr Polym Sci 2010; 35: 1350-75. http://dx.doi.org/10.1016/j.progpolymsci.2010.07.005

[114] Salavagione HJ, Martínez G, Ellis G. Recent Advances in the covalent modification of graphene with polymers. Macromol Rapid Commun 2011; 32: 1771-89. http://dx.doi.org/10.1002/marc.201100527

[115] Kuila T, Bose S, Mishra AK, Khanra P, Kim NH, Lee JH. Chemical functionalization of graphene and its applications. Progr Mater Sci 2012; 57: 1061-105. http://dx.doi.org/10.1016/j.pmatsci.2012.03.002

[116] Layek RK, Nandi AK. A review on synthesis and properties of polymer functionalized graphene. Polymer 2013; 54: 5087103. http://dx.doi.org/10.1016/j.polymer.2013.06.027

[117] Seeponkai N, Wootthikanokkhan J, Thanachayanont C. Synthesis and characterization of fullerene functionalized poly(vinyl chloride) (PVC) and dehydrochlorinated PVC using atom transfer radical addition and AIBN based fullerenation. J Appl Polym Sci 2013; 130: 2410-21. http://dx.doi.org/10.1002/app.39443

[118] Wootthikanokkhan J, Khunsriya P, Seeponkai N, Asawapirom U, Keawprajak A. Thermal behavior and photovoltaic performance of fullerene grafted dehydrochlorinated poly(vinyl chloride) in bulk heterojunction solar cells. Intern J Polym Mater 2015; 64: 392-9. http://dx.doi.org/10.1080/00914037.2014.958826

[119] Wu XL, Liu P. Poly(vinyl chloride)-grafted multi-walled carbon nanotubes via Friedel-Crafts alkylation. eXPRESS Polym Lett 2010; 4: 723-8. http://dx.doi.org/10.3144/expresspolymlett.2010.87

[120] Salavagione HJ, Martínez G, Ballesteros C. Functionalization of multi-walled carbon nanotubes by stereoselective nucleophilic substitution on PVC. Macromolecules 2010; 43: 9754-60.

http://dx.doi.org/10.1021/ma101780h

[121] Salavagione HJ, Martínez G. Importance of covalent linkages in the preparation of effective reduced graphene oxide-poly(vinyl chloride) nanocomposites. Macromolecules 2011; 44: 2685-92.

http://dx.doi.org/10.1021/ma102932c

[122] Yao K, Zhang G, Lin Y, Gong J, Na H, Tang T. One-pot approach to prepare high-performance graphene-reinforced poly(vinyl chloride) using lithium alkyl as covalent bonding agent. Polym Chem 2015; 6: 389-96.

http://dx.doi.org/10.1039/C4PY01110D
[123] Najafi SK. Use of recycled plastics in wood plastic composites-a review. Waste Manag 2013; 33: 1898-905. http://dx.doi.org/10.1016/j.wasman.2013.05.017

[124] Batayneh M, Marie I, Asi I. Use of selected waste materials in concrete mixes. Waste Manag 2007; 27: 1870-6. http://dx.doi.org/10.1016/j.wasman.2006.07.026

[125] Sajdak M, Muzyka R, Hrabak J, Słowik K. Use of plastic waste as a fuel in the co-pyrolysis of biomass: part III: optimisation of the co-pyrolysis process. J Anal Appl Pyrol 2015; 112: 298-305.

http://dx.doi.org/10.1016/j.jaap.2015.01.008

[126] Pant D, Singh R, Kumar S. Management of waste polyviny chloride (PVC) through chemical modification. J Sci Indus Res 2012; 71: 181-6.

[127] Yoshihara M, Grause G, Kameda T, Yoshioka T. Upgrading of poly(vinyl chloride) by chemical modifications using sodium sulfide. J Mater Cycles Waste Manag 2010; 12: 264-70. http://dx.doi.org/10.1007/s10163-010-0275-z

[128] Kameda T, Fukuda Y, Grause G, Yoshioka T. Chemical modification of flexible and rigid poly(vinyl chloride) by nucleophilic substitution with thiocyanate using a phasetransfer catalyst. Mater Chem Phys 2010; 124: 163-7. http://dx.doi.org/10.1016/j.matchemphys.2010.06.011

[129] Kameda T, Fukuda Y, Grause G, Yoshioka T. Chemical modification of rigid poly(vinyl chloride) by the substitution with nucleophiles. J Appl Polym Sci 2010; 116: 36-44. http://dx.doi.org/10.1002/app.31452

[130] Kameda T, Ono M, Grause G, Mizoguchi T, Yoshioka T. Chemical modification and dechlorination of polyvinyl chloride by substitution with thiocyanate as a nucleophile. Polym Eng Sci 2010; 50: 69-75. http://dx.doi.org/10.1002/pen.21512

[131] Kameda T, Grause G, Yoshioka T. Chemical modification of flexible poly(vinyl chloride) by nucleophilic substitution. SPE Plast Res Online 2010; p.3.

[132] Kameda T, Fukuda Y, Grause G, Yoshioka T. Effect of the nucleophilicity and solvent on the chemical modification of flexible poly(vinyl chloride) by substitution. Polym Eng Sci 2011; 51: 1108-15.

http://dx.doi.org/10.1002/pen.21693

[133] Grause G, Hosoya T, Hashimoto K, Kameda T, Yoshioka T. Nucleophilic substitution of poly(vinyl chloride) with iminoacetic acid and n-dodecanethiol. J Mater Cycles Waste Manag 2014; 16: 519-24. http://dx.doi.org/10.1007/s10163-013-0202-1

[134] Kameda T, Yoshihara M, Grause G, Yoshioka T. Chemical modification of poly(vinyl chloride) using sodium trisulfide. J Polym Res 2015; 22:88, p.5. http://dx.doi.org/10.1007/s10965-015-0718-2

[135] Roh DK, Park JT, Ahn SH, Ahn H, Ryu DY, Kim JH. Amphiphilic poly(vinyl chloride)-g-poly(oxyethylene methacrylate) graft polymer electrolytes: interactions, nanostructures and applications to dye-sensitized solar cells. Electrochim Acta 2010; 55: 4976-81.

http://dx.doi.org/10.1016/j.electacta.2010.03.106

[136] Ahn SH, Koh JH, Seo JA, Kim JH. Structure control of organized mesoporous $\mathrm{TiO} 2$ films templated by graft copolymers for dye-sensitized solar cells. Chem Commun 2010; 46: 1935-7.

http://dx.doi.org/10.1039/b919215h

[137] Ahn SH, Jeon H, Son KJ, Ahn H, Koh W-G, Ryu DY, Kim $\mathrm{JH}$. Efficiency improvement of dye-sensitized solar cells using graft copolymer-templated mesoporous $\mathrm{TiO} 2$ films as an interfacial layer. J Mater Chem 2011; 21: 1772-9. http://dx.doi.org/10.1039/C0JM02706E

[138] Park JT, Roh DK, Patel R, Kim E, Ryu DY, Kim JH. Preparation of $\mathrm{TiO} 2$ spheres with hierarchical pores via 
grafting polymerization and sol-gel process for dye-sensitized solar cells. J Mater Chem 2010; 20: 8521-30. http://dx.doi.org/10.1039/c0jm01471k

[139] Park JT, Chi WS, Kim SJ, Lee D, Kim JH. Mesoporous TiO2 Bragg stack templated by graft copolymer for dye-sensitized solar cell. Scientific Reports 2014; 4: 5505. http://dx.doi.org/10.1038/srep05505

[140] Patel R, Ahn SH, Seo JA, Kim SJ, Kim JH. Poly(vinyl chloride)-g-poly(2-(dimethylamino)ethyl methacrylate) graft copolymers templated synthesis of mesoporous $\mathrm{TiO} 2$ thin films for dye-sensitized solar cells. J Nanopart Res 2012; 14: $845, \mathrm{p} 12$. http://dx.doi.org/10.1007/978-3-319-05041-6 17

[141] Yeon SH, Patel R, Koh JK, Ahn SH, Kim JH. Preparation of porous $\mathrm{TiO} 2$ thin films by poly(vinyl chloride)-graft-poly $(\mathrm{N}$ vinyl pyrrolidone) and their applications to dye-sensitized solar cells. J Kor Electrochem Soc 2011; 14: 83-91. http://dx.doi.org/10.5229/JKES.2011.14.2.083

[142] Zheng X-m, Du L-y, Ma Y-h, Liu L-y, Yang W-t. Photoinduced synthesis of PVC macroinitiators and preparation of amphiphilic graft copolymers. Acta Polym Sin 2014; 2: 24854.

[143] Ameer AA, Abdallh MS, Ahmed AA, Yousif EA. Synthesis and characterization of polyvinyl chloride chemically modified by amines. Open J Polym Chem 2013; 3: 11-15. http://dx.doi.org/10.4236/ojpchem.2013.31003

[144] Witwit NA. Study of the optical properties of poly(vinyl chloride)-4-[(5-mercapto-1,3,4-thiadiazol-2-yl)diazenyl]phenol complexes. Eur J Chem 2014; 5: 652-6. http://dx.doi.org/10.5155/eurjchem.5.4.652-656.1100

[145] Abdallh MS. Synthesis and optical properties study of some metal complexes of poly(vinyl chloride)-pyridine-4carbohydrazide. J Al-Nahrain Univ 2013; 16: 24-9.

[146] Yousif E, Abdallh M, Hashim H, Salih N, Salimon J, Abdullah BM, Win Y-F. Optical properties of pure and modified poly(vinyl chloride). Intern J Indus Chem 2013; 4: p.8. http://dx.doi.org/10.1186/2228-5547-4-4

[147] Mu B, Lu C, Dong Y, Liu P. Preparation and characterization of PVC-based photoresponsive polymers containing azochromophores. J Macromol Sci Part A Pure Appl Chem 2010; 47: 833-38. http://dx.doi.org/10.1080/10601325.2010.492262

[148] Yousif E, Hameed A, Rasheed R, Mansoor H, Farina Y, Graisa A, Salih N, Salimon J. Synthesis and photostability study of some modified poly(vinyl chloride) containing pendant benzothiazole and benzimidozole ring. Intern $\mathrm{J}$ Chem 2010; $2: 65-80$. http://dx.doi.org/10.5539/ijc.v2n1p65

[149] Naif OA, Salih HK. Synthesis of new modified PVC and their photostability study. Tikrit J Pure Sci 2011; 16: 101-17.
[150] Yavuz E, Gursel Y, Senkal BF. Modification of poly(glycidyl methacrylate) grafted onto crosslinked PVC with iminopropylene glycol group and use for removing boron from water. Desalination 2013; 310: 145-50.

http://dx.doi.org/10.1016/j.desal.2012.07.015

[151] Ammari F, Meganem F. Poly(vinyl chloride) functionalization by aliphatic and aromatic amines: application to the extraction of some metal cations. Turk J Chem 2014; 38 : 638- 49.

http://dx.doi.org/10.3906/kim-1306-24

[152] Al-Jibouri MNA, Musa TM, Mubarak M, Al-Jibouri WM. Synthesis, characterization and adsorption study of new resin PVC-8-hydroxyquinoline-5-sulfonic acid with toxic metals. Sci J Chem 2013; 1: 38-49. http://dx.doi.org/10.11648/j.sjc.20130104.11

[153] Sun L, Liu C-p, Qi M-y, Liu J-s, Liu X-g, Cui Z-z. Adsorption properties of polyamine-diacetone acrylamide modified PVC resin to 4-chlorophenol. Chinese J Proc Eng, 2012; 12: 7759.

[154] Wang M-Q, Yan J, Du S-G, Zeng J-W, Chang W-P, Guo $\mathrm{Y}$, and $\mathrm{Li} \mathrm{H}-\mathrm{G}$. Adsorption characteristic of copper ions and its application in electroless nickel plating on a hydrogelfunctionalized poly(vinyl chloride) plastic. J Mater Sci 2013; 48: 7224-37.

http://dx.doi.org/10.1007/s10853-013-7539-7

[155] Wang M-Q, Yan J, Du S-G, Meng S-H. Copper nanoparticles seeded functionalized-PVC plastic surface for electroless nickel deposition. Surf Interf Anal 2013; 45: 1899-902. http://dx.doi.org/10.1002/sia.5337

[156] Singh A, Rawat MSM, Pande CS. Chemical modification and characterization of poly(vinyl chloride) by crosslinking of multifunctional amines. J Appl Polym Sci 2010. http://dx.doi.org/10.1002/app.32432

[157] Shaglaeva NS, Bayandin VV, Sultangareev RG, Vakul'skaya TI, Khutsishvili SS, Orkhokova EA, Prozorova GF. Copolymers of vinyl chloride obtained by polymer-analogous reactions of polyvinyl chloride with sodium salts of heteroaromatic H-N acids. Russian J Appl Chem 2013; 86 : 1576-80.

http://dx.doi.org/10.1134/S1070427213100169

[158] Coșkun M, Seven P. Synthesis, characterization and investigation of dielectric properties of two-armed graft copolymers prepared with methyl methacrylate and styrene onto PVC using atom transfer radical polymerization. React Funct Polym 2011; 71: 395-401. http://dx.doi.org/10.1016/j.reactfunctpolym.2010.12.012

[159] Lăzăroaie C, Rusen E, Mărculescu B, Zecheru T, Hubcă G. Chemical modification of PVC for polymer matrices with special properties. UPB Sci Bull Series B 2010; 72: 127-40.

[160] Li K-s, Huang $\mathrm{H}$, Niu H-m, Study on reactive compatibilization of PVC/PS catalyzed by anhydrous aluminum chloride. Acta Polym Sin 2013; 1: 142-8. 